Portland State University

PDXScholar

Dissertations and Theses

Dissertations and Theses

Summer 8-14-2014

\title{
Assessment of Similarity in Chemically Complex Samples
}

Jessica Elise Brown

Portland State University

Follow this and additional works at: https://pdxscholar.library.pdx.edu/open_access_etds

Part of the Civil and Environmental Engineering Commons, and the Complex Mixtures Commons Let us know how access to this document benefits you.

\section{Recommended Citation}

Brown, Jessica Elise, "Assessment of Similarity in Chemically Complex Samples" (2014). Dissertations and Theses. Paper 1954.

https://doi.org/10.15760/etd.1953

This Thesis is brought to you for free and open access. It has been accepted for inclusion in Dissertations and Theses by an authorized administrator of PDXScholar. Please contact us if we can make this document more accessible: pdxscholar@pdx.edu. 
Assessment of Similarity in Chemically Complex Samples

by

Jessica Elise Brown

A thesis submitted in partial fulfillment of the requirements for the degree of

Master of Science

in

Civil and Environmental Engineering

Thesis Committee:

James Pankow, Chair

Kelley Barsanti

Todd Rosenstiel

Portland State University

2014 
(C) 2014 Jessica Elise Brown

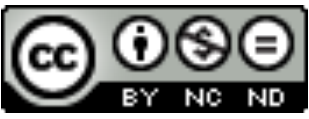

This work is licensed under the Creative Commons Attribution-NonCommerical 4.0 International License. To view a copy of this license, visit http://creativecommons.org/licenses/by-nc-nd/4.0/

Portions of this thesis are reproduced with permission from (Brown, J.E., W. Luo, L.M. Isabelle, and J.F. Pankow. 2014. "Candy Flavorings in Tobacco.” New England Journal of Medicine 370 (23): 2250-52.), Copyright (C) (2014) Massachusetts Medical Society. To view a copy of this work, visit http://www.nejm.org/doi/full/10.1056/NEJMc1403015 
Abstract

Concern within the public health community is mounting regarding what some deem as "candy-flavored tobacco". A recent study by King et al. (2014) found that $>40 \%$ of middle and high school student smokers use flavored cigarettes or flavored little cigars. This study investigated the validity of the “candy-flavored tobacco" designation by comparing flavor profiles of 18 flavored tobacco products with 15 candy and Kool-Aid products using gas chromatography mass spectrometry (GC/MS). Significant compositional overlap was found; nearly $75 \%$ of the compounds detected were present in at least one flavored tobacco and one candy or Kool-Aid product. Benzaldehyde and or benzyl alcohol were measured in cherry candies, Kool-Aid and tobacco. Similar levels of benzaldehyde were measured in the cherry Kool-Aid and wild cherry Cheyenne cigars at $3338 \pm 623$ and $3937 \pm 251 \mu \mathrm{g} /$ serving. Methyl anthranilate, 1-hexanol, $\gamma$-decalactone, and raspberry ketone were found in all grape, apple, peach and berry products, respectively. Vanillin and or ethyl vanillin were constituents of all flavored tobacco products analyzed.

Many flavorants, such as limonene, are also volatilizable biogenic organic compounds (VBOCs). A more comprehensive understanding of the identities and properties of VBOCs, precursors to secondary organic aerosol (SOA), would support air quality and climate change research and management. Our knowledge is limited by extreme compositional diversity within the VBOC class. Only recently have techniques such as two-dimensional gas chromatography time of 
flight mass spectrometry (GCxGC/TOFMS) been employed, and the complexity of the data poses analysis challenges. To address this, agglomerative hierarchical cluster analysis (HCA) was performed on data generated by GCxGC/TOFMS analysis of air samples collected during the Particle Investigations at a Northern Ozarks Tower: $\mathrm{NO}_{\mathrm{x}}$, Oxidant, Isoprene Research (PINOT NOIR) study. HCA resulted in the assignment of 204 compounds into 27 clusters: these clusters were grouped into 4 distinct types making the data significantly more manageable. The assignment of a cluster to a type was mostly based on the frequency with which compounds appeared in samples. Type I clusters contained compounds that were present in only one sample, suggesting meteorological influence. 


\section{Dedication}

This work is dedicated to the memory of Lorne Isabelle, who enthusiastically trained me on the GC/MS and laboratory work, encouraged me to practice selfcare and always made me smile and laugh in the lab. I will always be grateful for and remember Lorne, and his family will remain my thoughts. 


\section{Acknowledgements}

My deepest gratitude to my research advisor and committee chair, Dr. James Pankow, for challenging, encouraging and believing in me and for providing me with numerous opportunities for academic and career development as well as hours of assistance with writing. I feel honored to have had the opportunity to learn from you.

I would also like to acknowledge Dr. Wentai Luo and Lorne Isabelle for making time in their busy schedules to assist me with all aspects of my research. They made themselves consistently available to address my many questions.

To committee member Dr. Kelley Barsanti for your valuable insights and direction in regards to the HCA analysis.

Thank you to my committee member, Dr. Todd Rosenstiel, for meeting with me and offering assistance.

Thank you to Maysoun Hameed for spending several hours helping me with the statistical analysis portion of this thesis.

I would also like to thank my mother, Deanna, for her consistent and unconditional support, acceptance and love. Thank you to my father, Jeff, for always encouraging me to excel and pursue the sciences, to Julie and Kathy for all of their support and encouragement, and to my siblings Matt and Olivia for giving me so much joy. 
Table of Contents

Abstract....................................................................

Dedication.............................................................

Acknowledgments $\ldots \ldots \ldots \ldots \ldots \ldots \ldots \ldots \ldots \ldots \ldots \ldots \ldots \ldots \ldots \ldots \ldots \ldots \ldots \ldots$ iv

List of Figures...................................................vii

1. Flavorant Analyses

1.1. Introduction....................................................

1.2. Methods......................................................

1.2.1. Confectionary and Soft Drink Procedure....................... 3

1.2.2. Tobacco Procedure........................................5

1.2.3. Instrument Information.................................6

1.2.4. Quality Control..........................................

1.2.5. Data Processing and Quantification......................... 9

1.3. Results...................................................11

1.4. Discussion.................................................. 18

1.5. Conclusions ................................................21

2. HCA analyses

2.1. Introduction................................................ 22

2.1.1. The Environmental Relevance of VBOCs...................22

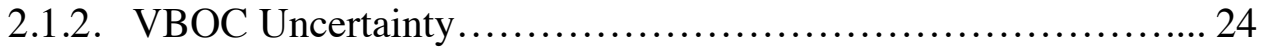

2.2. Methods..................................................26

2.2.1. Data Description.......................................26

2.2.2. Procedure.............................................27 
2.3. Results.................................................... 30

2.3.1. HCA Solution..............................................30

2.3.2. Cluster Types.......................................... 31

2.4. Discussion..................................................... 36

2.5. Conclusions ..............................................42

3. References...................................................... 43

4. Appendix A: Flavorant Analysis Tables..............................48

4.1. Table A.1. Prevalence of Use and Sales of Tobacco Products...........48

4.2. Table A.2. Flavorant Products Tested.............................49

4.3. Table A.3. Target Analytes Found in Samples.......................50

4.4. Table A.4.1-A.4.5. Flavorant Analyses Results.......................58

5. Appendix B: PINOT NOIR Tables................................72

5.1. Table B.1. Sample Information Used............................72

5.2. Table B.3. Cluster Results.....................................73

5.3. Table B.4. Cluster Environmental Variables.........................74

5.4. Table B.5.1-B.5.4. Compounds Assigned by Cluster..................77

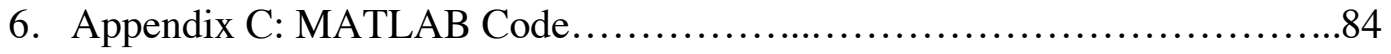




\section{List of Figures}

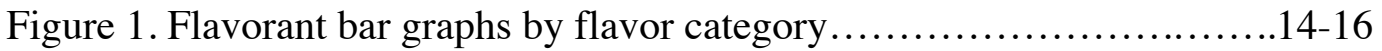

Figure 2. Total flavorant bar graphs................................. 17

Figure 3 . The dendrogram of 27 cluster solutions generated from HCA..........30

Figure 4. Cluster Types............................................ $34-35$

Figure 5. Representation of Spearman Correlation.............................39

Figure 6. Wind Direction Plots...........................................40

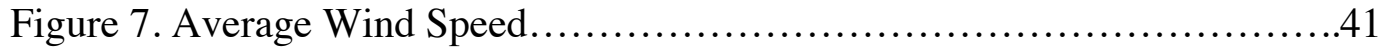




\section{Flavorant Analyses}

\subsection{Introduction:}

For many, tobacco use begins at a young age. In the U.S, among adults who had ever smoked cigarettes daily, $88 \%$ reported trying their first cigarette before the age of 18 (Center for Disease Control and Prevention 2012a). The World Health Organization (2011) estimates the number of smokers in the world at 1 billion, that tobacco use leads to 6 million deaths per year, and that $50 \%$ of contemporary smokers will ultimately die from a tobacco-related illness. The U.S. Center for Disease Control and Prevention (2008) has estimated the death rate attributed to U.S. cigarette smoking at 443,000 per year and that direct medical expenses as a result of tobacco were more than $\$ 96$ billion. It is therefore important to understand product design factors that may attract new tobacco users, including flavorant chemicals in product formulations.

Table A.1 outlines relevant prevalence of use and sales of cigars and moist snuff. Sales of large cigars and moist snuff have been increasing. The Government Accountability Office (2012) reports a 49\% percent increase of sales in large cigars, with 10.27 billion sticks sold in 2010, up from 6.88 billion in 2008. Delnevo et al. (2012) report a $72 \%$ and $334 \%$ increase in flavored moist snuff and pouched moist snuff from $2005-2011$, respectively, noting that $73 \%$ of pouched moist snuff is flavored. In 2011, $11.6 \%$ and $7.3 \%$ of U.S. high school students reported use of cigars and smokeless tobacco respectively within the last 30 days at the time of survey (Center for Disease Control and Prevention 2012b). This is in contrast to the 18 or older adult population, where $5.2 \%$ and $3.3 \%$ reported use of cigars and smokeless 
products, respectively (Substance Abuse \& Mental Health Services Administration 2012).

A recent study found that $42.4 \%$ of U.S. middle school or high school student self-identified smokers reported use of flavored cigarettes or flavored little cigars, that these users were less likely to report plans to quit than individuals smoking unflavored cigarettes at $9.8 \%$ and $18.4 \%$ respectively, and that $60 \%$ used "cigarettes" with flavors other than menthol (King et al. 2014). Many cigars, such as the Cheyenne cigars analyzed in this study, are similar in appearance to cigarettes. King et al. (2014) note that the youth reporting use of flavored cigarettes may actually be using flavored cigars; in 2009, flavored cigarettes (with the exception of menthol) were banned in the U.S. About $40 \%$ of flavored cigarette smokers reported using mentholated cigarettes, indicating that the remaining $60 \%$ used "cigarettes" with other flavors (King et al. 2014).

There is increasing concern within the public health community that these flavored tobacco products are "candy-flavored tobacco", marketed to children and make tobacco more attractive and palatable to youth (Miami Dade County 2012; Alpert, Koh, and Connolly 2008). This study investigated the validity of the "candyflavored tobacco" designation through comparison of flavorant profiles in tobacco and candy/Kool-Aid. The composition information of these products is proprietary, and to the best of our knowledge have not been analyzed by an outside party. Portions of this thesis are reproduced with permission from (Brown, J.E., W. Luo, L.M. Isabelle, and J.F. Pankow. 2014. “Candy Flavorings in Tobacco.” New England Journal of Medicine 370 (23): 2250-52.), Copyright Massachusetts Medical Society. 


\subsection{Methods}

Tobacco, candy and soft drink products were selected based on the availability of flavors falling into the apple, berry, cherry, grape and peach flavor categories. Efforts were made to analyze several candy and tobacco products in each flavor category. A product was placed in a flavor category based on its name; for example, "wild cherry", "peach mango" and "blueberry" were respectively placed in the cherry, peach and berry flavor category. Table A.2 provides the tobacco, confectionary and soft drink products analyzed and the corresponding sample amounts used for extraction.

\subsubsection{Confectionary and Soft Drink Procedure}

Individually wrapped Jolly Ranchers (apple, cherry, grape, peach and raspberry), and Life Savers (cherry and raspberry) in multi-flavor packages were purchased in Portland, OR during August 2013 along with packets of unsweetened Kool-Aid powder (cherry, peach mango, grape and raspberry lemonade). Zotz (apple, blueberry, grape and cherry) were purchased in February 2014. Products were stored in zip lock bags at $4^{\circ} \mathrm{C}$ prior to analysis.

Analyses were carried out in triplicate. The amounts extracted using a combination of water and methyl tert-butyl ether (MTBE) were: Life Savers, 2 candies; Jolly Ranchers, 1 candy; and Kool-Aid mix, 100 mg. For each analysis, 50 $\mu \mathrm{L}$ of a surrogate standard (SS) solution (1,3,5-trichlorobenzene (1,3,5-TCB) at 4000 $\mathrm{ng} / \mu \mathrm{L}$ in $\mathrm{MTBE}$ ) was included to monitor recoveries. Also included in the vials were $450 \mathrm{mg}, 700 \mathrm{mg}$, or $350 \mathrm{mg}$ of trisodium citrate, respectively to raise the $\mathrm{pH}$ of each 
water extract from about 2-3 to the 5-7 range to avoid acid hydrolysis of some flavor chemicals. Analytes were "salted out" from the water into the MTBE through addition of $2.0 \mathrm{~g}$ of sodium chloride. Extraction of each sample proceeded in a $40 \mathrm{~mL}$ amber VOA vial using $10 \mathrm{~mL}$ of deionized water to dissolve the sample, and $10 \mathrm{~mL}$ of MTBE to extract the flavor chemicals. Kool-Aid sample vials were placed on the shaker for $0.5 \mathrm{~h}$. Life Saver and Jolly Rancher samples were allowed to sit for $8 \mathrm{~h}$ at $4^{\circ} \mathrm{C}$ to allow product dissolution then placed on the shaker for $0.5 \mathrm{~h}$. Each sample vial was then subjected to vortex mixing $3 \times$ for $10 \mathrm{~s}$ each, and allowed to sit for $2 \mathrm{~h}$ for phase separation. A $1 \mathrm{~mL}$ aliquot of each extract was placed in an autosampler vial with $10 \mu \mathrm{L}$ of an internal standard (IS) solution (1,2,3-trichlorobenzene (1,2,3-TCB) at $2000 \mathrm{ng} / \mu \mathrm{L}$ in MTBE).

The calibration standards contained the target analytes at concentrations ranging from 1 to $50 \mathrm{ng} / \mu \mathrm{L}$ per compound. The target analyte list included 85 compounds obtained from Sigma Aldrich Inc. (St. Louis, MO), the Good Scents Company, Inc. (Oak Creek, WI), and other vendors. The target analytes were determined through solid phase microextraction (SPME) analysis and subsequent GC/MS analysis of most products except Kool-Aid and Cheyenne, in which preliminary extractions were performed. Table A.3, created by W. Luo and edited by J. Brown, gives the 70 analytes found in one or more of the samples. In addition to the 70 chemicals listed in Table A.3, a combination of $o$ - and/or $m$-tolualdehyde as isomers of $p$-tolualdehyde was found in cherry Life Savers. 


\subsubsection{Tobacco Procedure}

The analysis of 18 flavored tobacco wraps, large cigars and moist snuff are described in this work (Table A.2). Most of the tobacco products were purchased in August 2013 at retail stores in Portland, OR. Grape Kayak moist snuff as well as grape and blueberry Zig Zag Wraps were purchased in Portland, OR February 2014. Cheyenne brand large cigars were purchased online in January 2013. These products were stored at $4^{\circ} \mathrm{C}$ in zip lock bags until analyzed. An unflavored reference moist snuff (“CRP2”) was obtained from North Carolina State University in July 2012 for use as an unflavored tobacco control material; it was stored as received (in cans) at $4^{\circ} \mathrm{C}$ until analyzed.

Analyses were carried out in triplicate. Sample amounts were as follows: a) 1 stick for the Cheyenne products (each filter was removed and analyzed separately; the final values in the data tables are the sum of filter and tobacco); b) 1 cigarillo for Swisher Sweet products (plastic tip removed prior to analysis); c) 1.0 g cylinder cut from the center for the Phillies Blunt cigars; d) 1 blunt wrap for Zig Zag Wraps and Royal Blunt Wraps; and e) $1.0 \mathrm{~g}$ for the moist snuff products. Except for the moist snuff products, each sample was cut into small pieces with clean medical suture scissors and placed in a 40-mL amber glass "VOA" vial fitted with a Teflon septum in a screw cap. For most samples, added to each vial were $50 \mu \mathrm{L}$ of the $4000 \mathrm{ng} / \mu \mathrm{L}$ 1,3,5-TCB SS solution, plus $10 \mathrm{~mL}=V_{1}$ of MTBE as the extraction solvent. For the Cheyenne filters, the amounts were $25 \mu \mathrm{L}$ of surrogate standard solution and $V_{l}=5$ $\mathrm{mL}$ of MTBE. For the Swisher Sweet cigarillos (2.3-2.7 g each, tobacco only), $100 \mu \mathrm{L}$ of the SS solution and $V_{1}=20 \mathrm{~mL}$ of MTBE. Extraction proceeded with gentle 
shaking for $1 \mathrm{~h}$, quiescence at $4{ }^{\circ} \mathrm{C}$ for $8 \mathrm{~h}$, and gentle shaking at room temperature for $0.5 \mathrm{~h}$.

\subsubsection{Instrument Information}

Analyses for candy, Kool-Aid and tobacco MTBE extracts were performed using an Agilent (Santa Clara, CA) 7690 autosampler, Agilent 7890A gas chromatograph (GC), and Agilent 5975C mass spectrometer (MS). A volume of 1.0 $\mu \mathrm{L}$ of each extract was injected by the autosampler through the septum and into the inlet. The injection operated with a 5:1 split; for every 5 parts injected, 1 part went to the column. The split functions to decrease the total mass entering the column, thereby allowing for improved separation of compounds. Helium was used as the carrier gas. The total flow was $6.5636 \mathrm{~mL} / \mathrm{min}$ with $1.000 \mathrm{~mL} / \mathrm{min}$ directed out the septum purge. A flow of $4.6363 \mathrm{~mL} / \mathrm{min}$ exited the split vent and the remaining flow of 0.9273 $\mathrm{mL} / \mathrm{min}$ proceeded through the column attached to the inlet in a temperaturecontrolled oven. The GC column type was Agilent DB-5MS UI (ultra inert), of $30 \mathrm{~m}$ length, $0.25 \mathrm{~mm}$ internal diameter (i.d.), and $0.25 \mu \mathrm{m}$ film thickness. The relatively nonpolar column has a stationary phase composition of 5\% phenyl and $95 \%$ dimethyl polysiloxane.

W. Luo developed the instrument method. A suitable temperature program was determined experimentally. Within minor variations, the GC temperature program for all analyses was: $45^{\circ} \mathrm{C}$ hold for $3 \mathrm{~min} ; 5^{\circ} \mathrm{C} / \mathrm{min}$ to $100^{\circ} \mathrm{C} ; 2^{\circ} / \mathrm{min}$ to $130^{\circ} \mathrm{C} ; 5^{\circ} \mathrm{C} / \mathrm{min}$ to $160^{\circ} \mathrm{C}$; then $20^{\circ} \mathrm{C} / \mathrm{min}$ to $300^{\circ} \mathrm{C}$. Excellent separation was achieved for most compounds, and those that coeluted had distinct ions allowing for quantification. 


\subsubsection{Quality Control}

A blank containing MTBE and $20 \mathrm{ng} / \mu \mathrm{L}$ IS was run at the beginning of each series of runs to ensure a clean GC column and check for contaminants in the solvent. All candy/Kool-Aid SS recoveries were in the range 83 to $114 \%$; no SS-based adjustments were made. Quality assurance (QA) steps besides the use of the SS and IS compounds in each analysis included verification of adequate extraction efficiency by removal of as much of the $1^{\text {st }}$ extract as possible and a subsequent $2^{\text {nd }}$ extraction with MTBE, as well as spike-recovery efficiency tests with the actual products. The equation used to calculate extraction efficiencies (EE) for each detected compound $(i)$ is shown below:

$$
\mathrm{EE}_{i}=\frac{c_{1 i} v_{1}}{c_{1_{i}} v_{1}+c_{2_{i}}\left(v_{2}+v_{R}\right)-c_{1 i} v_{R}} \cdot 100 \% \quad \text { Equation } 1
$$

The concentration in the $1^{\text {st }}$ and $2^{\text {nd }}$ extract are denoted by $c_{1}$ and $c_{2}$, respectively; $v_{1}$ and $v_{2}$ represents the volume of MTBE added for the $1^{\text {st }}$ and $2^{\text {nd }}$ extraction, respectively; $v_{R}$ corresponds to approximate volume of extract left over after removal.

Recoveries $(R)$ for each compound $(i)$ were calculated using the following equation:

$$
R_{i}=\frac{c_{S P i}-c_{S i}}{c_{S T D i}} \bullet 100 \%
$$

Where $c_{S P}, c_{S}$ and $c_{S T D}$ refer to the concentration measured in the spiked extract, the average concentration of $i$ in the unspiked sample and the concentration originally added, respectively. 
For the above-trace compounds in the Supplementary Tables, the $1^{\text {st }}$ extraction efficiencies were $>88 \%$ for all compounds for Jolly Rancher candies; $>94 \%$ for Life Saver candies except for furfural (85\%) and furfuryl alcohol (88\%); 100\% for KoolAid. For recovery experiments, spiking occurred into samples that already contained some amounts of the analytes being spiked. The pre-spike levels were estimated as the averages reported here. The average spike recoveries for Jolly Ranchers were in the range $82-116 \%$ for all analytes, with most $>90 \%$. For Zotz, the spike recoveries were $82-115 \%$, with most $>90 \%$, except for furfuryl alcohol and $\alpha$-terpineol, at $71 \%$ and $78 \%$ respectively.

All tobacco SS recoveries were in the range $87-114 \% .1^{\text {st }}$ extraction efficiencies were: for Skoal Cherry moist snuff, $>92 \%$ for all compounds except amyl butyrate (83\%) and isoamyl butanoate (86\%); for Zig Zag Apple blunt wraps, >98\% for all compounds; for Cheyenne Xotic Berry "large cigars", $>81 \%$ for all compounds (as the net for the separate rod and filter extractions). Spike-recovery efficiency values for the tobacco samples were estimated as $88-115 \%$ for all analytes. Adjustments were not made for SS recovery, extraction efficiency, or spike recovery.

Some of the compounds found in the analyses here can arise naturally in tobacco (Rodgman and Perfetti 2013). Vanillin has been reported at 0.9 to $1.8 \mu \mathrm{g} / \mathrm{g}$ in a range of types of tobacco leaf (Barbu A. Demian 1993). Since we did not have access to the unflavored versions of the tobacco products we examined, the "CRP2" reference moist snuff was analyzed as an unflavored tobacco control. 


\subsubsection{Data Processing and Quantification}

The base peak was used as the quantitation ion unless it was associated with noise (such as mass 44 for $\mathrm{CO}_{2}$ ) or in the case of coelution where the distinct ion was not the base peak. In this case, the next most abundant ion was selected. The relative ratios of 3 qualifying ions were used verify identification. The peak area, or response, of each analyte quantitation ion was recorded and imported into an excel spreadsheet. A response factor $(\mathrm{RF})$ was calculated for each analyte $(i)$ in the calibration standards using:

$$
\mathrm{RF}_{i}=\frac{A_{c i}}{C_{c i}} \bullet \frac{C_{s}}{A_{s}}
$$

Equation 3.

Where $A_{c}$ was the response of the particular calibration standard analyte quantitation ion, $C_{c}$ was the calibration standard concentration specific to the analyte, $C_{s}$ was the concentration of the IS $(20 \mathrm{ng} / \mu \mathrm{L})$ and $A_{s}$ was the response of the IS.

The unknown concentration $\left(C_{x}\right)$ was then calculated using the average response factor $\left(\mathrm{RF}_{\mathrm{avg}}\right)$ and the equation:

$$
C_{x}=\frac{A_{x}}{\mathrm{RF}_{\mathrm{avg}}} \cdot \frac{C_{s}}{A_{s}}
$$

Equation 4.

Where $A_{x}$ was the unknown analyte response.

The calibration standards $(1,2,5,20$ and $50 \mathrm{ng} / \mu \mathrm{L})$ were run twice and the $\mathrm{RF}_{\mathrm{avg}}$ from each compound was calculated from all 10 runs. If the relative standard deviation of the $\mathrm{RF}_{\mathrm{avg}}$ was greater than $15 \%$, adjustments were made to lower the value by deleting outliers or narrowing the concentration range.

Compounds detected with a calculated concentration of $<0.3 \mathrm{ng} / \mu \mathrm{L}$ were defined as trace. Individual detection and quantitation limits were not measured due to 
the number of compounds analyzed. In looking at a $1 \mathrm{ng} / \mu \mathrm{L}$ standard, the lowest response of all the analytes had an estimated signal to noise ratio of 1/300. 


\subsection{Results}

A total of 63 compounds were found in the candy/Kool-Aid products analyzed.

Of the 59 target analytes discovered in the tobacco products, 52 were also found in the candy/Kool-Aid. Tables A.4.1-A.4.4 in Appendix A provide the levels found in each product in $\mu \mathrm{g}$ per serving. The concentration of each compound in a sample is reported as the average of three replicates along with the sample standard deviation. In the reference moist snuff CRP2, the analytes cis-linalool oxide, trans-linalool oxide, methyl salicylate and phenethyl alcohol were found at $0.3,0.5,0.5$, and $2.7 \mu \mathrm{g} / \mathrm{g}$, respectively.

Products in each flavor category (e.g. grape, cherry, berry, apple and peach) shared the same flavorants. Figure 1.A-E gives a bar graph for concentrations of benzaldehyde and benzyl alcohol, methyl anthranilate, 1-hexanol, $\gamma$-decalactone and $\gamma$-undecalactone, and raspberry ketone present in each product assigned to that flavor category. A trace amount of benzaldeyde and $\gamma$-decalactone was detected in cherry Swisher Sweet cigarillo and peach Kool-Aid, respectively; this is not shown in the figure. The error bars give the standard deviation for 3 replicates. Serving size values are defined in appendix A, table A.4.1-A.4.5. In Figure 1.B methyl anthranilate levels represent $1 \mathrm{~g}$ of the approximately $7 \mathrm{~g}$ serving size of the Phillies Blunt.

All cherry products contained benzaldehyde and or benzyl alcohol (Figure 1.A). The Jolly Rancher and Zotz had markedly less of these flavorants, with Jolly Rancher having the least. Kool-Aid and Zig Zag had the largest standard deviations in the figure. Similar levels of benzaldehyde were found in Cherry Kool-Aid, wild cherry Cheyenne cigars and cherry Skoal moist snuff at $3338 \pm 623,3937 \pm 251,2632 \pm 43$ 
$\mu \mathrm{g} / \mathrm{unit}$, respectively. Cherry Life Savers had comparable levels of benzyl alcohol as cherry Zig Zag Wraps, at $2231 \pm 61 \mu \mathrm{g} / \mathrm{unit}$ and $2391 \pm 664 \mu \mathrm{g} / \mathrm{unit}$. The flavorants ptolualdehyde, p-anisaldehyde and piperonal were also observed in multiple products. Vanillin or ethyl vanillin were found in all cherry flavored samples except Life Saver, with higher levels in tobacco products. These vanilla flavorants were detected in all tobacco products, often at appreciable levels, but not in grape, apple or peach candy and Kool-Aid.

All products designated in the grape category contained methyl anthranilate (Figure 1.B), a common grape flavor compound. Grape Jolly Rancher, Kool-Aid, Cheyenne cigar, and Kayak moist snuff were found to have similar levels of methyl anthranilate, at $1019 \pm 2,1137 \pm 153,1790 \pm 40$, and $1195 \pm 27 \mu \mathrm{g} /$ unit respectively. The largest standard deviations corresponded to the Phillies Blunt and Kool-Aid. Ethyl butanoate was detected in most of the grape products.

All apple products contained 1-hexanol (Figure 1.C) at $968 \pm 54,53 \pm 11,143$ $\pm 3,486 \pm 4,144 \pm 23$ and $142 \pm 15 \mu \mathrm{g} / \mathrm{unit}$ in Jolly Rancher, Zotz, Kayak moist snuff, Skoal moist snuff, Royal Blunt Wraps XXL, and Zig Zag wrap, respectively. Every peach product analyzed contained $\gamma$-decalactone, benzaldehyde and benzyl alcohol benzaldehyde. The peach flavorant $\gamma$-undecalactone was found in all peach tobacco products and is shown in Figure 1.D along with $\gamma$-decalactone; Kool-Aid had the highest standard deviation. Raspberry ketone was measured in all berry products (Figure 1.E), with levels ranging from $123 \pm 4 \mu \mathrm{g}$ /unit in the raspberry Life Saver to $784 \pm 39 \mu \mathrm{g} / \mathrm{unit}$ in berry blend Skoal snuff and with Kool-Aid again having the largest standard deviation for this compound. 
Figure 2 provides a bar graph of total $\mu \mathrm{g}$ of flavorants per serving for each product, except the Phillies blunt. For Phillies blunt, the bar represents about $1 / 7^{\text {th }}$ of the total mass of the unit in order to normalize portion sizes. A serving size was defined as 1 candy (Jolly Rancher, Life Saver, Zotz), 0.5-0.8 g of Kool-Aid powder (depending on flavor), $1 \mathrm{~g}$ of moist snuff (Skoal and Kayak), 1 cigar (Cheyenne, Swisher Sweet and Phillies Blunt), and 1 blunt wrap (Zig Zag and Royal Blunt). The highest total flavorants were detected in the large grape Phillies blunt ( 35 $\mathrm{mg} /$ serving) with about $18 \mathrm{mg} /$ serving of methyl anthranilate; however, the Phillies Blunt weighed between 2-5 times that of the other cigars. Cherry Skoal moist snuff had about $13 \mathrm{mg} / \mathrm{serving}$ and berry blend Skoal moist snuff about $11 \mathrm{mg} / \mathrm{serving}$ of total flavorants with methyl salicylate and or ethyl salicylate contributing to the bulk of the mass. About $11 \mathrm{mg} / \mathrm{serving}$ of total flavorants were found in raspberry lemonade Kool-Aid, with limonene contributing about $10 \mathrm{mg} / \mathrm{serving}$. Berry, cherry and peach flavored Kool-Aid had more total flavorants than the candies, with levels similar to most tobacco products. Tobacco products assigned to the cherry, apple, peach and berry categories had greater total flavorant than the candies products within these designations. 


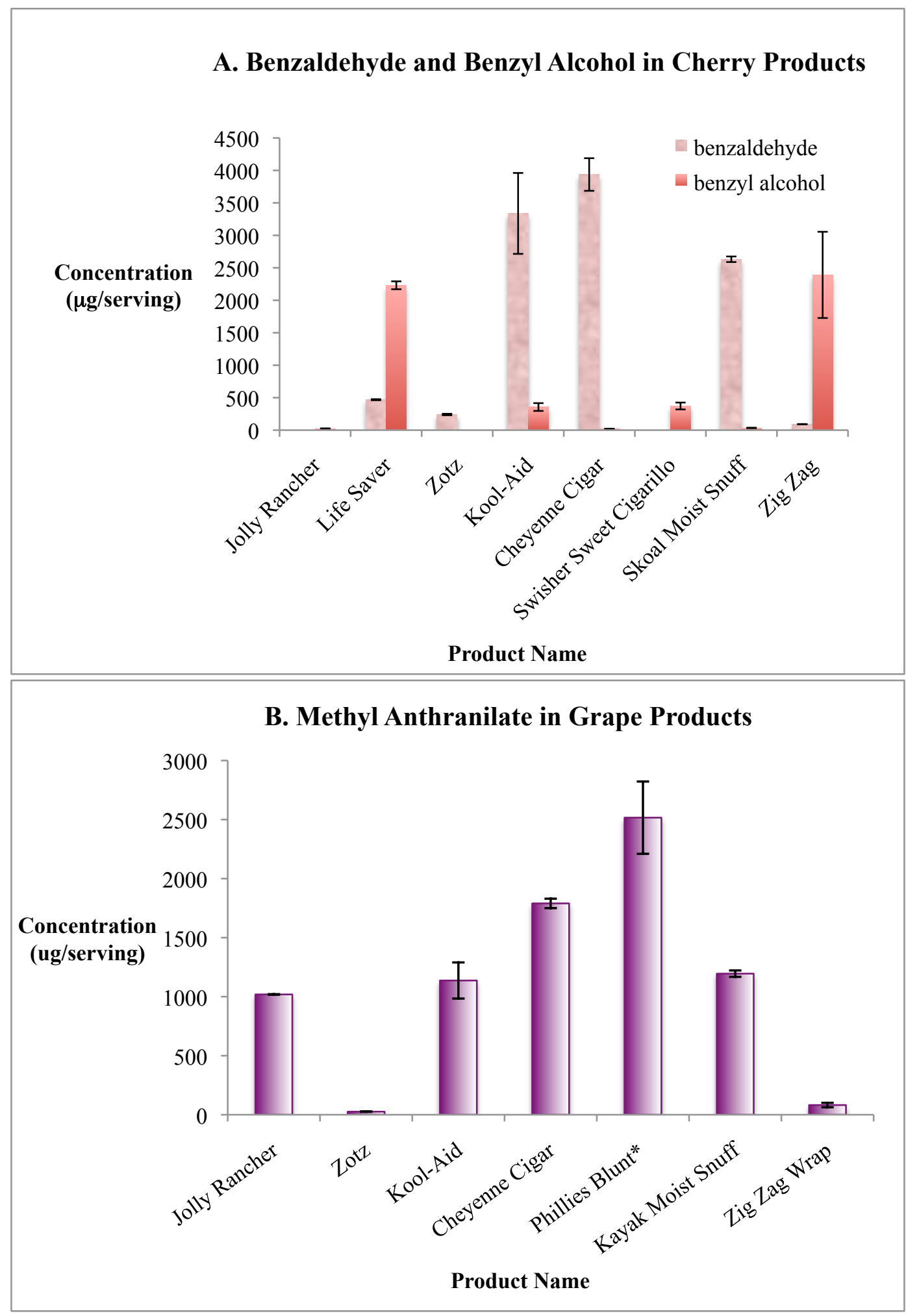



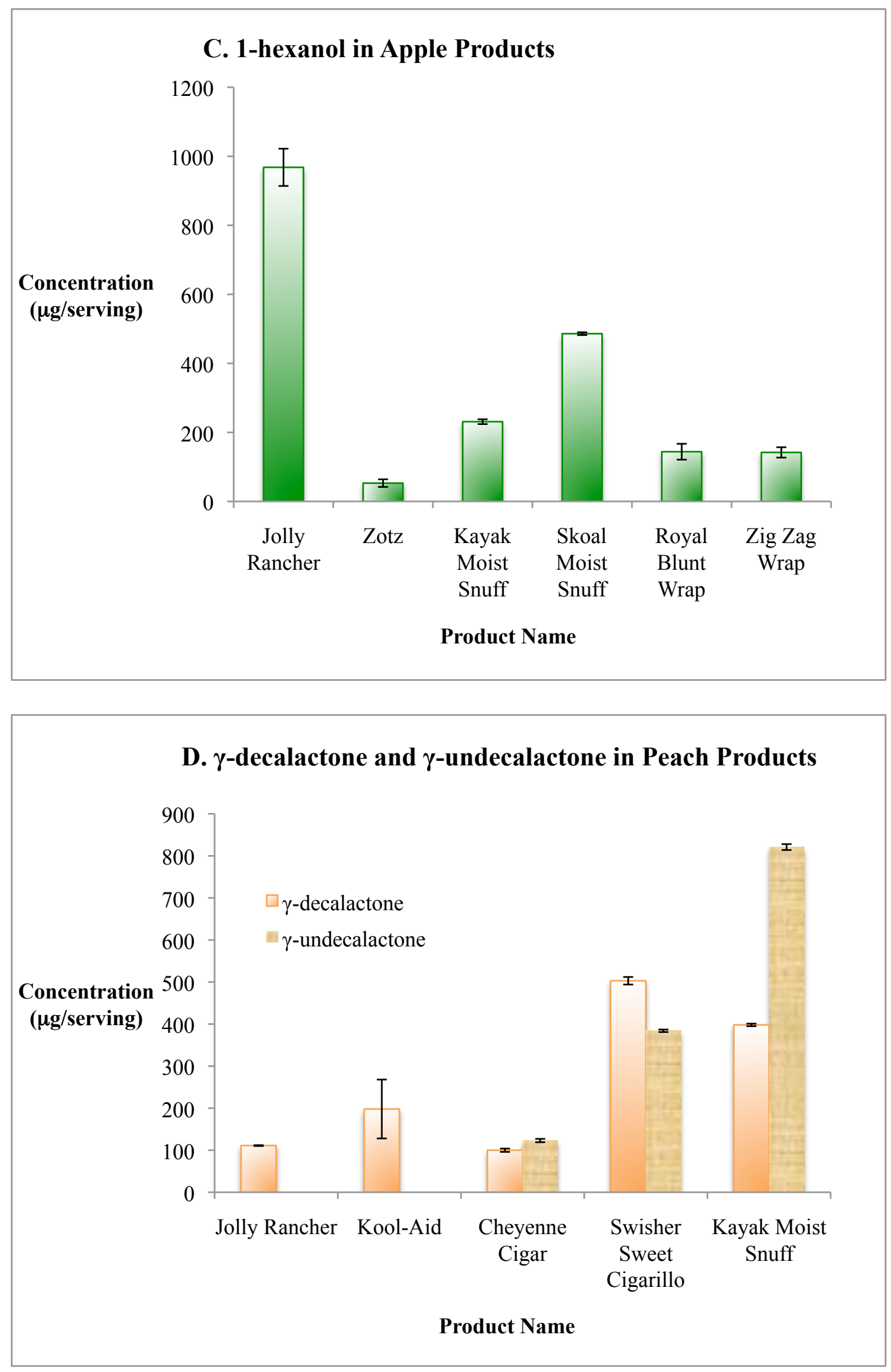


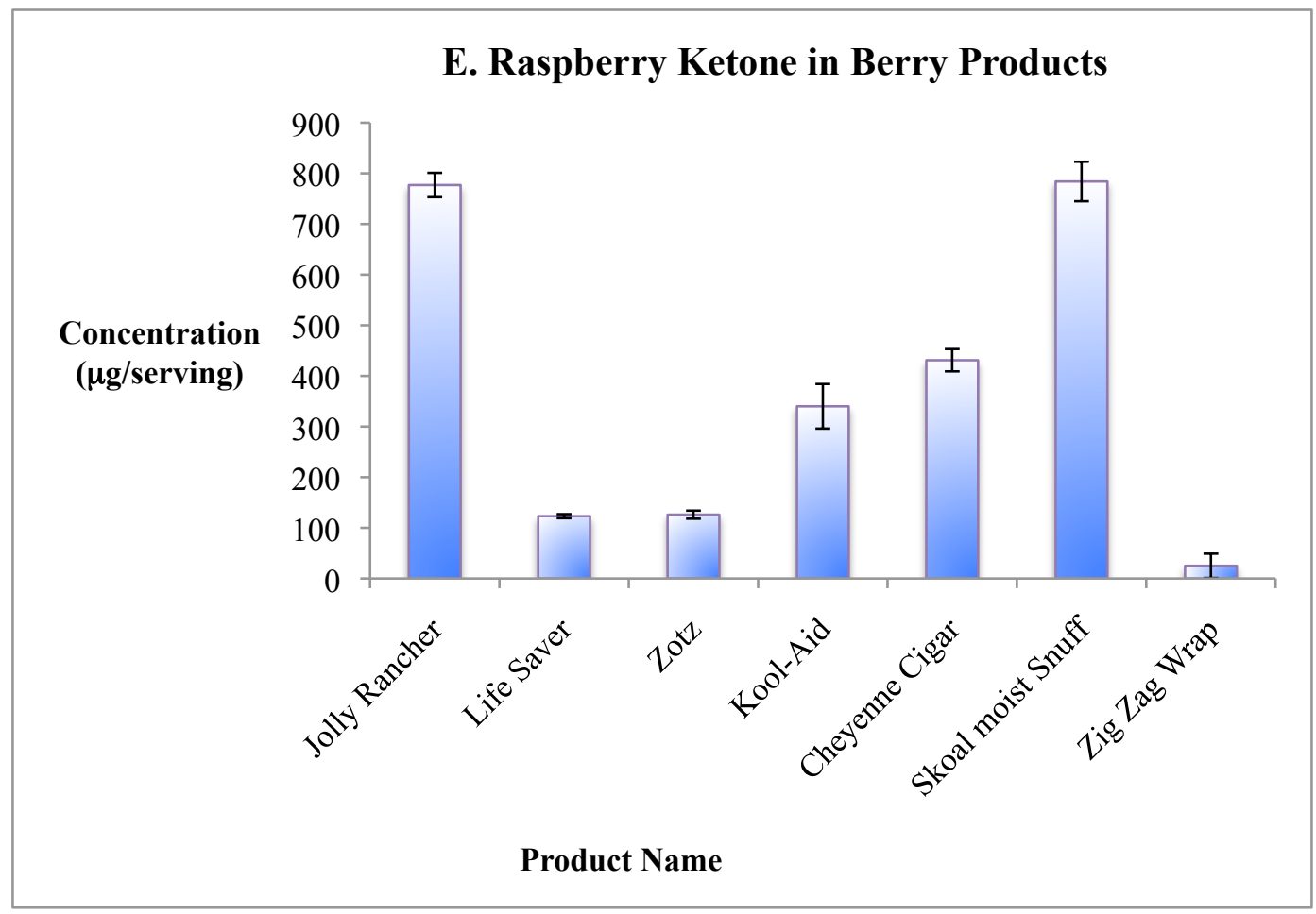

Figure 1.A-E. Bar graphs of the mass of benzaldehyde and benzyl alcohol, methyl anthranilate, 1-hexanol, $\gamma$-decalactone and $\gamma$-undecalactone, and raspberry ketone found per serving in each product assigned to the cherry, grape, apple, peach and berry flavor categories. Trace amounts were not plotted. The error bars give the standard deviation for 3 replicates. See Appendix A, tables A.4.1-A.4.5, for serving size definitions.

*In Figure 1.B flavorant levels represent $1 \mathrm{~g}$ of the approximately $7 \mathrm{~g}$ Phillies Blunt. 


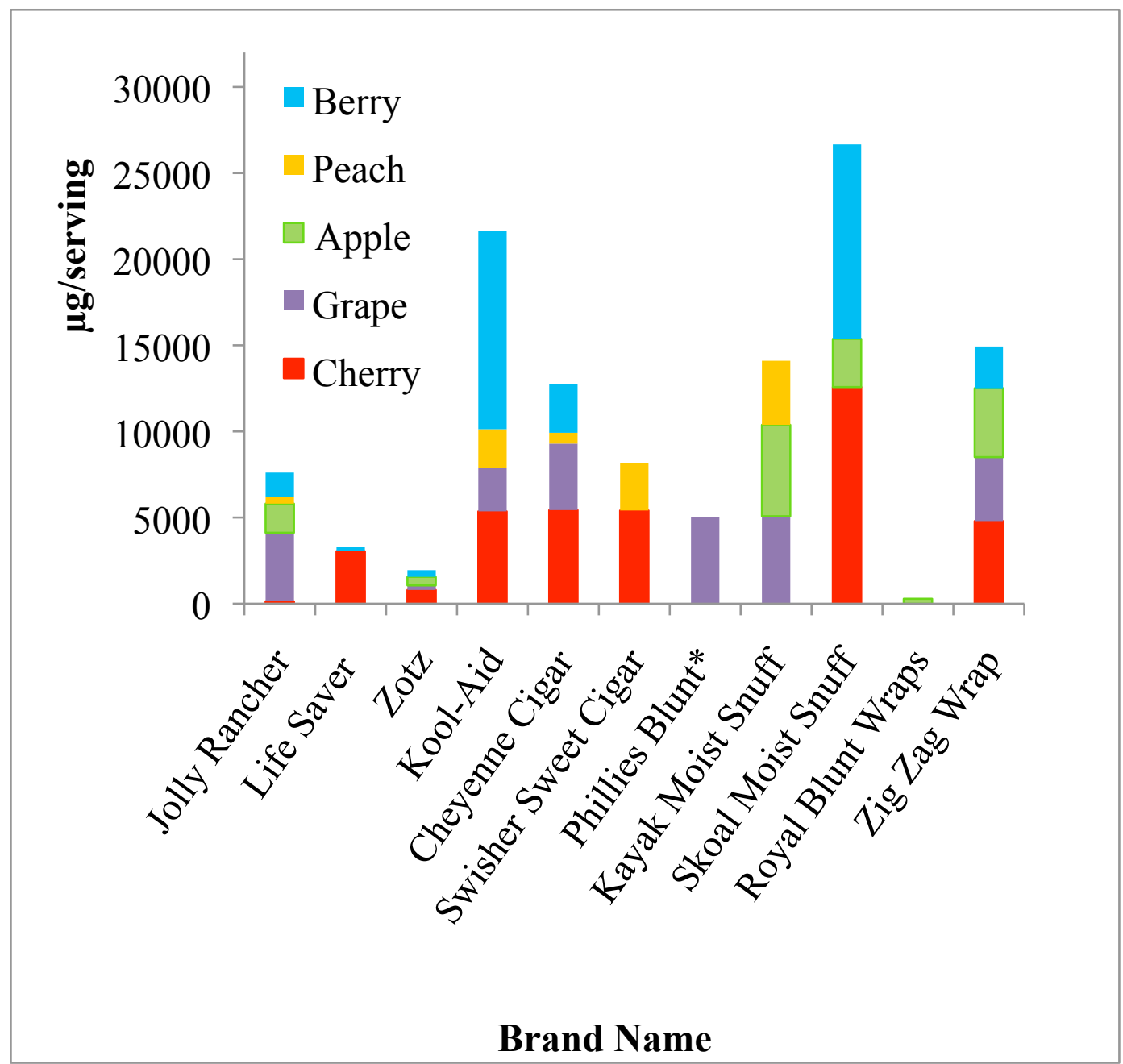

Figure 2. A bar graph of total $\mu$ g of flavorants per serving for each product tested. Trace levels were not included in the total flavorant calculations. See Appendix A, tables A.4.1-A.4.5, for serving size definitions.

* Total flavorant levels represent $1 \mathrm{~g}$ of the approximately $7 \mathrm{~g}$ Phillies Blunt. 


\subsection{Discussion}

Table A.2 gives the average of the relative standard deviation (RSD) of each above trace compound (generated by analysis of three replicates) detected in a sample, along with the range of RSD. Above trace compounds were found at $\geq 0.3 \mathrm{ng} / \mu \mathrm{L}$ in solution. With the exception of the Phillies Blunt, apple Zotz and raspberry Jolly Rancher, all cigars and candies had a low average RSD of $<15 \%$ with most $<10 \%$. Cherry and peach-mango Kool-Aid, grape Phillies Blunt and all blunt wraps had higher average RSDs $(>15 \%)$ than the other samples.

Reproducibility appears to be dependent on homogeneity within and between each product, and seems to vary between brands. The high RSD values for the KoolAid products indicate uneven flavorant distribution throughout the powder; only a portion of the powder within each packet was analyzed. A $1 \mathrm{~g}$ cylinder was removed from the Phillies Blunt ( $\sim$ g) for analysis, and the high average RSD may have resulted from lack of within sample homogeneity. The average RSD for moist snuff was generally much lower even though the analyses involved measurement of $1 \mathrm{~g}$ of snuff from each can, indicating a greater within sample homogeneity for moist snuff than Kool-Aid and Phillies Blunt. For the candies, blunt wraps and cigars, the entire unit was analyzed. The high average RSD for blunt wraps may have therefore been a result of lack of consistency of the flavor application between each product.

Compounds detected in tobacco at trace or low levels (roughly $<5 \mu \mathrm{g} / \mathrm{g}$ ) may be naturally occurring. The "CRP2" reference tobacco was found to have low levels of several analytes. GC/MS analysis of flue-cured tobacco measured $0.17 \mu \mathrm{g} / \mathrm{g}$ of benzyl 
alcohol (Wu et al. 2013), along with other compounds not included in our target analyte list.

The levels of flavorants found in moist snuff tobacco products are similar in magnitude to that found in a study of mint smokeless tobacco products where menthone, menthol, ethyl salicylate, menthyl acetate, carvone and limonene were detected at levels ranging between 170 and $4140 \mu \mathrm{g} / \mathrm{g}$ (Chen et al. 2010). A recent study also used MTBE to extract 10 analytes including ethyl salicylate, methyl salicylate, L-menthol and eugenol from U.S. cigar filler and snuff products, Southeast Asian products and clove cigarette fillers; comparable levels were found and the authors noted the identification of benzaldehyde and piperonal in a wild cherry cigar filler (Lisko, Stanfill, and Watson 2014).

Some have raised concerns regarding toxicity associated with flavor additives (Chen et al. 2010; Lisko, Stanfill and Watson 2014). The chemistry of flavorant compounds and nicotine is largely unknown, along with the health risks of consuming large quantities of flavorants via smoking and chewing tobacco. Research investigating the effect of tobacco additives on toxicity is limited and often sponsored by the tobacco industry. Several tobacco industry studies on additives including flavor compounds concluded that toxicity was unaffected (Carmines 2002; Gaworski et al. 2011; Coggins et al. 2011). The 2002 study by Carmines concluded that 333 additives, including flavorants, did not increase the toxicity of cigarettes. A subsequent analysis of Carmines data found increased total particulate matter and levels of toxins with the introduction of additives; the authors argue "industry scientific research on the use of cigarette additives cannot be taken at face value" (Wertz et al. 2011). More studies are 
needed to fully understand the effect of additives, including flavor chemicals, on toxicity.

There are several limitations to this study. A more complete analysis should include limits of detection and quantitation, but this was not feasible due to the number of analytes. Reproducibility increases with more replicates, but this requires a significant amount of resources and labor. Ideally the internal and surrogate standards would better correspond to the structure of the analytes, but the complexity of the samples made finding a more representative standard difficult. 


\section{5. Conclusions}

Significant compositional overlap was found between flavored tobacco products and Jolly Ranchers, Life Savers, Zotz and Kool-Aid. The results of this study indicate that "candy-flavored tobacco" is a chemically valid designation. Many of the compounds listed in Table A.3 are included in the flavorant compilation in Burdock (2009) with some entries including "usual" and "maximum" levels in hard candy, soft candy and or non-alcoholic beverages. Toxicological concerns regarding flavorant additives should be addressed. Further areas for research include the characterization and quantification the constituents of novel products such as electronic cigarettes, toxicological assessment of flavorant additives, and their impact on youth tobacco users. 
2. HCA Analysis

\subsection{Introduction}

\subsubsection{The Environmental Relevance of VBOCs}

Many flavorants, such as p-cymene, linalool, limonene, $\beta$-myrcene, $\alpha$-pinene, and $\gamma$-terpinene, are also volatilizable biogenic organic compounds (VBOCs). Plants emit an estimated $1100 \mathrm{TgCyr}^{-1}$ of VBOCs into the atmosphere, a mass 7 to 10 times that of anthropogenic emissions (Muller 1992; Piccot, Watson, and Jones 1992; Guenther et al. 1995). VBOCs have been defined based on vapor pressure comprising non-methane volatile organic compounds (VOCs) with vapor pressure $\geq 10^{-4}$ atm and semivolatile organic compounds (SVOCs) with vapor pressure between $10^{-4}-10^{-11}$ atm included due to evidence of SVOC contribution to particulate matter formation (Pankow et al. 2012). An important classification within the VBOC group includes the terpenes. The hemiterpene isoprene $\left(\mathrm{C}_{5} \mathrm{H}_{8}\right)$, comprises about half of the annual VBOC emissions, with estimates ranging between 500 and $560 \mathrm{TgCyr}^{-1}(\mathrm{~A}$. Guenther et al. 2006; Wang and Shallcross 2000; Muller 1992) and functions to protect leaves from rapid temperature changes due to sunlight and reactive oxidation species (Sharkey, Wiberley, and Donohue 2007). Monoterpenes $\left(\mathrm{C}_{10} \mathrm{H}_{16}\right)$ such as $\alpha$-pinene, $\beta$-pinene, sabinene and limonene have been estimated to comprise $40-80 \%$ of non-isoprene terpene emissions (Kanakidou et al. 2005; Pankow et al. 2001). Sesquiterpenes $\left(\mathrm{C}_{15} \mathrm{H}_{24}\right)$ and oxygenated or hydrogenated terpenes are also environmentally significant. 
A more comprehensive understanding of the identities and properties of volatilizable biogenic organic compounds (VBOCs) would support air quality and climate change research and management (Porter et al. 2012; Guenther 2002). VBOCs react with nitrogen oxides $\left(\mathrm{NO}_{\mathrm{x}}\right)$ to form ozone in the presence and sunlight. The oxidation and subsequent condensation of VBOCs yields secondary organic aerosol (SOA), a contributor to particulate matter (PM) (Amin, Hatfield, and Huff Hartz 2013; Claeys et al. 2004; Creasey, Heard, and Lee 2001; Pankow et al. 2001). Kanakidou et al. (2005) estimated that biogenic VOCs account for 9-50 $\mathrm{TgCyr}^{-1}$ of SOA produced assuming an organic matter to organic carbon ratio of 1:4.

Ozone and PM are the two criteria pollutants of greatest concern in the U.S. due to nonattainment of the National Ambient Air Quality Standards (NAAQS); about $40 \%$ of the U.S. population resided in counties exceeding NAAQS for PM and or ozone in 2010 (US EPA 2011). Tropospheric or ground level ozone is known to reduce lung function, cause respiratory symptoms, aggravate lung diseases and increase the risk of premature mortality; PM exposure has been shown to cause heart and lung disease aggravation and development as well as premature mortality (US EPA 2011).

Tropospheric ozone harms vegetation, can reduce $\mathrm{CO}_{2}$ uptake by plants (US EPA 2011; Stocker et al. 2014) and is radiatively active as a greenhouse gas (Stocker et al. 2014). VBOCs have been shown to impact hydroxyl radical concentrations which may subsequently affect the lifetime of methane, a potent greenhouse gas (Collins et al. 2002; Hofzumahaus et al. 2009; Lelieveld, Crutzen, and Dentener 1998). The emission of VBOCs is a significant source of carbon entering the 
atmosphere, affecting carbon cycling and calculations of carbon fluxes (Alex Guenther 2002). PM reduces visibility through scattering and absorption of solar radiation and it plays a largely uncertain role in radiative forcing (a measure of the solar radiation energy budget) through cloud nucleation and aerosol radiation interactions (Stocker et al. 2014; Schulz et al. 2006; Hansen and Sato 2001).

\subsubsection{VBOC Uncertainty}

Despite their abundance and importance, biogenic emissions and their atmospheric reaction products are extremely complex and largely uncharacterized. These uncertainties are demonstrated by GCxGC/TOFMS analysis of the emissions of two tree species resulting in thousands of VBOC peaks for which a large percentage remained unidentified; the authors argue that the total annual mass of VBOC emissions as well as the importance of unidentified compounds is an area of substantial uncertainty and that even studies measuring a relatively large number of VBOCs find that "the measured fluxes and atmospheric concentrations do not appear to account for total VBOC mass emissions" (Pankow et al. 2012). Researchers involved in atmospheric modeling indicate a need for more information regarding biogenic SOA precursors for modeling efforts (Guenther et al. 2012; Carlton et al. 2010; Aiyyer et al. 2007). Kanakidou et al. (2005) cite sources of uncertainties stemming from lack of understanding of specific emission factors by species and environmental conditions, and that the understanding of emissions of SOA precursors, such as sesquiterpenes, is unsatisfactory. 
The compositional complexity captured by GCxGC/TOFMS poses data processing challenges (Roskamp 2013) and hinders pattern recognition. Cluster analysis is an unsupervised multivariate method that employs similarity measures to group variables together (Pérez Pastor, García Alonso, and Quejido Cabezas 2002). Agglomerative hierarchical cluster analysis (HCA) has been used to determine $\mathrm{PM}_{10}$ sources in Kathmandu Valley, Nepal (Giri et al. 2007) and aerosol sources in Mexico City (Miranda et al. 2004). The PINOT NOIR data analysis portion of this work uses HCA to group the data into clusters thereby making the data more manageable. 


\subsection{Methods}

\subsubsection{Data Description}

This work employed HCA of data generated by M. Roskamp from air samples she collected during the Particle Investigations at a Northern Ozarks Tower: $\mathrm{NO}_{\mathrm{x}}$, Oxidant, Isoprene Research (PINOT NOIR) study. The ambient samples were collected on adsorption/thermal desorption (ATD) cartridges within the tree canopy during an "extreme drought" period, purged with $500 \mathrm{~mL}$ of dry ultra-pure helium to remove moisture and shipped to and stored at PSU. More information regarding the site, sampling and instrumentation procedures can be found in Roskamp (2013).

Roskamp's data processing yielded compounds identified in each sample and their corresponding concentrations. Samples were run using two-dimensional gas chromatography time of flight mass spectrometry (GCxGC/TOFMS) and the concentration for compounds of interest were calculated using standard response factors. The data was generated from 13 samples collected between July $29^{\text {th }}$ and August $3^{\text {rd }}, 2012$. Table B.1 provides the file name, date, time and temperature and relative humidity measurements taken at the time of collection. In the case of duplicate samples, that with the highest number of compounds detected was selected for this analysis. The first and second column retention times were calculated as Kovats Retention Index Value $(I)$ and Second Dimension Retention Ratio $(R)$ as described by Pankow et al. (2012). In summary, the data included concentration as well as I and R values for compounds detected in 13 samples analyzed by GCxGC/TOFMS and collected in the northern Ozarks. 


\subsubsection{Procedure}

The data was first formatted into a matrix. The $I$ and $R$ values were reduced into a one-dimensional combined retention time $\left(\mathrm{RT}_{\mathrm{c}}\right)$ for ease of formatting the matrix and plotting results using:

$$
\mathrm{RT}_{\mathrm{c}}=I+0.1 R \quad \text { Equation } 5 .
$$

Constituents with the same $I$ value and the same name were grouped as one compound; those with the same $\mathrm{RT}_{\mathrm{c}}$ but a different identification were combined if they did not occur in the same sample simultaneously.

Agglomerative hierarchical clustering was selected as the best clustering method for the data in MATLAB. The spearman distance, average linkage and cophenetic correlation were all calculated in MATLAB (2014a). Appendix C provides the code used for the analysis. The pdist function produces a dissimilarity matrix $(Y)$ by calculating the pairwise distance between pairs of objects. The Spearman distance grouped data more appropriately than Euclidean, Seuclidean, Mahalanobis, Minoski, correlation (Pearson) or Hamming metrics. The Spearman distance measures the strength of the monotonic relationship between paired data. It was calculated by using (MATLAB 2014a):

$$
d_{s t}=1-\frac{\left(r_{s}-\bar{r}_{s}\right)\left(r_{t}-\bar{r}_{t}\right)^{\prime}}{\sqrt{\left(r_{s}-\bar{r}_{s}\right)\left(r_{s}-\bar{r}_{s}\right)^{\prime}} \sqrt{\left(r_{t}-\bar{r}_{t}\right)\left(r_{t}-\bar{r}_{t}\right)^{\prime}}} \quad \text { Equation } 6 .
$$

Where $r_{s}$ and $r_{t}$ are the rank vectors of $x_{s}$ and $x_{t}$, and where

$$
\bar{r}_{s}=\frac{1}{n} \sum_{j} r_{s j}=\frac{(n+1)}{2} \quad \text { and } \quad \bar{r}_{t}=\frac{1}{n} \sum_{j} r_{t j}=\frac{(n+1)}{2}
$$


Where $r_{s j}$ is the rank of $x_{s j}$ taken over $x_{1 j}, x_{2 j}, \ldots . ., x_{\mathrm{n} j}$ and is computed by MATLAB's tiedrank function.

The linkage function in MATLAB yields matrix $\mathrm{Z}$ and represents the dendrogram based on the dissimilarity matrix calculated by pdist. Methods available for the Spearman distance were average, complete, single and weighted average linkages. Average linkage generated the highest cophenetic correlation of 0.79972 and was calculated using (MATLAB 2014a):

$$
d_{(r, s)}=\frac{1}{n_{r} n_{s}} \sum_{i=1}^{n_{r}} \sum_{j=1}^{n_{s}} \operatorname{dist}\left(x_{r i}, x_{s j}\right)
$$

Where $d_{(r, s)}$ is the distance between clustered objects, $d\left(x_{r i}, x_{s j}\right)$ is the distance between objects, and $n_{r}$ and $n_{s}$ are the number of objects in clusters $r$ and $s$, respectively.

Cophenetic correlation $(c)$ describes the degree of agreement between the dendrogram and dissimilarity produced by linkage and pdist, respectively. It was calculated using (MATLAB 2014a):

$$
c=\frac{\sum_{i<j}\left(Y_{i j}-y\right)\left(Z_{i j}-z\right)}{\sqrt{\sum_{i<j}\left(Y_{i j}-y\right)^{2} \sum_{i<j}\left(Z_{i j}-z\right)^{2}}}
$$

$Y_{i j}$ is the distance between objects $i$ and $j$ in $Y, Z_{i j}$ is the cophenetic distance between objects $i$ and $j$ in $Z$, and $y$ and $z$ are the average of $Y$ and $Z$, respectively.

The optimal number of clusters was determined by close examination of cluster solutions between 10 and 50 in an Excel spreadsheet. Once an appropriate range of possible solutions was narrowed down, the changes in compound assignment with progressively increasing clusters were carefully tracked. The maximum number of clusters was found when this writer deemed the movement of one or more 
compounds to its own cluster (in this case sabinene and $\beta$-myrcene moving out of cluster 14) as unnecessary. Cluster validation options, such as Calinski-Harabasz, Davies-Bouldin, Gap and Silhouette criterion and the evalcluster function, were explored in MATLAB, but did not support the Spearman distance. 


\subsection{HCA Results}

\subsubsection{HCA Solution}

27 clusters yielded an acceptable balance of data consolidation and similarity of temporal trends. In each cluster, there are between 1-39 distinct compounds appearing in 1-13 samples and having 1-91 entries, defined as a compound specific to a sample (Table B.2). Figure 3 is a color-coded dendrogram and presents the HCA solution of 27 clusters. The dendrogram was cut at an average linkage distance of about 0.4. Most clusters fall in between 0.2-0.4 (dashed line). The black branches connecting clusters give the distance between clusters, which range from approximately $0.42-1.11$.

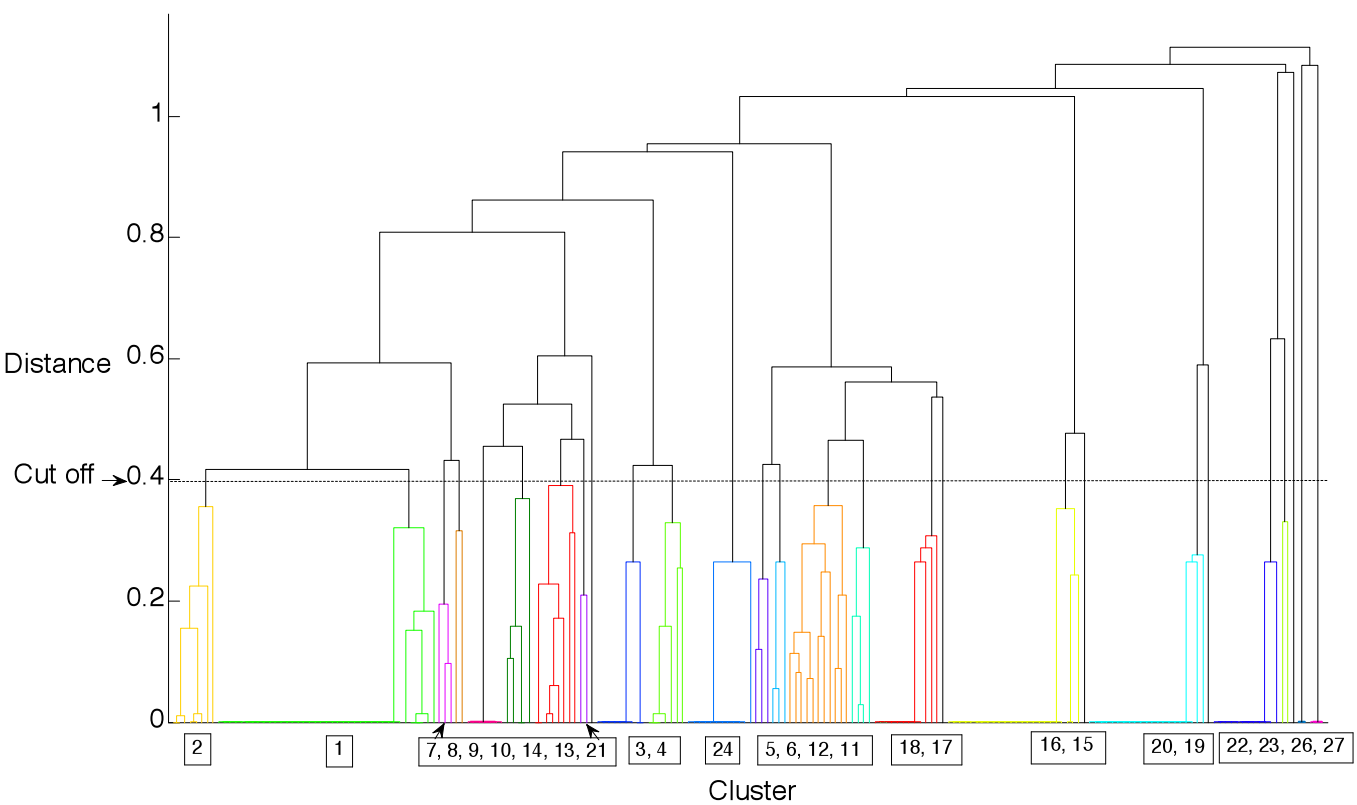

Figure 3. The dendrogram of 27 cluster solutions generated from HCA. Each cluster is separated by color and labeled. Black lines give the distance between each cluster. Individual compounds are embedded within each cluster. The dashed line gives the cut off distance used to generate the 27 clusters. 


\subsubsection{Cluster Types}

To facilitate analysis, clusters were classified as type I, II, III or IV (see Figure 4.A-D). Each ordered pair represents a compound found in a sample; marker shape and color correspond to its assigned cluster. Table B.3 provides information pertaining to each cluster, including date, time of day, temperature and relative humidity. The identification and retention times of compounds in each cluster are shown in Table B.4.1-B.4.4.

Clusters 1, 3, 9, 16, 18, 20, 22, 24, 25, 26 and 27 have been identified as Type 1. As shown in Figure 4.A, most of the 11 type I clusters generally contain a wide range of individual compounds predominantly detected in only one sample. For example, the majority of compounds detected in cluster 1,16 and 20 correspond to the sample collected on 7/31/12 at 4:30 PM, 7/30/12 at $2 \mathrm{PM}$ and 7/31/12 at 2:30 PM, respectively. The standard deviation of the temperature and relative humidity averages for type I clusters are low, ranging from between $\pm 0.0-2.3$ and $0.0-7.4$, respectively. Compounds included in type I clusters had relatively low concentrations in contrast to the other cluster types, with the bulk measured at $<1 \mu \mathrm{g} \mathrm{m}^{-3}$, and the maximum at 2.8 $\mu \mathrm{g} \mathrm{m}^{-3}$. Compounds assigned to type I clusters include 1-decene (at two retention times), 2-methyl-2-butenal, 2,6-dimethyl-1-octene (at three retention times), at least 5 acid species, sabinene, terpinolene, undecanal, undecane, $\beta$-phellandrene and 10 unknown compounds. Cluster 25 contains only entry, a compound identified as 4,8dimethyl-1,7-nonadien-4-ol and detected on 8/2/12 at 11:10 AM. Clusters 26 and 27 have 2 and 3 entries, respectively; all are distinct compounds. About $70 \%$ of the 204 compounds used in this analysis were assigned to the type I clusters; about $41 \%$ were 
assigned to clusters 1, 16 and 20. All compounds found in type I clusters, including ones not listed here, are presented in Table B.4.1.

As shown in Table B.4.2, type II clusters $(15,17,19$ and 21$)$ contain just one compound; all were found in $\geq 4$ samples. Thus, as compared with type I clusters, type II clusters occupy a narrower range of RT (less compound diversity), but a wider range of sample numbers (Figure 4.B). Cluster 15 contains $\beta$-pinene, detected in samples collected on 7/29/12 at 2:00 PM and 4:30 PM, 7/30/12 at 2:00 PM and 7/31/12 at 2:30 PM. Trans-3-decene, $\alpha$-thujene and 1,4-dimethyl cyclooctane $\left(\mathrm{RT}_{\mathrm{c}}=1083.080056\right)$ were the identifications of the other three compounds isolated into their own clusters, respectively. Note that 1,4-dimethyl cyclooctane was identified at two other $\mathrm{RT}_{\mathrm{c}} \mathrm{s}$, including 1571.0818 and 1551.0806; this compound likely was misidentified as it should only comprise two cis and trans isomers. As visualized by dendrogram presented in Figure 3, the distance of these 4 compounds to any other compound calculated by linkage was greater than 0.4. Compounds falling into type II clusters have an average concentration range of $0.08-2.60 \mu \mathrm{g} \mathrm{m}^{-3}$.

Figure 4.C corresponds to type III clusters $(2,4,7,8,10,11,13,14$ and 23). The number of compounds assigned to each cluster ranges from 2-8, all of which were detected in $\geq 2$ but not all $(<13)$ samples. For example, of the 8 compounds assigned to cluster 2, all were detected on 7/31/12 at 2:30 PM and 4:30 PM, with a few detected in 5 other samples. Compounds in this type include 2-decenol, 2-ethylhexyl salicylate, 3carene, $\alpha$-cedrene, decanal, dodecyl acrylate, geranyl acetone, homosalate, longifolene, sabinene (this compound was also identified at a different retention time 
in a Type I cluster), thujospene, Z-ocimene, and $\beta$-myrcene. Type III clusters range in concentration from 0.03-25.5 $\mu \mathrm{g} \mathrm{m}^{-3}$.

Type IV clusters (5, 6 and 12) include one or more compounds detected in every sample, as depicted visually in figure 4.D. This cluster type comprised $8 \%$ of the compounds. Isoprene was grouped into cluster 5 with 3-methylene nonane and methyl 4,6-decadienyl ether. Cluster 6 contained methacrolein with methyl vinyl ketone and 3-methylheptal acetate. Limonene, p-cymene and $\alpha$-pinene were detected in all samples and included in cluster 12 with 8 other compounds. The concentration of compounds in type IV clusters ranged from 0.02-92.05 $\mu \mathrm{g} \mathrm{m}^{-3}$, with isoprene, methacrolein and methyl vinyl ketone contributing to the bulk of the mass. 

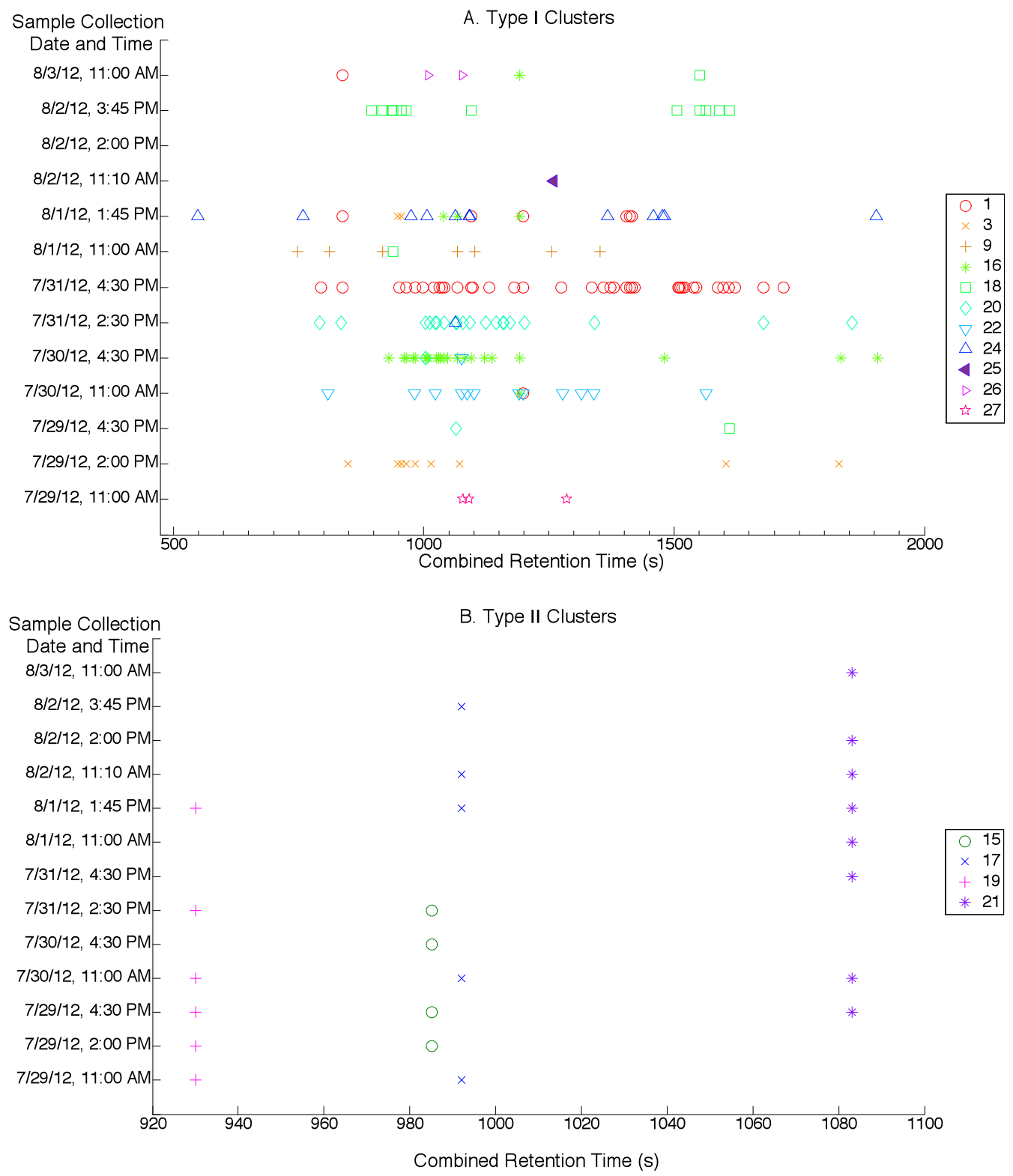

Figure 4. A-B. Figure 4 plots distinct compounds as defined by their combined retention time against the sample collection date and time. Figure 4.A. Clusters are distinguished by marker style and color. For most clusters, Figure 4.A and 4.B depict compound and sample diversity, respectively. 


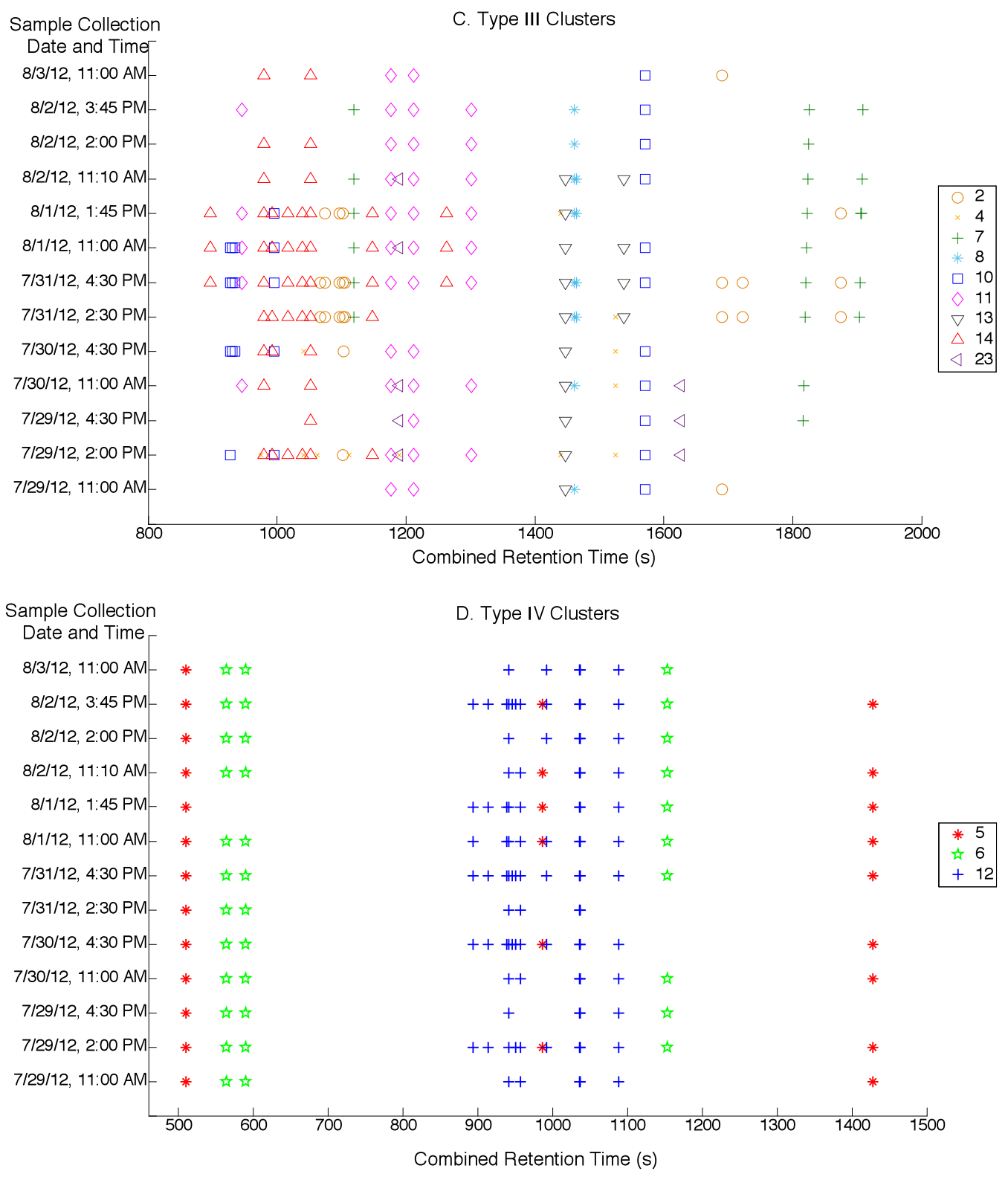

Figure 4.C-D. Figure 4.C show all compounds assigned to type III clusters. All compounds in these clusters were detected in more than one sample. Figure 4.D. includes type IV clusters, in which there was at least one compound entry in every sample. 


\subsection{Discussion}

\subsubsection{Cluster validation}

The efficacy of the Spearman distance is depicted in Figure 5.A-B, where the sample versus concentration for compounds assigned to cluster 6 and 12 is plotted, respectively. The Spearman metric has captured temporal behavior; unlike the Euclidean distance, it is not sensitive to magnitude of concentration. The compounds in cluster 6 merge at an average linkage distance of about 0.27 . Cluster 12 exhibits a higher distance between compounds, at approximately 0.36. Figure 5.B shows the effect of this distance graphically, and the compounds appear to be less correlated than those assigned to cluster 6 . To generate clusters with greater similarity the distance criteria could be increased, but many more clusters would result. The challenge of cluster analysis is in finding the right balance of consolidation of data into as few clusters as possible while maintaining reasonable similarity between the clusters. Cluster validation options in MATLAB were explored, but functions such as evalcluster did not support the Spearman distance. Further work should utilize code or another program to validate cluster solutions.

Figure 5.A provides a plot of temperature on a second y-axis. Because the sampling occurred between 11:00 AM and 4:30 PM temperature remained fairly stable and the correlation between cluster 6 compound concentration and temperature was low. Sharp increases in concentration of most of the compounds shown in Figure 5AB occurred on 8/1/12 and 8/2/12 at 11:00 AM and 3:45 PM; this also occurred for isoprene (not shown). The high concentration samples may have been a result of an 
error; analysis of the duplicate sample taken on 8/2/12 3:45 PM yielded significantly lower concentrations. The incorporation of more samples, as well as their duplicates, would make the results more robust.

The discovery of four cluster types demonstrates the pattern recognizing power of HCA. The separation of those compounds emerging primarily in one sample from those that were detected in multiple samples provides information regarding which compounds were consistently present during the sampling time and which appeared likely result of some combination of environmental factors. The assignment of clusters to certain types allowed for dimension and noise reduction, and provided an opportunity to assess environmental effects on chemistry

A significant finding was that almost $30 \%$ of the compounds were designated to cluster 1 and 20, both type I clusters. Cluster 1 and 20 capture compounds primarily emerging on 7/31/12 at 4:30 PM and 2:30 PM, respectively. According to EPA data collected by Chris Geron (2012), wind direction was predominantly northeast and east-northeast on 7/31/12 (Figure 6.B) and on this day the highest temperature, lowest relative humidity, and lowest average wind speed (Figure 7) were recorded. Note that data was not collected on 7/30/12. Ashland is located $10 \mathrm{~km}$ east of the site (Roskamp 2013), and it is possible that anthropogenic sources of pollution were a contributing factor to the unique species observed on 7/31/12. At least 5 compounds containing benzene rings were present in cluster 1 and 20 . The stagnant air, high temperature and low relative humidity likely contributed to the emergence of these compounds, most found only on $7 / 31 / 12$, and was likely responsible for the highest measured 
concentrations of the sunscreen compounds homosalate and 2-ethylhexyl salicylate (cluster 7). 

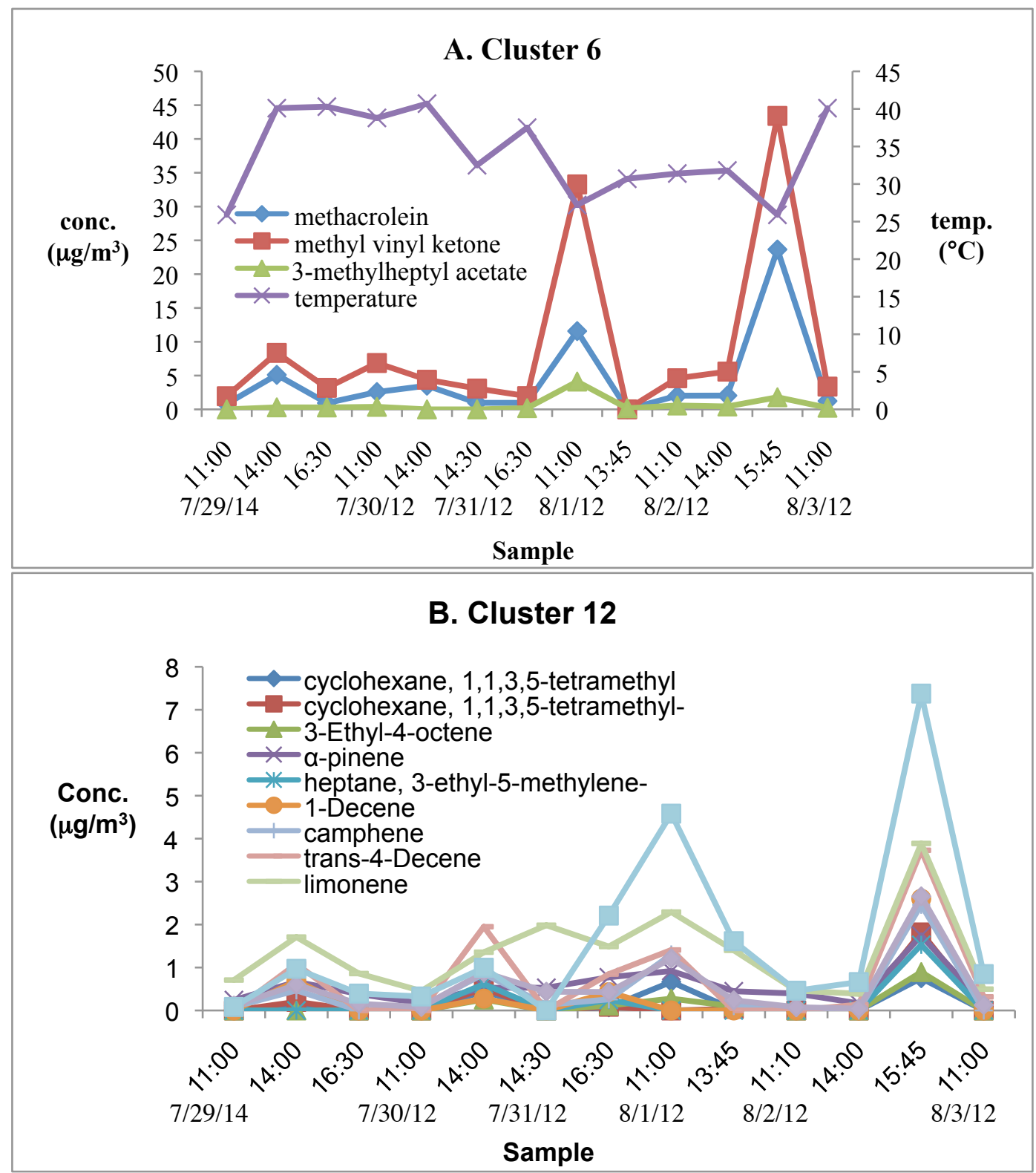

Figure 5.A-B. This figure shows how the spearman correlation was used to group variables. For Figure 5.A., the greatest distance of compounds is less than 0.3 in cluster 6 and the three compounds appear to be increasing and decreasing in a similar fashion. Temperature is also included, and was not well correlated with sample concentration. In Figure 5.B, the increased distance of just under 0.4 between some compounds in cluster 12 shows less agreement between compounds. 
A. $7 / 29 / 12$

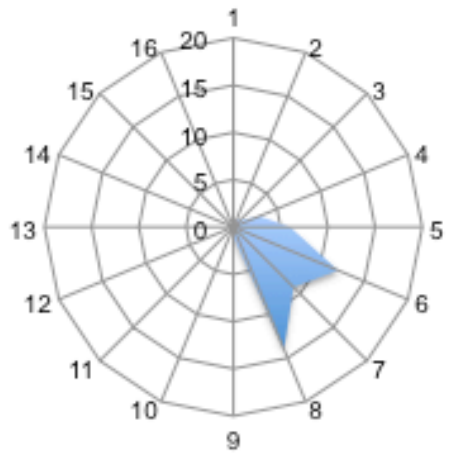

C. $8 / 1 / 12$

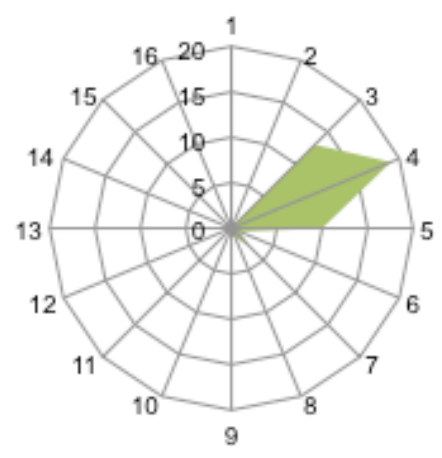

E. $8 / 3 / 12$

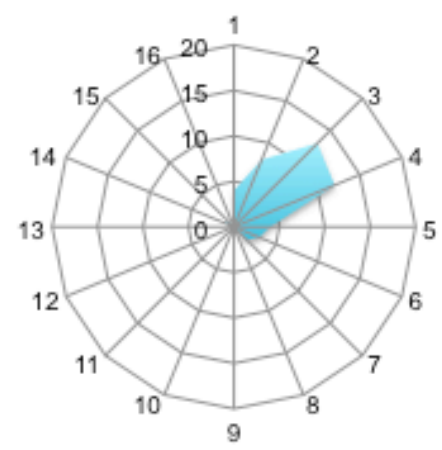

B. $7 / 31 / 12$

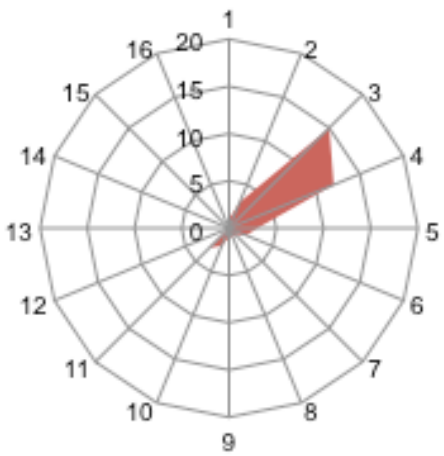

D. $8 / 2 / 12$

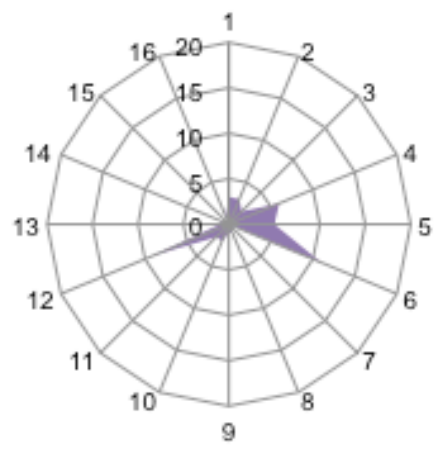

F. All Days

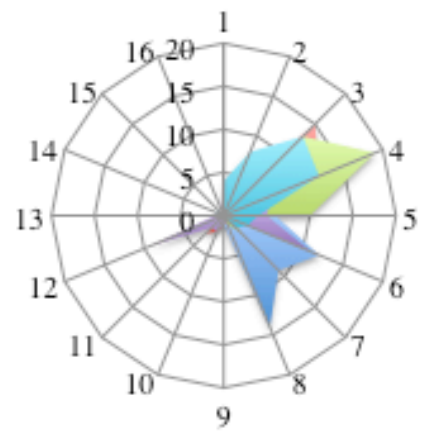

Direction

$1 \mathrm{~N}$ 2 NNE

$3 \mathrm{NE}$

4 ENE

$5 \mathrm{E}$

$6 \mathrm{ESE}$

$7 \mathrm{SE}$

8 SSE

$9 \mathrm{~S}$

10 SSW

$11 \mathrm{SW}$

12 WSW

$13 \mathrm{~W}$

14 WNW

$15 \mathrm{NW}$

$16 \mathrm{NNW}$

Figure 6.A-F. Site specific wind direction. Direction labels given by key on the right. Data was not available for 7/30/12. 


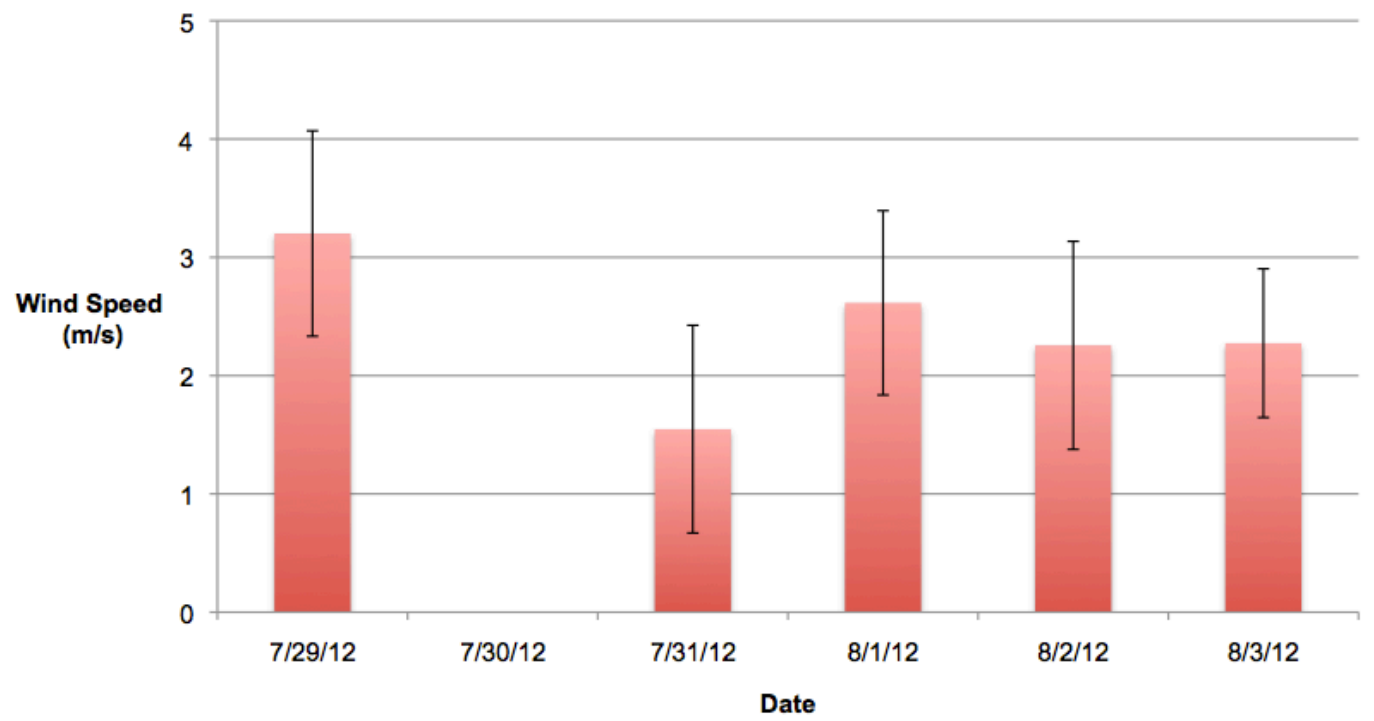

Figure 7. A bar graph of average wind speed data for each day. Data was not available for $7 / 30 / 12$. The error bars give the standard deviation for each average. 


\subsection{HCA conclusions}

HCA reduced 204 compounds in 13 samples to 27 clusters that describe temporal behavior of one or more compounds, demonstrating the usefulness of HCA in consolidating large amounts of data. Cluster analysis is sometimes paired with other statistical techniques such as principal component analysis (PCA) (Heringa et al. 2012; Saucy, Anderson, and Buseck 1991). For example, Saucy, Anderson, and Busbck (1991) wrote "PCA of such a data set can yield information about the temporal behavior of the particle types that were previously identified by cluster analysis". PCA requires more observations (samples) than variables (compounds) and could be used to understand how environmental variables such as relative humidity, temperature and anthropogenic sources of pollution contribute to cluster behavior. 
3. References

Alpert, H. R., H. Koh, and G.N. Connolly. 2008. "Free Nicotine Content and Strategic Marketing of Moist Snuff Tobacco Products in the United States: 2000-2006." Tobacco Control 17 (5): 332-38.

Amin, H.S., M.L. Hatfield, and K.E. Huff Hartz. 2013. "Characterization of Secondary Organic Aerosol Generated from Ozonolysis of $\alpha$-Pinene Mixtures." Atmospheric Environment 67 (March): 323-30.

Demian, Barbu A. 1993. "Trace Analysis of Vanillin In Tobacco." http://legacy.library.ucsf.edu/documentStore/u/q/1/uq146e00/Suq146e00.pdf.

Brown, J.E., W. Luo, L.M. Isabelle, and J.F. Pankow. 2014. "Candy Flavorings in Tobacco.” New England Journal of Medicine 370 (23): 2250-52.

Burdock, George A. 2009. Fenaroli's Handbook of Flavor Ingredients, Sixth Edition. Boca Raton, FL: CRC Press.

Carmines, E. L. 2002. "Evaluation of the Potential Effects of Ingredients Added to Cigarettes. Part 1: Cigarette Design, Testing Approach, and Review of Results." Food and Chemical Toxicology 40 (1): 77-91.

Center for Disease Control and Prevention. 2008. "Smoking-Attributable Mortality, Years of Potential Life Lost, and Productivity Losses --- United States, 2000-2004.” Morbidity and Mortality Weekly Report (MMWR) 57 (45): 1226-28.

Center for Disease Control and Prevention. 2012a. "Smoking and Tobacco Use; 2012 Surgeon General's Report." Smoking and Tobacco Use. http://www.cdc.gov/tobacco/data_statistics/sgr/2012/.

Center for Disease Control and Prevention. 2012b. "Current Tobacco Use Among Middle and High School Students - United States, 2011." Morbidity and Mortality Weekly Report 61 (31): 581-85.

Chen, C., L.M. Isabelle, W.B. Pickworth, and J.F. Pankow. 2010. "Levels of Mint and Wintergreen Flavorants: Smokeless Tobacco Products vs. Confectionery Products." Food and Chemical Toxicology 48 (2): 755-63.

Claeys, M., B. Graham, G. Vas, W. Wang, R. Vermeylen, V. Pashynska, J. Cafmeyer, et al. 2004. "Formation of Secondary Organic Aerosols through Photooxidation of Isoprene.” Science 303 (5661): 1173-76.

Coggins, C.R.E., J.S. Edmiston, A.M. Jerome, T.B. Langston, E.J. Sena, D.C. Smith, and M. J. Oldham. 2011. "A Comprehensive Evaluation of the Toxicology of Cigarette Ingredients: Essential Oils and Resins." Inhalation Toxicology 23 (June): 41-69. 
Collins, W.J., R.G. Derwent, C.E. Johnson, and D.S. Stevenson. 2002. "The Oxidation of Organic Compounds in the Troposphere and Their Global Warming Potentials." Climatic Change 52 (4): 453-79.

Creasey, D.J., D.E. Heard, and J.D. Lee. 2001. "OH and $\mathrm{HO}_{2}$ Measurements in a Forested Region of North-Western Greece.” Atmospheric Environment 35 (27): 4713-24.

Delnevo, C.D., O.A. Wackowski, D.P. Giovenco, M.T.B. Manderski, M. Hrywna, and P.M. Ling. 2012. "Examining Market Trends in the United States Smokeless Tobacco Use: 2005-2011." Tobacco Control 23 (2): 107-12.

Gaworski, C.L., M.J. Oldham, K.A. Wagner, C. Coggins, and G.J. Patskan. 2011. “An Evaluation of the Toxicity of 95 Ingredients Added Individually to Experimental Cigarettes: Approach and Methods." Inhalation Toxicology 23 (51): $1-12$.

Giri, D., V.K. Murthy, P.R. Adhikary, and S.N. Khanal. 2007. "Cluster Analysis Applied to Atmospheric $\mathrm{PM}_{10}$ Concentration Data for Determination of Sources and Spatial Patterns in Ambient Air-Quality of Kathmandu Valley." Current Science (00113891) 93 (5): 684-88.

Government Accountability Office. 2012. "Tobacco Taxes: Large Disparities in Rates for Smoking Products Trigger Significant Market Shifts to Avoid Higher Taxes. Report to Congressional Committees." http://www.gao.gov/assets/600/590192.pdf.

Guenther, A., T. Karl, P. Harley, C. Wiedinmyer, P.I. Palmer, and C. Geron. 2006. "Estimates of Global Terrestrial Isoprene Emissions Using MEGAN (Model of Emissions of Gases and Aerosols from Nature)." Atmospheric Chemistry \& Physics 6 (November): 3181-3210.

Guenther, Alex. 2002. "The Contribution of Reactive Carbon Emissions from Vegetation to the Carbon Balance of Terrestrial Ecosystems." Chemosphere 49 (8): 837-44.

Guenther, A., C.N. Hewitt, D. Erickson, R. Fall, C. Geron, T. Graedel, P. Harley, et al. 1995. "A Global-Model of Natural Volatile Organic-Compound Emissions." Journal of Geophysical Research-Atmospheres 100 (D5): 8873-92.

Hansen, James E., and Makiko Sato. 2001. "Trends of Measured Climate Forcing Agents." Proceedings of the National Academy of Sciences 98 (26): 14778-83.

Heringa, M.F., P.F. DeCarlo, R. Chirico, T. Tritscher, M. Clairotte, C. Mohr, M. Crippa, et al. 2012. "A New Method to Discriminate Secondary Organic Aerosols from Different Sources Using High-Resolution Aerosol Mass Spectra." Atmospheric Chemistry \& Physics 12 (4): 2189-2203. 
Hofzumahaus, A., F. Rohrer, K. Lu, B. Bohn, T. Brauers, C.C. Chang, H. Fuchs, et al. 2009. "Amplified Trace Gas Removal in the Troposphere." Science 324 (5935): 1702-4.

Kanakidou, M., J.H. Seinfeld, S.N. Pandis, I. Barnes, F.J. Dentener, M.C. Facchini, R. Van Dingenen, et al. 2005. "Organic Aerosol and Global Climate Modelling: A Review." Atmospheric Chemistry \& Physics 5 (4): 1053-1123.

King, B.A., S.R. Dube, and M.A. Tynan. 2013. "Flavored Cigar Smoking Among U.S. Adults: Findings From the 2009-2010 National Adult Tobacco Survey." Nicotine \& Tobacco Research 15 (2): 608-14.

King, B.A., M.A. Tynan, S.R. Dube, and R. Arrazola. 2014. "Flavored-Little-Cigar and Flavored-Cigarette Use Among U.S. Middle and High School Students." Journal of Adolescent Health 54 (1): 40-46.

Lelieveld, J., P.J. Crutzen, and F.J. Dentener. 1998. "Changing Concentration, Lifetime and Climate Forcing of Atmospheric Methane." Tellus 50B (April): $128-50$.

Lisko, J.G., S.B. Stanfill, and C.H. Watson. 2014. "Quantitation of Ten Flavor Compounds in Unburned Tobacco Products.” Analytical Methods 6 (13): 4698-4704.

MATLAB. 2014a. MATLAB and Statistics Toolbox Release 2014a. Natick, Massachusetts, United States: The MathWorks, Inc.

Miami Dade County. 2012. "Candy-Flavored Tobacco Products: Miami-Dade County Tobacco Update."

http://www.healthymiamidade.org/system/js/back/ckfinder/userfiles/files/Toba cco/Candy-Flavored\%20Tobacco\%20Newsletter\%20Q3_2012.pdf.

Miranda, J., V.A. Barrera, A.A. Espinosa, O.S. Galindo, A. Núñez-Orosco, R.C. Montesinos, A. Leal-Castro, and J. Meinguer. 2004. "PIXE Analysis of Atmospheric Aerosols from Three Sites in Mexico City." Nuclear Instruments and Methods in Physics Research Section B: Beam Interactions with Materials and Atoms, Proceedings of the Sixteenth International Conference on Ion Beam Analysis, 219-220 (June): 157-60.

Muller, J.F. 1992. “Geographical-Distribution and Seasonal-Variation of Surface Emissions and Deposition Velocities of Atmospheric Trace Gases." Journal of Geophysical Research-Atmospheres 97 (D4): 3787-3804.

Pankow, J.F., W. Luo, A.N. Melnychenko, K.C. Barsanti, L.M. Isabelle, C. Chen, A. B. Guenther, and T.N. Rosenstiel. 2012. "Volatilizable Biogenic Organic Compounds (VBOCs) with Two Dimensional Gas Chromatography-Time of Flight Mass Spectrometry (GCxGC-TOFMS): Sampling Methods, VBOC 
Complexity, and Chromatographic Retention Data." Atmospheric

Measurement Techniques 5 (2): 345-61.

Pankow, J.F., J.H. Seinfeld, W.E. Asher, and G.B. Erdakos. 2001. "Modeling the Formation of Secondary Organic Aerosol. 1. Application of Theoretical Principles to Measurements Obtained in the $\alpha$-Pinene/, $\beta$-Pinene/, Sabinene/, $\Delta^{3}$-Carene/, and Cyclohexene/Ozone Systems." Environmental Science \& Technology 35 (6): 1164-72.

Pérez P., R. M., S. García Alonso, and A.J. Quejido Cabezas. 2002. "Volatile Organic Compounds in the Area of Madrid: A Chemometrical Approach." Environmental Monitoring \& Assessment 75 (1): 33-50.

Piccot, S.D., J.J. Watson, and J.W. Jones. 1992. “A Global Inventory of Volatile Organic-Compound Emissions from Anthropogenic Sources." Journal of Geophysical Research-Atmospheres 97 (D9): 9897-9912.

Rodgman, Alan, and Thomas A. Perfetti. 2013. The Chemical Components of Tobacco and Tobacco Smoke, Second Edition. CRC Press. http://www.crcpress.com/product/isbn/9781466515482.

Roskamp, Melissa Jordan. 2013. "Characterization of Secondary Organic Aerosol Precursors Using Two-Dimensional Gas Chromatography with Time of Flight Mass Spectrometry (GCxGC/TOFMS)". Dissertations and Theses. Paper 1411.

Saucy, D.A., J.R. Anderson, and P.R. Buseck. 1991. “Aerosol Particle Characteristics Determined by Combined Cluster and Principal Component Analysis." Journal of Geophysical Research 96 (D4): 7407-14.

Schulz, M., C. Textor, S. Kinne, Y. Balkanski, S. Bauer, T. Berntsen, T. Berglen, et al. 2006. "Radiative Forcing by Aerosols as Derived from the AeroCom PresentDay and Pre-Industrial Simulations." Atmospheric Chemistry \& Physics 6 (12/3): 5225-46.

Sharkey, T.D., A.E. Wiberley, and A.R. Donohue. 2007. "Isoprene Emission from Plants: Why and How." Annals of Botany 101 (1): 5-18.

Stocker, T., Q. Dahe, G.K. Plattner, and L.V. Alexander. 2014. “Technical Summary. In: Climate Change 2013: The Physical Science Basis. Contribution of Working Group I to the Fifth Assessment Report of the Intergovernmental Panel on Climate Change". Cambridge University Press, Cambridge, United Kingdom and New York, NY, USA.

Substance Abuse \& Mental Health Services Administration. 2012. "Results from the 2011 Nation Survey on Drug Use and Health: Summary of National Findings." http://www.samhsa.gov/data/NSDUH/2k11Results/NSDUHresults2011.htm. 
US EPA, OAR. 2011. "Our Nation's Air - Status and Trends through 2010 I AirTrends I US EPA.” http://www.epa.gov/airtrends/2011/.

Wang, K.Y., and D. E Shallcross. 2000. "Modelling Terrestrial Biogenic Isoprene Fluxes and Their Potential Impact on Global Chemical Species Using a Coupled LSM-CTM Model.” Atmospheric Environment 34 (18): 2909-25.

Wertz, M.S., T. Kyriss, S. Paranjape, and S.A. Glantz. 2011. "The Toxic Effects of Cigarette Additives. Philip Morris' Project Mix Reconsidered: An Analysis of Documents Released through Litigation." PLoS Medicine 8 (12): 1-15.

World Health Organization. 2011. "WHO Report on the Global Tobacco Epidemic, 2011: Warnings about the Dangers of Tobacco." http://whqlibdoc.who.int/publications/2011/9789240687813_eng.pdf. 


\section{Appendix A. Flavorant Analysis Tables}

\subsection{Prevalence of Use and Sales of Tobacco Products}

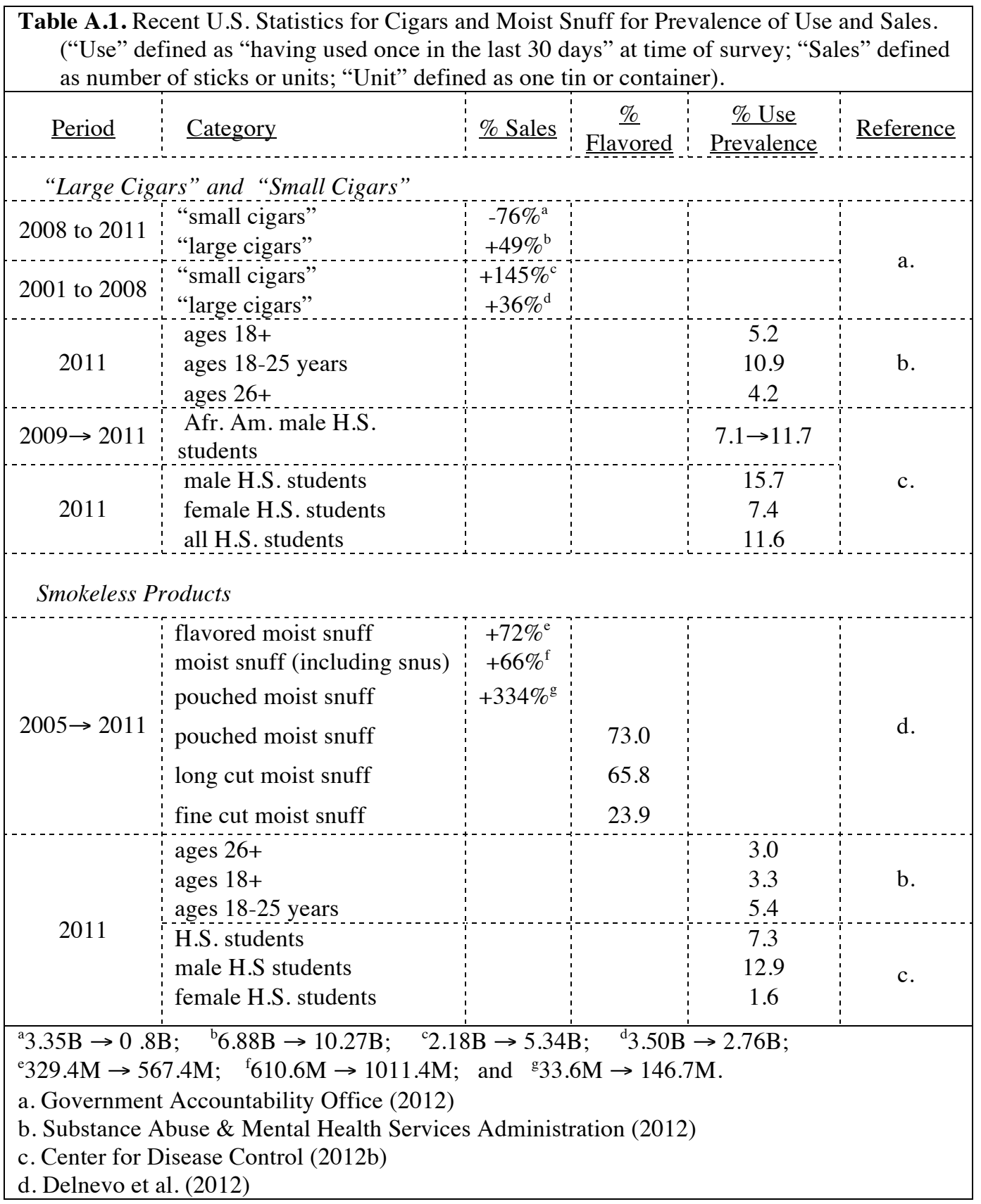




\subsection{Products Tested}

\begin{tabular}{|c|c|c|c|}
\hline $\begin{array}{l}\text { Product Brand } \\
\text { Name }\end{array}$ & $\begin{array}{l}\text { Product Flavor } \\
\text { Name }\end{array}$ & $\begin{array}{l}\text { Sample Size Used for } \\
\text { Extractions }\end{array}$ & $\begin{array}{l}\text { Average relative } \\
\text { standard deviation } \\
\text { (range) for above } \\
\text { trace compounds } \\
(\%)\end{array}$ \\
\hline \multicolumn{4}{|l|}{$\begin{array}{l}\text { Tobacco } \\
\text { Tobacco Wraps }\end{array}$} \\
\hline Zig Zag & $\begin{array}{l}\text { cherry } \\
\text { grape } \\
\text { apple } \\
\text { blueberry }\end{array}$ & 1 wrap, cut into pieces & $\begin{array}{l}30(2-45) \\
20(1-45) \\
22(4-72) \\
31(1-95)\end{array}$ \\
\hline $\begin{array}{l}\text { Royal Blunt } \\
\text { Wrap }\end{array}$ & sour apple XXL & 1 wrap, cut into pieces & $17(10-26)$ \\
\hline \multicolumn{4}{|l|}{ Large Cigars } \\
\hline Phillies Blunt & grape & $\begin{array}{l}\sim 1 \mathrm{~g} \text { cylinder cut from center } \\
\text { of cigar }\end{array}$ & $22(2-173)$ \\
\hline Cheyenne Cigars & $\begin{array}{l}\text { wild cherry } \\
\text { grape } \\
\text { peach } \\
\text { xotic berry }\end{array}$ & $\begin{array}{l}1 \text { cigar stick, with filter } \\
\text { removed, cut into pieces, and } \\
\text { extracted separately }\end{array}$ & $\begin{array}{l}14(5-48) \\
12(5-43) \\
10(5-17) \\
8(5-29)\end{array}$ \\
\hline $\begin{array}{l}\text { Swisher Sweet } \\
\text { Cigarillos }\end{array}$ & $\begin{array}{l}\text { cherry } \\
\text { peach }\end{array}$ & $\begin{array}{l}1 \text { cigar, with tip removed } \\
\text { (cherry) }\end{array}$ & $\begin{array}{l}7(3-14) \\
11(1-27)\end{array}$ \\
\hline \multicolumn{4}{|l|}{ Moist Snuff } \\
\hline Skoal & $\begin{array}{l}\text { cherry } \\
\text { apple } \\
\text { berry }\end{array}$ & $\sim 1 \mathrm{~g}$ & $\begin{array}{l}3(1-11) \\
2(1-7) \\
5(1-57)\end{array}$ \\
\hline Kayak & $\begin{array}{l}\text { grape } \\
\text { apple } \\
\text { peach }\end{array}$ & $\sim 1 \mathrm{~g}$ & $\begin{array}{l}13(1-173) \\
4(1-14) \\
2(0-4)\end{array}$ \\
\hline \multicolumn{4}{|l|}{$\begin{array}{l}\text { Non-tobacco } \\
\text { Candy }\end{array}$} \\
\hline Jolly Ranchers & $\begin{array}{l}\text { cherry } \\
\text { grape } \\
\text { apple } \\
\text { peach } \\
\text { raspberry }\end{array}$ & 1 candy & $\begin{array}{l}5(3-6) \\
2(0-4) \\
5(4-8) \\
3(1-8) \\
17(2-135)\end{array}$ \\
\hline Life Savers & $\begin{array}{l}\text { cherry } \\
\text { raspberry }\end{array}$ & 2 candies & $\begin{array}{l}6(2-27) \\
10(3-44)\end{array}$ \\
\hline Zotz & $\begin{array}{l}\text { cherry } \\
\text { grape } \\
\text { apple } \\
\text { blue raspberry }\end{array}$ & 1 candy & $\begin{array}{l}5(1-8) \\
12(4-51) \\
33(6-88) \\
9(6-18)\end{array}$ \\
\hline \multicolumn{4}{|l|}{ Soft Drink } \\
\hline Kool-Aid & $\begin{array}{l}\text { Cherry } \\
\text { grape } \\
\text { peach mango } \\
\text { raspberry lemonade }\end{array}$ & $\sim 100 \mathrm{mg}$ & $\begin{array}{l}18(1-25) \\
12(3-15) \\
30(2-43) \\
9(3-17) \\
\end{array}$ \\
\hline
\end{tabular}




\subsection{Target Analytes Found in Samples}

Table A.3. The 70 compounds found in selected candy, Kool-Aid, and tobacco products.

For analytes with chirality, differentiation by chirality was not carried out. The Chemical Abstract Services Registry Number (CASRN) values given are those used to prepare the analytical standards.

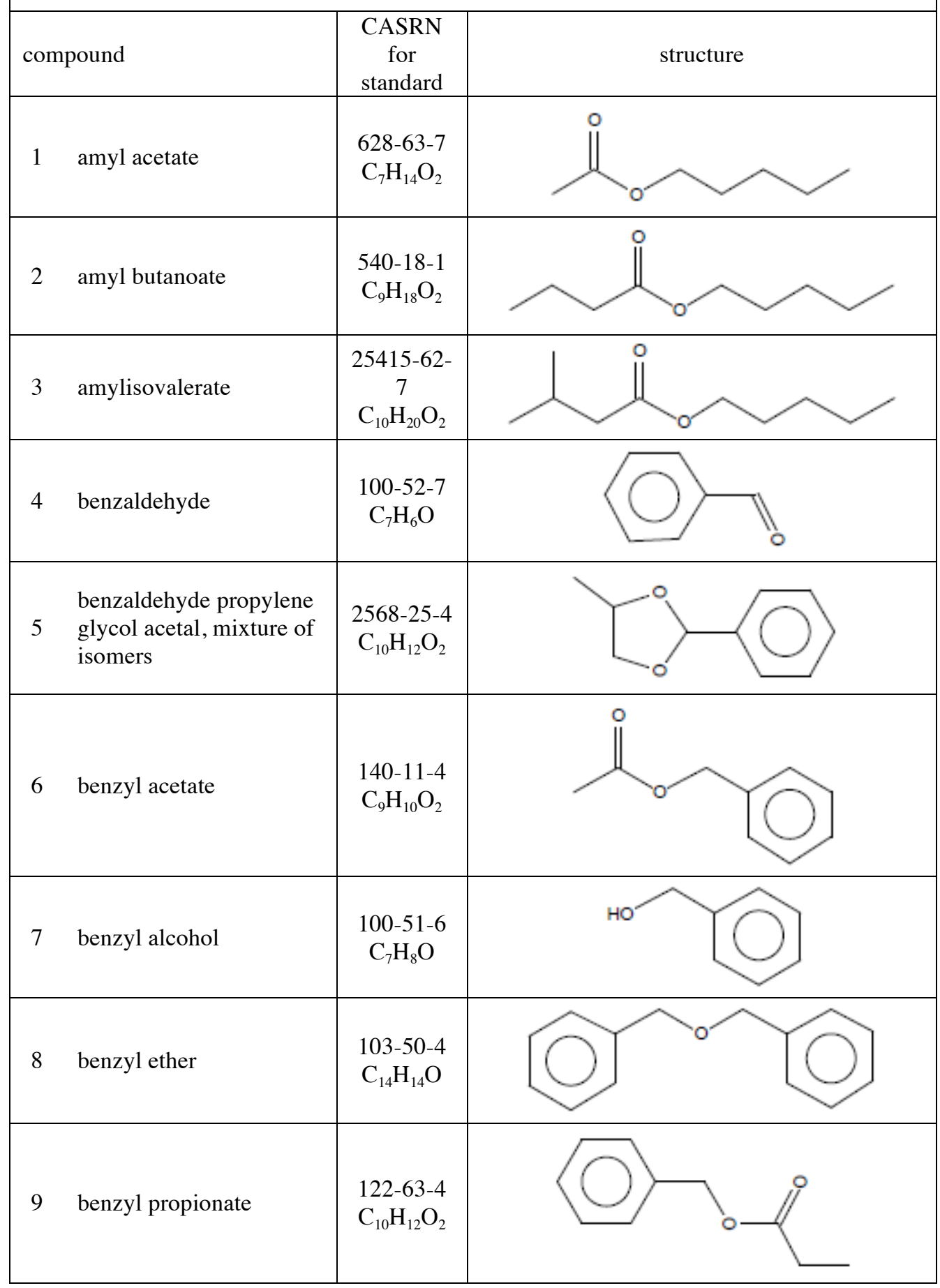




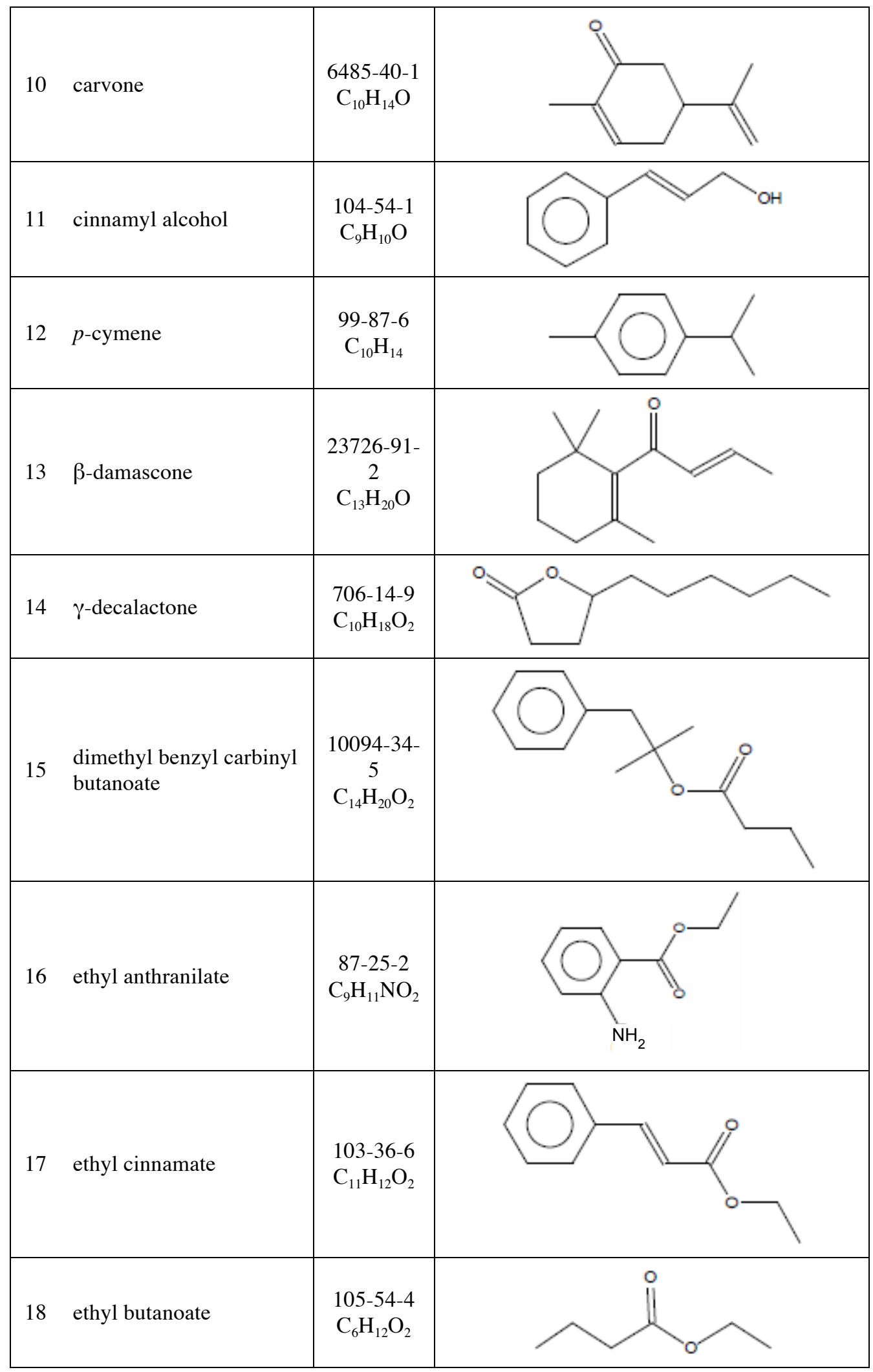




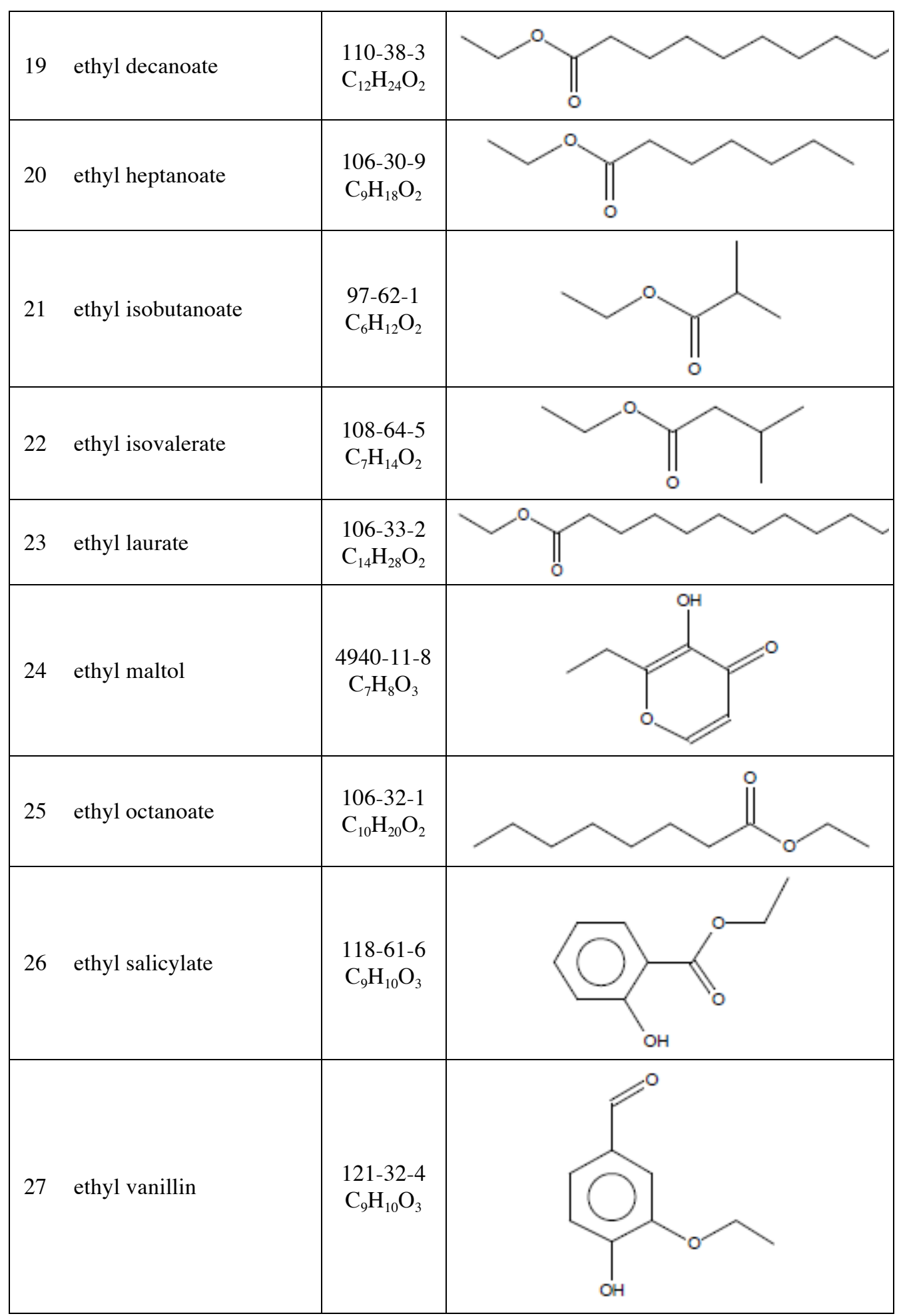




\begin{tabular}{|c|c|c|c|}
\hline & eugenol & $\begin{array}{c}97-53-0 \\
\mathrm{C}_{10} \mathrm{H}_{12} \mathrm{O}_{2}\end{array}$ & ( \\
\hline 29 & furfural & $\begin{array}{l}98-01-1 \\
\mathrm{C}_{5} \mathrm{H}_{4} \mathrm{O}_{2}\end{array}$ & \\
\hline 30 & furfuryl alcohol & $\begin{array}{l}98-00-0 \\
\mathrm{C}_{5} \mathrm{H}_{6} \mathrm{O}_{2}\end{array}$ & \\
\hline 31 & 1-hexanol & $\begin{array}{c}111-27-3 \\
\mathrm{C}_{6} \mathrm{H}_{14} \mathrm{O}\end{array}$ & \\
\hline 32 & (E)-2-hexen-1-ol & $\begin{array}{c}928-95-0 \\
\mathrm{C}_{6} \mathrm{H}_{12} \mathrm{O} \\
\end{array}$ & \\
\hline 33 & (Z)-3-hexen-1-ol & $\begin{array}{c}928-96-1 \\
\mathrm{C}_{6} \mathrm{H}_{12} \mathrm{O}\end{array}$ & \\
\hline 34 & (Z)-3-hexen-1-yl acetate & $\begin{array}{c}3681-71-8 \\
\mathrm{C}_{8} \mathrm{H}_{14} \mathrm{O}_{2}\end{array}$ & $\checkmark$ \\
\hline 35 & (Z)-3-hexen-1-yl formate & $\begin{array}{c}33467-73- \\
1 \\
\mathrm{C}_{7} \mathrm{H}_{12} \mathrm{O}_{2}\end{array}$ & \\
\hline 36 & hexyl 2-methylbutanoate & $\begin{array}{c}10032-15- \\
2 \\
\mathrm{C}_{11} \mathrm{H}_{22} \mathrm{O}_{2}\end{array}$ & \\
\hline & hexyl acetate & $\begin{array}{l}142-92-7 \\
\mathrm{C}_{8} \mathrm{H}_{16} \mathrm{O}_{2}\end{array}$ & \\
\hline & hexyl hexanoate & $\begin{array}{c}6378-65-0 \\
\mathrm{C}_{12} \mathrm{H}_{24} \mathrm{O}_{2}\end{array}$ & \\
\hline
\end{tabular}




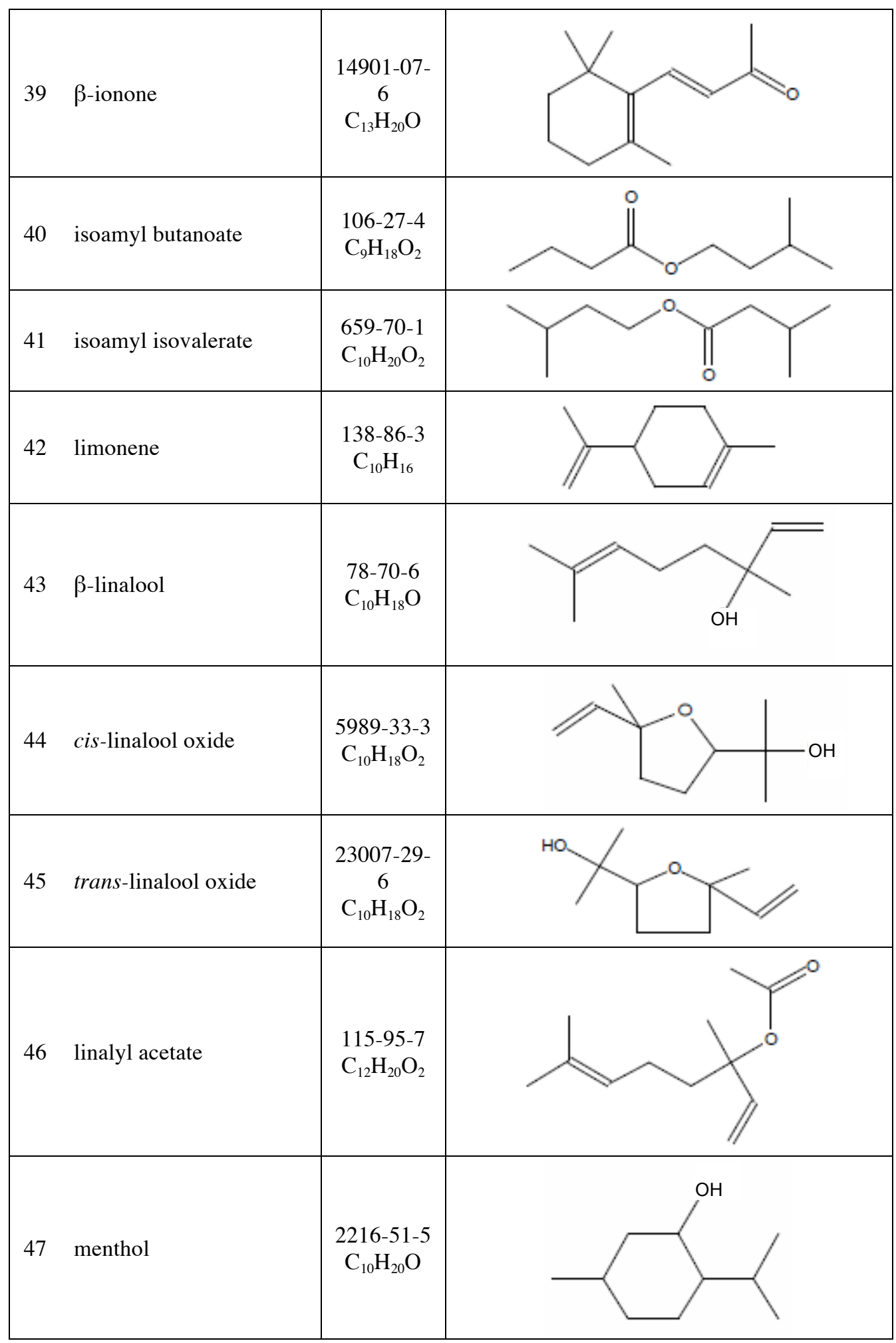




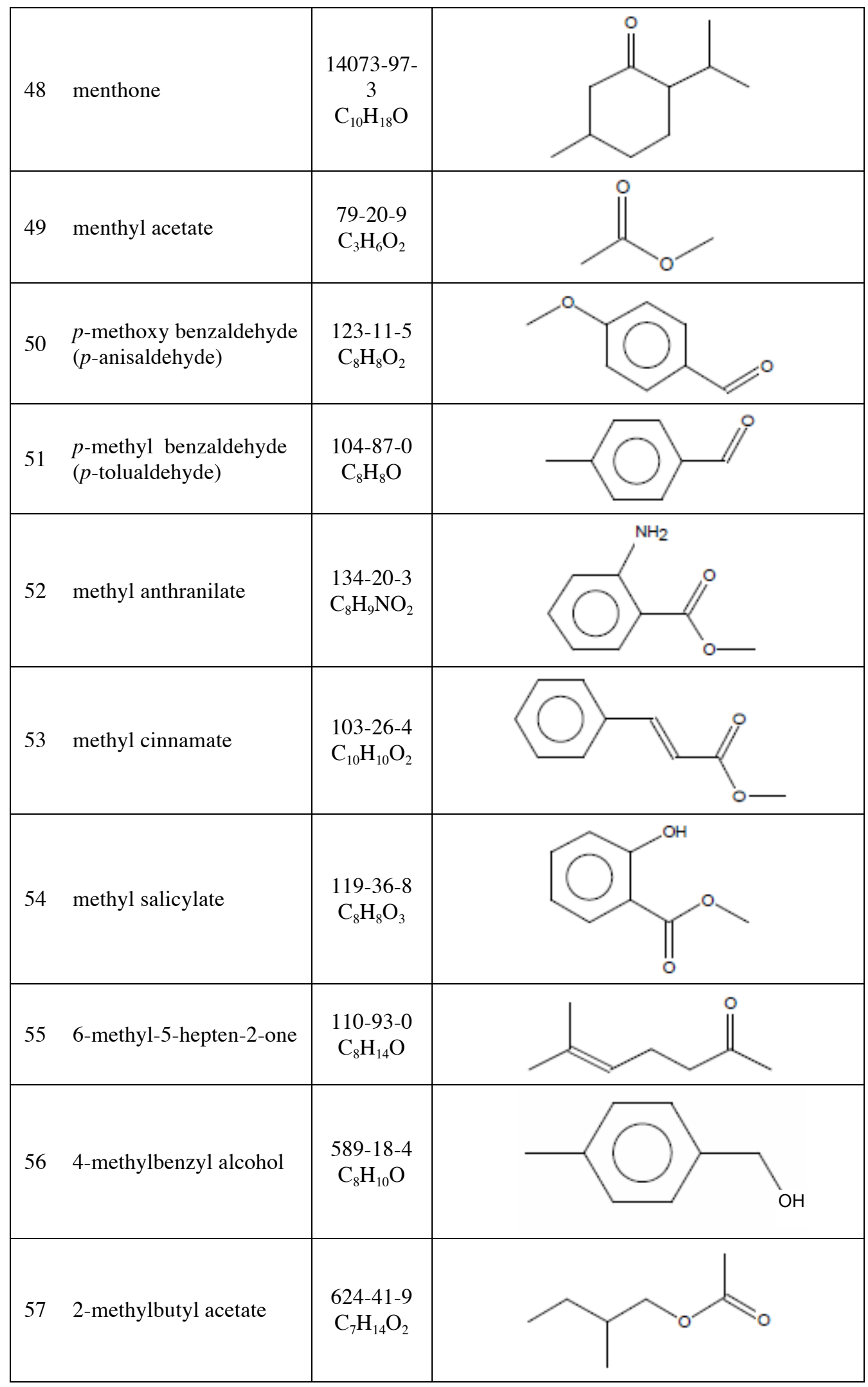




\begin{tabular}{|c|c|c|c|}
\hline & myrcene & $\begin{array}{c}123-35-3 \\
\mathrm{C}_{10} \mathrm{H}_{16}\end{array}$ & 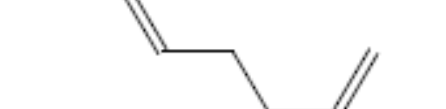 \\
\hline 59 & neryl acetate & $\begin{array}{l}141-12-8 \\
\mathrm{C}_{12} \mathrm{H}_{20} \mathrm{O}_{2}\end{array}$ & \\
\hline 60 & 1-pentanol & $\begin{array}{l}71-41-0 \\
\mathrm{C}_{5} \mathrm{H}_{12} \mathrm{O}\end{array}$ & \\
\hline 61 & phenethyl alcohol & $\begin{array}{l}60-12-8 \\
\mathrm{C}_{8} \mathrm{H}_{10} \mathrm{O}\end{array}$ & \\
\hline 62 & $\alpha$-pinene & $\begin{array}{c}80-56-8 \\
\mathrm{C}_{10} \mathrm{H}_{16}\end{array}$ & \\
\hline & piperonal & $\begin{array}{c}120-57-0 \\
\mathrm{C}_{8} \mathrm{H}_{6} \mathrm{O}_{3}\end{array}$ & \\
\hline 64 & raspberry ketone & $\begin{array}{c}5471-51-2 \\
\mathrm{C}_{10} \mathrm{H}_{12} \mathrm{O}_{2}\end{array}$ & \\
\hline & $\begin{array}{l}\text { raspberry ketone methyl } \\
\text { ether }\end{array}$ & $\begin{array}{l}104-20-1 \\
\mathrm{C}_{11} \mathrm{H}_{14} \mathrm{O}_{2}\end{array}$ & \\
\hline 66 & $\gamma$-terpinene & $\begin{array}{l}99-85-4 \\
\mathrm{C}_{10} \mathrm{H}_{16}\end{array}$ & \\
\hline
\end{tabular}




\begin{tabular}{|c|c|c|c|}
\hline & 4-terpineol & $\begin{array}{c}20126-76- \\
5 \\
\mathrm{C}_{10} \mathrm{H}_{18} \mathrm{O}\end{array}$ & 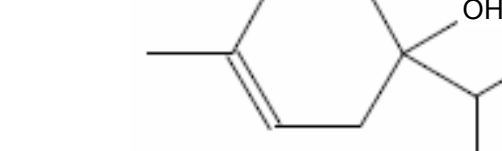 \\
\hline & $\alpha$-terpineol & $\begin{array}{c}10482-56- \\
1 \\
\mathrm{C}_{10} \mathrm{H}_{18} \mathrm{O}\end{array}$ & \\
\hline & $\gamma$-undecalactone & $\begin{array}{l}104-67-6 \\
\mathrm{C}_{11} \mathrm{H}_{20} \mathrm{O}_{2}\end{array}$ & \\
\hline 70 & vanillin & $\begin{array}{c}121-33-5 \\
\mathrm{C}_{8} \mathrm{H}_{8} \mathrm{O}_{3}\end{array}$ & \\
\hline
\end{tabular}




\subsection{Flavorant Analyses Results}

\begin{tabular}{|c|c|c|c|}
\hline product & compound & $\begin{array}{l}\text { CASRN }^{1} \text { for } \\
\text { standard }\end{array}$ & $\begin{array}{l}\text { micrograms }(\mu \mathrm{g}) \\
\text { per "serving" }\end{array}$ \\
\hline \multirow{7}{*}{$\begin{array}{l}\text { Jolly Rancher } \\
\text { "Cherry" } \\
1 \text { serving = } 1 \text { candy } \\
\quad(\sim 6.1 \mathrm{~g})\end{array}$} & benzyl alcohol & $100-51-6$ & $25 \pm 1$ \\
\hline & furfural & $98-01-1$ & $25 \pm 1$ \\
\hline & furfuryl alcohol & $98-00-0$ & $8 \pm 1$ \\
\hline & $\begin{array}{l}p \text {-methoxy benzaldehyde } \\
\text { ( } p \text {-anisaldehyde) }\end{array}$ & $123-11-5$ & $14 \pm 1$ \\
\hline & $\begin{array}{l}p \text {-methyl benzaldehyde } \\
\text { (p-tolualdehyde) }\end{array}$ & $104-87-0$ & $47 \pm 2$ \\
\hline & piperonal & $120-57-0$ & $6 \pm 0$ \\
\hline & vanillin & $121-33-5$ & $13 \pm 1$ \\
\hline \multirow{17}{*}{$\begin{array}{l}\text { Life Saver } \\
\text { "Cherry" } \\
1 \text { serving = } 1 \text { candy } \\
\quad(\sim 3.6 \mathrm{~g})\end{array}$} & amyl acetate & $628-63-7$ & $33 \pm 1$ \\
\hline & amyl butanoate & $540-18-1$ & $34 \pm 1$ \\
\hline & benzaldehyde & $100-52-7$ & $469 \pm 8$ \\
\hline & benzyl acetate & $140-11-4$ & $9 \pm 0$ \\
\hline & benzyl alcohol & $100-51-6$ & $2231 \pm 61$ \\
\hline & eugenol & $97-53-0$ & $8 \pm 0$ \\
\hline & furfural & $98-01-1$ & $46 \pm 1$ \\
\hline & furfuryl alcohol & $98-00-0$ & $2 \pm 0$ \\
\hline & $\beta$-ionone & $14901-07-6$ & Trace $^{2}$ \\
\hline & limonene & $138-86-3$ & $24 \pm 2$ \\
\hline & $\beta$-linalool & $78-70-6$ & $3 \pm 0$ \\
\hline & methyl salicylate & $119-36-8$ & $2 \pm 0$ \\
\hline & $\begin{array}{l}p \text {-methyl benzaldehyde } \\
\text { ( } p \text {-tolualdehyde) }\end{array}$ & $104-87-0$ & $140 \pm 4$ \\
\hline & 2-methylbutyl acetate & $624-41-9$ & $38 \pm 2$ \\
\hline & raspberry ketone & $5471-51-2$ & $2 \pm 1$ \\
\hline & $\mathrm{y}$-terpinene & $99-85-4$ & Trace \\
\hline & y-undecalactone & $104-67-6$ & Trace \\
\hline \multirow{12}{*}{$\begin{array}{l}\text { "Cotz } \\
1 \text { serving = } 1 \text { candy } \\
(\sim 5.1 \mathrm{~g})\end{array}$} & amyl acetate & $628-63-7$ & $170 \pm 7$ \\
\hline & amyl butanoate & $540-18-1$ & Trace \\
\hline & benzaldehyde & $100-52-7$ & $241 \pm 11$ \\
\hline & $\begin{array}{l}\text { benzaldehyde propylene } \\
\text { alvcol acetal\& }\end{array}$ & $2568-25-4$ & $78 \pm 6$ \\
\hline & ethyl butanoate & $105-54-4$ & $14 \pm 0$ \\
\hline & ethyl decanoate & $110-38-3$ & $5 \pm 0$ \\
\hline & ethyl laurate & $106-33-2$ & $25 \pm 1$ \\
\hline & eugenol & $97-53-0$ & $15 \pm 1$ \\
\hline & furfural & $98-01-1$ & $30 \pm 0$ \\
\hline & furfuryl alcohol & $98-00-0$ & $120 \pm 7$ \\
\hline & limonene & $138-86-3$ & $3 \pm 0$ \\
\hline & vanillin & $121-33-5$ & $91 \pm 5$ \\
\hline \multirow{2}{*}{$\begin{array}{l}\text { Kool-Aid Mix } \\
\text { "Cherry" }\end{array}$} & amylisovalerate & $25415-62-7$ & $33 \pm 8$ \\
\hline & benzaldehyde & $100-52-7$ & $3338 \pm 623$ \\
\hline
\end{tabular}




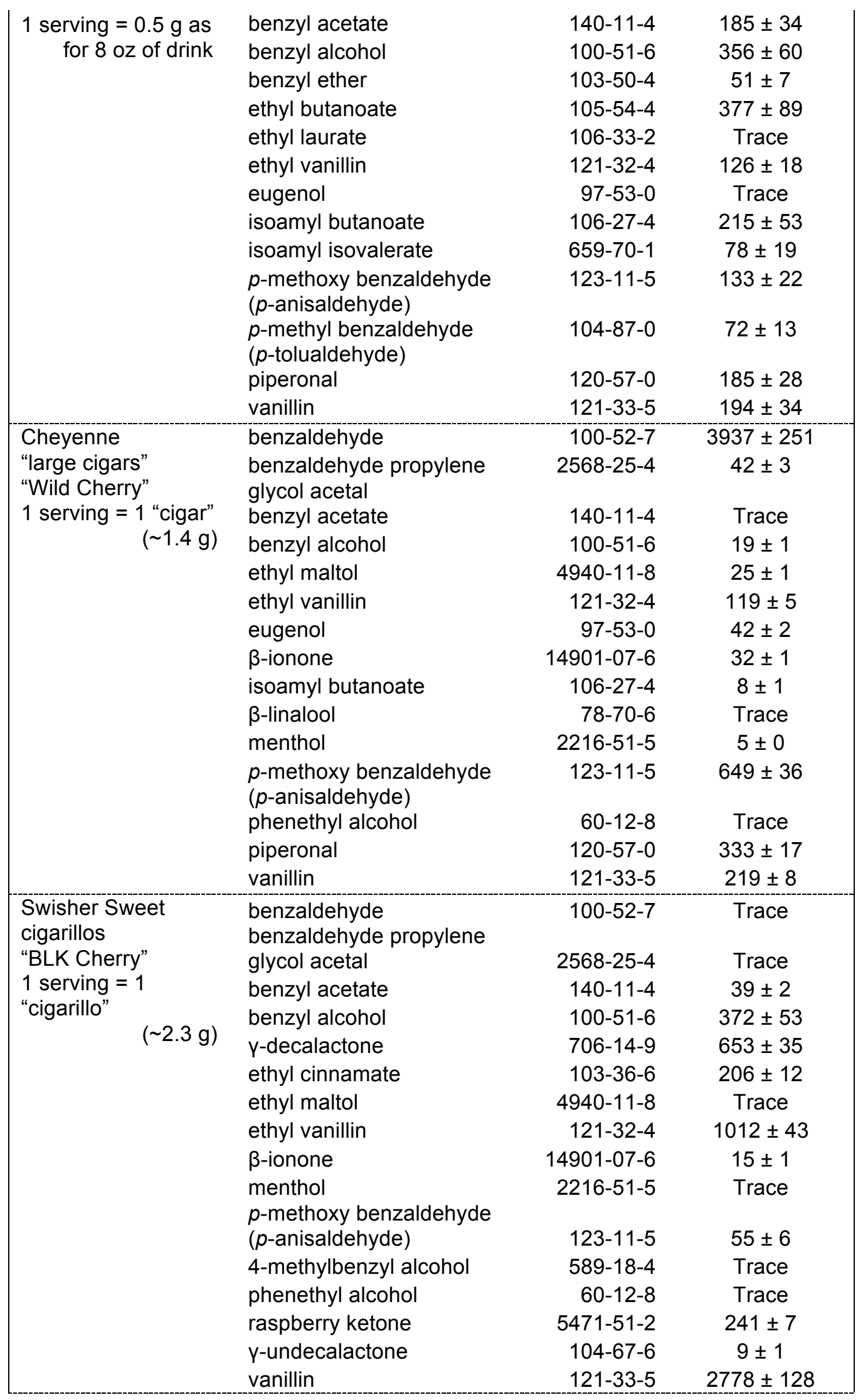




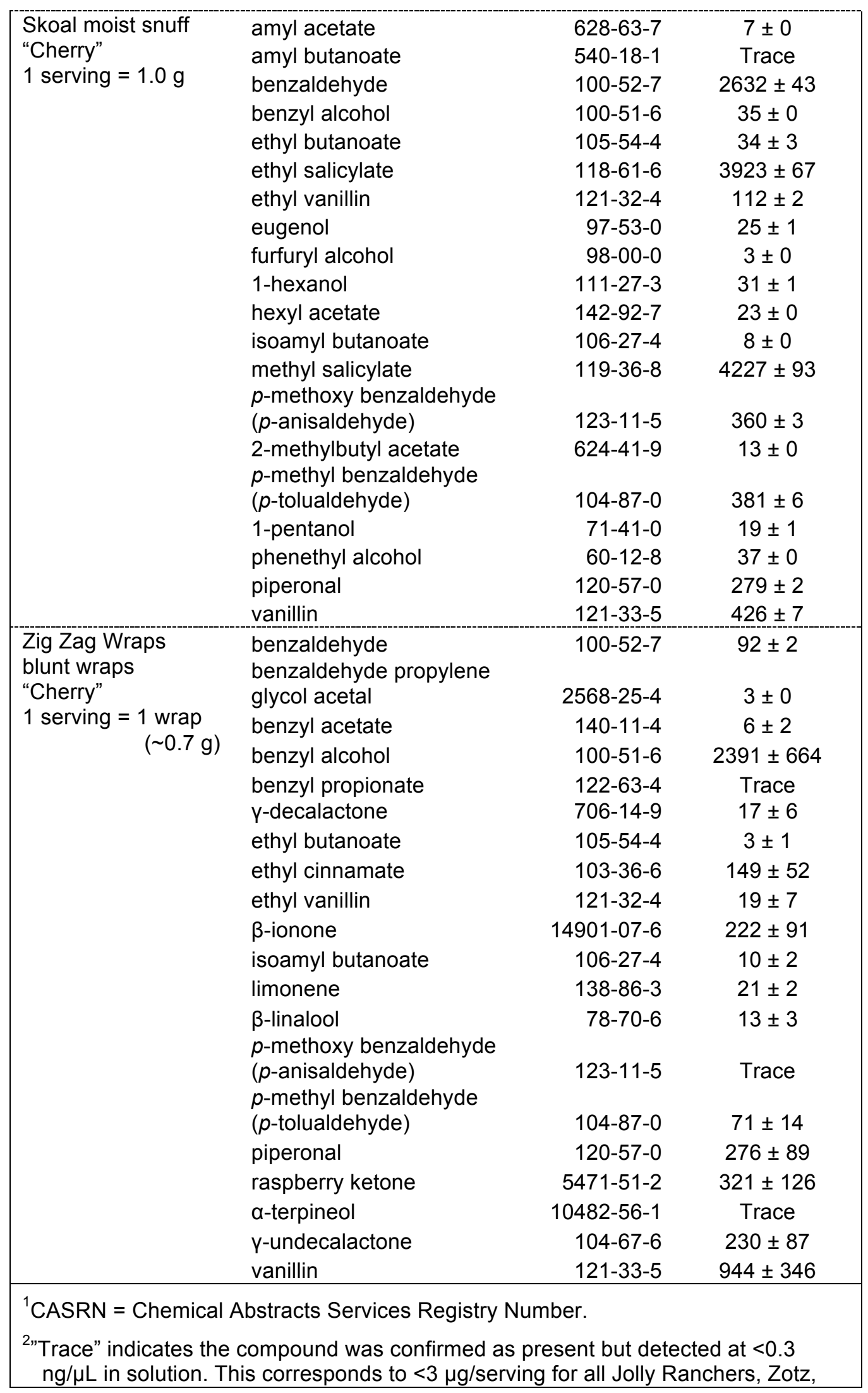


moist snuff and tobacco wrap products, $<1.5 \mu \mathrm{g} /$ serving for Life Savers, $<4.5$ $\mu \mathrm{g} / \mathrm{serving}$ for Cheyenne cigars, $<6 \mu \mathrm{g} / \mathrm{serving}$ for Swisher Sweet cigarillos, and $<15 \mu \mathrm{g} / \mathrm{serving}$ for "cherry" Kool-Aid.

$\S$ Sum of syn and anti isomers of the acetal.

\begin{tabular}{|c|c|c|c|}
\hline product & compound & $\begin{array}{l}\text { CASRN }^{1} \text { for } \\
\text { standard }\end{array}$ & $\begin{array}{l}\text { micrograms }(\mu \mathrm{g}) \\
\text { per "serving" }\end{array}$ \\
\hline \multirow{24}{*}{$\begin{array}{l}\text { Jolly Rancher } \\
\text { "Grape" } \\
1 \text { serving = } 1 \text { candy } \\
(\sim 6.0 \mathrm{~g})\end{array}$} & benzaldehyde & $100-52-7$ & $134 \pm 2$ \\
\hline & cinnamyl alcohol & $104-54-1$ & $837 \pm 13$ \\
\hline & ethyl anthranilate & $87-25-2$ & $47 \pm 1$ \\
\hline & ethyl butanoate & $105-54-4$ & $736 \pm 8$ \\
\hline & ethyl decanoate & $110-38-3$ & $25 \pm 0$ \\
\hline & ethyl isobutanoate & $97-62-1$ & $85 \pm 2$ \\
\hline & ethyl isovalerate & $108-64-5$ & $6 \pm 0$ \\
\hline & ethyl laurate & $106-33-2$ & $87 \pm 1$ \\
\hline & ethyl maltol & $4940-11-8$ & $57 \pm 0$ \\
\hline & ethyl octanoate & $106-32-1$ & Trace $^{2}$ \\
\hline & furfural & $98-01-1$ & $11 \pm 0$ \\
\hline & (E)-2-hexen-1-ol & $928-95-0$ & $9 \pm 0$ \\
\hline & hexyl acetate & $142-92-7$ & $34 \pm 0$ \\
\hline & limonene & $138-86-3$ & $483 \pm 7$ \\
\hline & $\beta$-linalool & $78-70-6$ & Trace \\
\hline & linalyl acetate & $115-95-7$ & $51 \pm 1$ \\
\hline & methyl anthranilate & $134-20-3$ & $1019 \pm 2$ \\
\hline & 2-methylbutyl acetate & $624-41-9$ & Trace \\
\hline & myrcene & $123-35-3$ & Trace \\
\hline & neryl acetate & $141-12-8$ & Trace \\
\hline & phenethyl alcohol & $60-12-8$ & $5 \pm 0$ \\
\hline & raspberry ketone & $5471-51-2$ & $29 \pm 1$ \\
\hline & $\begin{array}{l}\text { raspberry ketone methyl } \\
\text { ether }\end{array}$ & $104-20-1$ & $315 \pm 2$ \\
\hline & a-terpineol & $10482-56-1$ & Trace \\
\hline \multirow{11}{*}{$\begin{array}{l}\text { Zotz } \\
\text { "Grape" } \\
1 \text { serving = } 1 \text { candy } \\
(\sim 5.0 \mathrm{~g})\end{array}$} & cinnamyl alcohol & $104-54-1$ & $15 \pm 1$ \\
\hline & ethyl butanoate & $105-54-4$ & $32 \pm 7$ \\
\hline & ethyl cinnamate & $103-36-6$ & $3 \pm 0$ \\
\hline & ethyl decanoate & $110-38-3$ & $7 \pm 0$ \\
\hline & ethyl heptanoate & $106-30-9$ & $25 \pm 2$ \\
\hline & ethyl octanoate & $106-32-1$ & $3 \pm 0$ \\
\hline & ethyl salicylate & $118-61-6$ & Trace \\
\hline & furfural & $98-01-1$ & $35 \pm 2$ \\
\hline & furfuryl alcohol & $98-00-0$ & $98 \pm 50$ \\
\hline & (Z)-3-hexen-1-ol & $928-96-1$ & $11 \pm 0$ \\
\hline & (Z)-3-hexen-1-yl acetate & $3681-71-8$ & $4 \pm 0$ \\
\hline
\end{tabular}




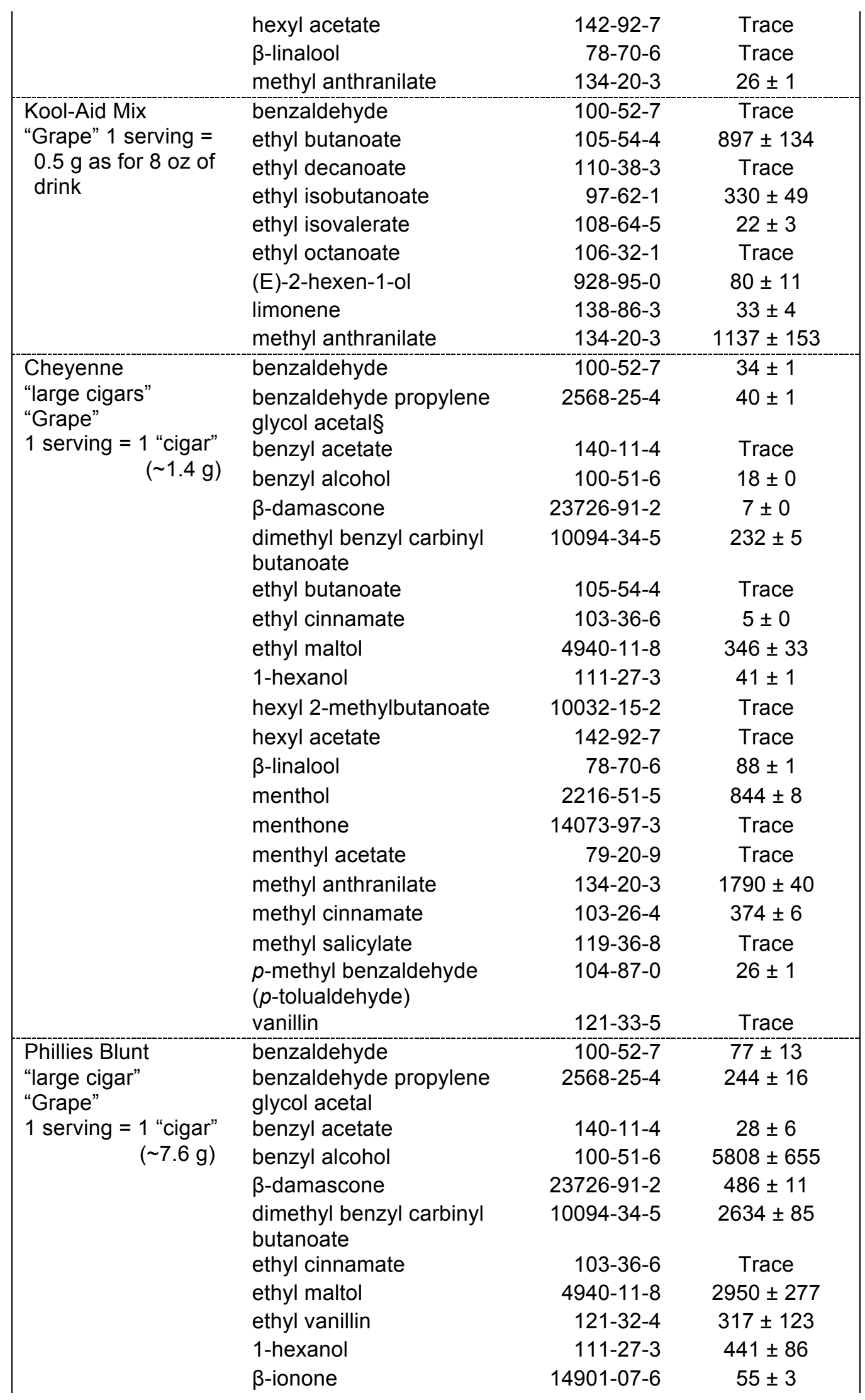




\begin{tabular}{|c|c|c|c|}
\hline & $\begin{array}{l}\beta \text {-linalool } \\
\text { menthol } \\
\text { menthyl acetate } \\
\text { methyl anthranilate } \\
\text { methyl cinnamate } \\
\text { piperonal } \\
\text { raspberry ketone } \\
\text { 4-terpineol } \\
\text { vanillin }\end{array}$ & $\begin{array}{r}78-70-6 \\
2216-51-5 \\
79-20-9 \\
134-20-3 \\
103-26-4 \\
120-57-0 \\
5471-51-2 \\
20126-76-5 \\
121-33-5\end{array}$ & $\begin{array}{c}424 \pm 15 \\
1559 \pm 180 \\
\text { Trace } \\
17552 \pm 2135 \\
\text { Trace } \\
41 \pm 11 \\
624 \pm 75 \\
775 \pm 82 \\
673 \pm 120\end{array}$ \\
\hline $\begin{array}{l}\text { Kayak Moist Snuff } \\
\text { "Grape" } \\
1 \text { serving }=1.0 \mathrm{~g}\end{array}$ & $\begin{array}{l}\text { amyl acetate } \\
\text { amyl butanoate } \\
\text { benzaldehyde } \\
\text { benzaldehyde propylene } \\
\text { glycol acetal } \\
\text { benzyl acetate } \\
\text { benzyl alcohol } \\
\text { cinnamyl alcohol } \\
\text { ethyl butanoate } \\
\text { ethyl decanoate } \\
\text { ethyl heptanoate } \\
\text { ethyl laurate } \\
\text { ethyl maltol } \\
\text { ethyl octanoate } \\
\text { ethyl salicylate } \\
\text { eugenol } \\
\text { furfuryl alcohol } \\
\text { isoamyl butanoate } \\
\text { limonene } \\
\beta \text {-linalool } \\
\text { cis-linalool oxide } \\
\text { trans-linalool oxide } \\
\text { menthol } \\
\text { methyl anthranilate } \\
\text { methyl salicylate } \\
6 \text {-methyl-5-hepten-2-one } \\
\text { 2-methylbutyl acetate } \\
\text { 1-pentanol } \\
\text { phenethyl alcohol } \\
\text { piperonal } \\
\text { raspberry ketone } \\
\text { raspberry ketone methyl } \\
\text { ether } \\
\text { 4-terpineol }\end{array}$ & $\begin{array}{r}628-63-7 \\
540-18-1 \\
100-52-7 \\
2568-25-4 \\
\\
140-11-4 \\
100-51-6 \\
104-54-1 \\
105-54-4 \\
110-38-3 \\
106-30-9 \\
106-33-2 \\
4940-11-8 \\
106-32-1 \\
118-61-6 \\
97-53-0 \\
98-00-0 \\
106-27-4 \\
138-86-3 \\
78-70-6 \\
5989-33-3 \\
23007-29-6 \\
2216-51-5 \\
134-20-3 \\
119-36-8 \\
110-93-0 \\
624-41-9 \\
71-41-0 \\
60-12-8 \\
120-57-0 \\
5471-51-2 \\
104-20-1 \\
20126-76-5\end{array}$ & $\begin{array}{c}\text { Trace } \\
43 \pm 2 \\
10 \pm 0 \\
16 \pm 0 \\
\text { Trace } \\
78 \pm 14 \\
56 \pm 4 \\
193 \pm 11 \\
8 \pm 0 \\
31 \pm 1 \\
8 \pm 0 \\
54 \pm 1 \\
8 \pm 0 \\
\text { Trace } \\
5 \pm 0 \\
69 \pm 2 \\
93 \pm 4 \\
171 \pm 7 \\
547 \pm 15 \\
4 \pm 1 \\
4 \pm 0 \\
80 \pm 15 \\
1195 \pm 27 \\
51 \pm 1 \\
\text { Trace } \\
10 \pm 1 \\
31 \pm 2 \\
14 \pm 3 \\
4 \pm 0 \\
163 \pm 6 \\
77 \pm 2 \\
14 \pm 25 \\
\end{array}$ \\
\hline & vanillin & $121-33-5$ & $2046 \pm 49$ \\
\hline $\begin{array}{l}\text { Zig Zag } \\
\text { "blunt wrap" } \\
\text { "Grape" } \\
1 \text { serving = } 1 \text { wrap } \\
(\sim 0.7 \mathrm{~g})\end{array}$ & $\begin{array}{l}\text { benzaldehyde } \\
\text { benzyl acetate } \\
\text { benzyl alcohol } \\
\text { y-decalactone } \\
\text { ethyl maltol }\end{array}$ & $\begin{array}{r}100-52-7 \\
140-11-4 \\
100-51-6 \\
706-14-9 \\
4940-11-8\end{array}$ & $\begin{array}{c}8 \pm 0 \\
23 \pm 5 \\
2163 \pm 99 \\
4 \pm 2 \\
72 \pm 11\end{array}$ \\
\hline
\end{tabular}




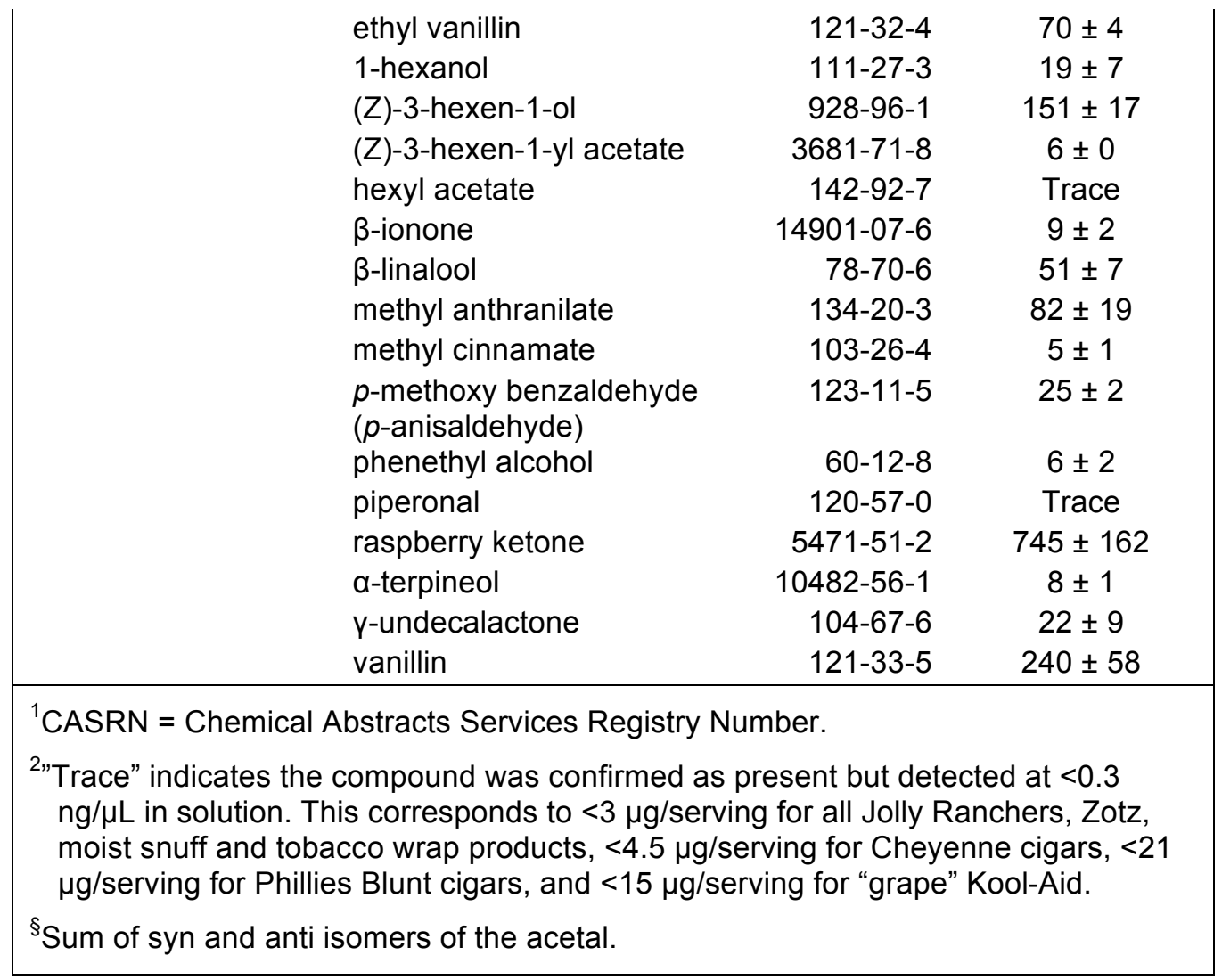

\begin{tabular}{|c|c|c|c|}
\hline product & compound & $\begin{array}{l}\text { CASRN }^{1} \text { for } \\
\text { standard }\end{array}$ & $\begin{array}{c}\text { micrograms }(\mu \mathrm{g}) \\
\text { per "serving" }\end{array}$ \\
\hline \multirow{9}{*}{$\begin{array}{l}\text { Jolly Rancher } \\
\text { "Apple" } \\
1 \text { serving = } 1 \text { candy } \\
\qquad(\sim 6.1 \mathrm{~g})\end{array}$} & ethyl decanoate & $110-38-3$ & $121 \pm 6$ \\
\hline & ethyl laurate & $106-33-2$ & $67 \pm 3$ \\
\hline & ethyl maltol & $4940-11-8$ & $40 \pm 2$ \\
\hline & ethyl octanoate & $106-32-1$ & $68 \pm 4$ \\
\hline & furfural & $98-01-1$ & $9 \pm 1$ \\
\hline & 1-hexanol & $111-27-3$ & $968 \pm 54$ \\
\hline & hexyl acetate & $142-92-7$ & $12 \pm 0$ \\
\hline & 2-methylbutyl acetate & $624-41-9$ & $376 \pm 30$ \\
\hline & 1-pentanol & $71-41-0$ & $3 \pm 0$ \\
\hline \multirow{7}{*}{$\begin{array}{l}\text { Zotz } \\
\text { "Apple" } \\
1 \text { serving = } 1 \text { candy } \\
(\sim 5.0 \mathrm{~g})\end{array}$} & $\begin{array}{l}\text { dimethyl benzyl carbinyl } \\
\text { butanoate }\end{array}$ & $10094-34-5$ & Trace $^{2-}$ \\
\hline & ethyl butanoate & $105-54-4$ & $31 \pm 9$ \\
\hline & furfural & $98-01-1$ & $19 \pm 8$ \\
\hline & furfuryl alcohol & $98-00-0$ & $104 \pm 27$ \\
\hline & 1-hexanol & $111-27-3$ & $53 \pm 11$ \\
\hline & (Z)-3-hexen-1-ol & $928-96-1$ & $35 \pm 5$ \\
\hline & (Z)-3-hexen-1-yl acetate & $3681-71-8$ & $72 \pm 8$ \\
\hline
\end{tabular}




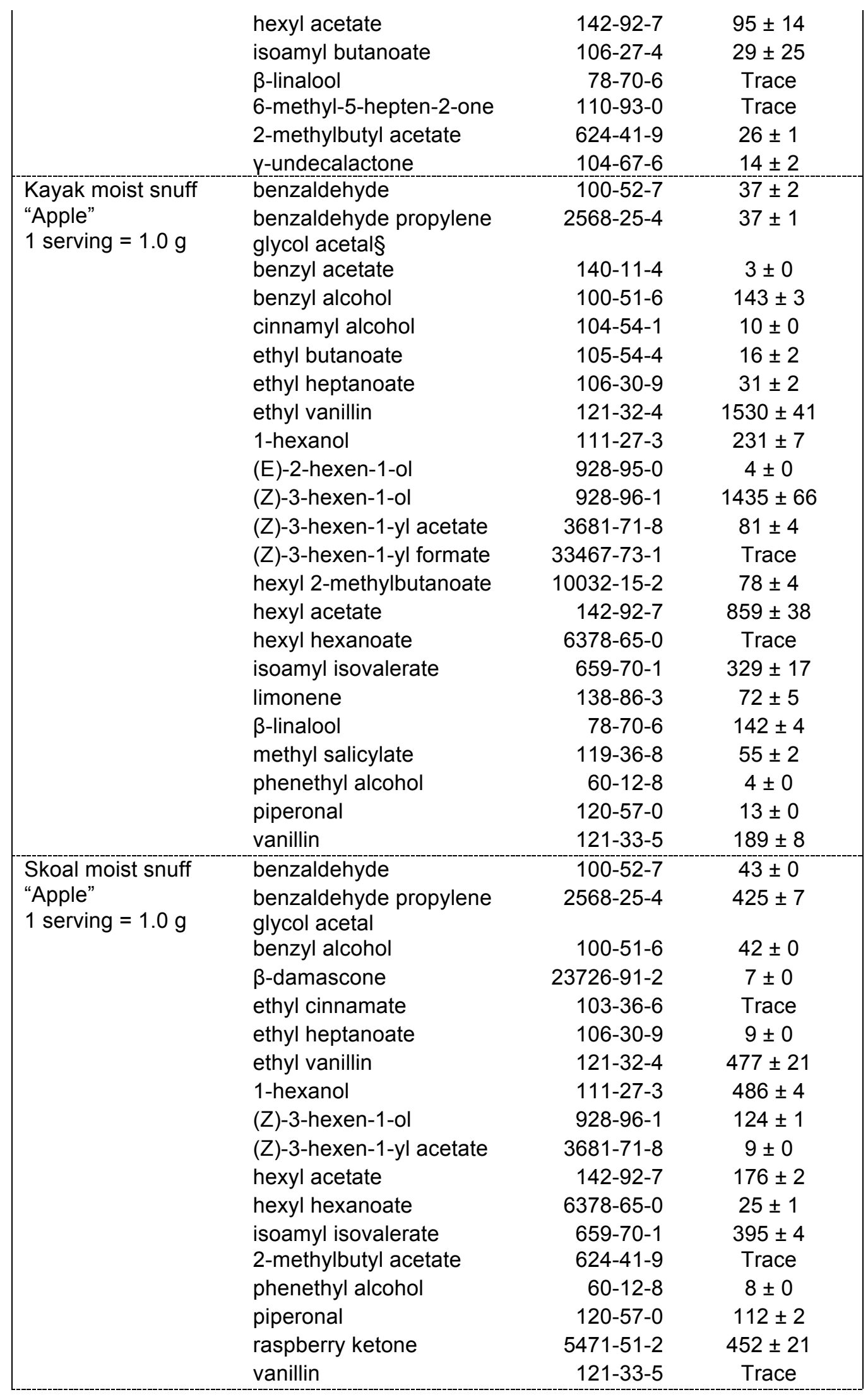




\begin{tabular}{|c|c|c|c|}
\hline $\begin{array}{l}\text { Royal Blunt Wraps } \\
\text { XXL } \\
\text { "blunt wraps" } \\
\text { "Sour Apple" } \\
1 \text { serving = } 1 \text { wrap } \\
\quad(\sim 0.9 \mathrm{~g})\end{array}$ & $\begin{array}{l}\text { 1-hexanol } \\
\text { menthol } \\
\text { 1-pentanol } \\
\text { phenethyl alcohol } \\
\text { vanillin }\end{array}$ & $\begin{array}{r}111-27-3 \\
2216-51-5 \\
71-41-0 \\
60-12-8 \\
121-33-5\end{array}$ & $\begin{array}{l}144 \pm 23 \\
\text { Trace } \\
15 \pm 4 \\
\text { Trace } \\
123 \pm 12\end{array}$ \\
\hline $\begin{array}{l}\text { Zig Zag Wraps } \\
\text { "blunt wraps" } \\
\text { "Apple" } \\
1 \text { serving = } 1 \text { wrap } \\
\qquad(\sim 0.9 \mathrm{~g})\end{array}$ & $\begin{array}{l}\text { benzaldehyde } \\
\text { benzaldehyde propylene } \\
\text { glycol acetal } \\
\text { benzyl acetate } \\
\text { benzyl alcohol } \\
\text { cinnamyl alcohol } \\
\text { Y-decalactone } \\
\text { ethyl cinnamate } \\
\text { ethyl maltol } \\
\text { ethyl vanillin } \\
\text { eugenol } \\
\text { 1-hexanol } \\
\text { hexyl 2-methylbutanoate } \\
\beta \text {-linalool } \\
\text { methyl cinnamate } \\
\text { phenethyl alcohol } \\
\text { piperonal } \\
\text { raspberry ketone } \\
\text { Y-undecalactone } \\
\text { vanillin }\end{array}$ & $\begin{array}{r}100-52-7 \\
2568-25-4 \\
\\
140-11-4 \\
100-51-6 \\
104-54-1 \\
706-14-9 \\
103-36-6 \\
4940-11-8 \\
121-32-4 \\
97-53-0 \\
111-27-3 \\
10032-15-2 \\
78-70-6 \\
103-26-4 \\
60-12-8 \\
120-57-0 \\
5471-51-2 \\
104-67-6 \\
121-33-5\end{array}$ & $\begin{array}{c}20 \pm 3 \\
\text { Trace } \\
\\
9 \pm 1 \\
3341 \pm 150 \\
5 \pm 1 \\
13 \pm 6 \\
\text { Trace } \\
46 \pm 7 \\
\text { Trace } \\
205 \pm 18 \\
142 \pm 15 \\
\text { Trace } \\
3 \pm 1 \\
12 \pm 1 \\
\text { Trace } \\
\text { Trace } \\
19 \pm 5 \\
31 \pm 22 \\
139 \pm 10\end{array}$ \\
\hline \multicolumn{4}{|c|}{$\begin{array}{l}{ }^{1} \text { CASRN = Chemical Abstracts Services Registry Number. } \\
2 " \text { Trace" indicates the compound was confirmed as present but detected at }<0.3 \\
\text { ng/ } \mu \mathrm{L} \text { in solution. This corresponds to }<3 \mu \mathrm{g} / \mathrm{serving} \text { for all Jolly Rancher, Zotz, } \\
\text { moist snuff and tobacco wrap products. }\end{array}$} \\
\hline
\end{tabular}

\begin{tabular}{|c|c|c|c|}
\hline product & compound & $\begin{array}{l}\text { CASRN }^{1} \text { for } \\
\text { standard }\end{array}$ & $\begin{array}{l}\text { micrograms }(\mu \mathrm{g}) \\
\text { per "serving" }\end{array}$ \\
\hline \multirow{9}{*}{$\begin{array}{l}\text { Jolly Rancher } \\
\text { "Peach" } \\
\begin{aligned} 1 \text { serving = } 1 \text { candy } \\
(\sim 6.1 \mathrm{~g})\end{aligned}\end{array}$} & benzaldehyde & $100-52-7$ & $102 \pm 2$ \\
\hline & benzyl acetate & $140-11-4$ & $106 \pm 2$ \\
\hline & benzyl alcohol & $100-51-6$ & $18 \pm 0$ \\
\hline & $p$-cymene & $99-87-6$ & Trace $^{2}$ \\
\hline & y-decalactone & $706-14-9$ & $111 \pm 1$ \\
\hline & furfural & $98-01-1$ & $10 \pm 0$ \\
\hline & furfuryl alcohol & $98-00-0$ & $5 \pm 0$ \\
\hline & (E)-2-hexen-1-ol & $928-95-0$ & $7 \pm 0$ \\
\hline & limonene & $138-86-3$ & $25 \pm 1$ \\
\hline
\end{tabular}




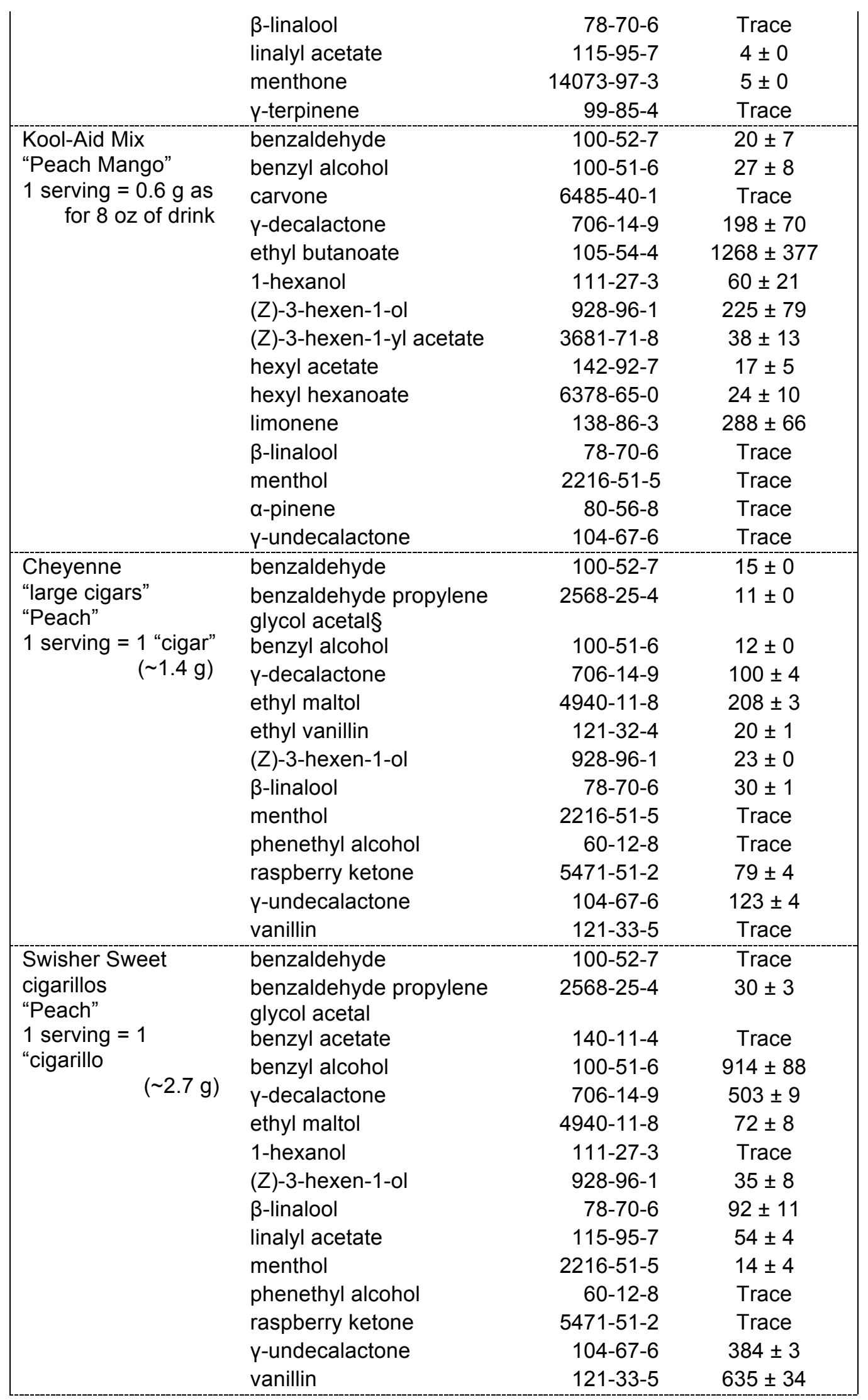




\begin{tabular}{|c|c|c|c|}
\hline $\begin{array}{l}\text { Kayak moist snuff } \\
\text { "Peach" } \\
1 \text { serving }=1.0 \mathrm{~g}\end{array}$ & $\begin{array}{l}\text { benzaldehyde } \\
\text { benzyl acetate } \\
\text { benzyl alcohol } \\
\text { benzyl propionate } \\
\beta \text {-damascone } \\
\text {-decalactone } \\
\text { ethyl cinnamate } \\
\beta \text {-linalool } \\
\text { cis-linalool oxide } \\
\text { trans-linalool oxide } \\
\text { menthol } \\
\text { methyl salicylate } \\
\text { phenethyl alcohol } \\
\gamma \text {-undecalactone } \\
\text { vanillin }\end{array}$ & $\begin{array}{r}100-52-7 \\
140-11-4 \\
100-51-6 \\
122-63-4 \\
23726-91-2 \\
706-14-9 \\
103-36-6 \\
78-70-6 \\
5989-33-3 \\
23007-29-6 \\
2216-51-5 \\
119-36-8 \\
60-12-8 \\
104-67-6 \\
121-33-5\end{array}$ & $\begin{array}{c}\text { Trace } \\
\text { Trace } \\
308 \pm 4 \\
70 \pm 1 \\
19 \pm 0 \\
398 \pm 3 \\
\text { Trace } \\
761 \pm 13 \\
5 \pm 0 \\
4 \pm 0 \\
185 \pm 2 \\
6 \pm 0 \\
4 \pm 0 \\
821 \pm 7 \\
1137 \pm 5\end{array}$ \\
\hline \multicolumn{4}{|c|}{$\begin{array}{l}{ }^{1} \text { CASRN }=\text { Chemical Abstracts Services Registry Number. } \\
2 \text { "Trace" indicates the compound was confirmed as present but detected at }<0.3 \\
\text { ng/ } \mu \mathrm{L} \text { in solution. This corresponds to }<3 \mu \mathrm{g} / \mathrm{serving} \text { for all Jolly Ranchers and } \\
\text { moist snuff products, }<4.5 \mu \mathrm{g} / \mathrm{serving} \text { for Cheyenne cigars, }<6 \mu \mathrm{g} / \mathrm{serving} \text { for } \\
\text { Swisher Sweet cigarillos and }<18 \mu \mathrm{g} / \mathrm{serving} \text { for "peach-mango" Kool-Aid. }\end{array}$} \\
\hline
\end{tabular}

\begin{tabular}{|c|c|c|c|}
\hline product & compound & $\begin{array}{r}\text { CASRN }^{1} \text { for } \\
\text { standard }\end{array}$ & $\begin{array}{l}\text { micrograms }(\mu \mathrm{g}) \\
\text { per "serving" }\end{array}$ \\
\hline \multirow{13}{*}{$\begin{array}{l}\text { Jolly Rancher } \\
\text { "Raspberry" } \\
1 \text { serving = } 1 \text { candy } \\
(\sim 6.1 \mathrm{~g})\end{array}$} & benzaldehyde & $100-52-7$ & Trace $^{2}$ \\
\hline & $\beta$-damascone & 23726-91-2 & $7 \pm 0$ \\
\hline & ethyl butanoate & $105-54-4$ & Trace \\
\hline & furfural & $98-01-1$ & $14 \pm 1$ \\
\hline & 1-hexanol & $111-27-3$ & $26 \pm 1$ \\
\hline & (Z)-3-hexen-1-ol & $928-96-1$ & $120 \pm 3$ \\
\hline & (E)-2-hexen-1-ol & $928-95-0$ & $30 \pm 1$ \\
\hline & (Z)-3-hexen-1-yl acetate & $3681-71-8$ & $294 \pm 7$ \\
\hline & (Z)-3-hexen-1-yl formate & $33467-73-1$ & $20 \pm 2$ \\
\hline & hexyl acetate & $142-92-7$ & $91 \pm 3$ \\
\hline & $\beta$-ionone & $14901-07-6$ & Trace \\
\hline & limonene & $138-86-3$ & $24 \pm 32$ \\
\hline & raspberry ketone & $5471-51-2$ & $777 \pm 24$ \\
\hline \multirow{5}{*}{$\begin{array}{l}\text { Life Saver } \\
\text { "Raspberry" } \\
1 \text { serving = } 1 \text { candy } \\
(\sim 3.6 \mathrm{~g})\end{array}$} & benzyl acetate & $140-11-4$ & $31 \pm 2$ \\
\hline & benzyl alcohol & $100-51-6$ & $16 \pm 3$ \\
\hline & $\beta$-damascone & $23726-91-2$ & $3 \pm 0$ \\
\hline & furfural & $98-01-1$ & Trace \\
\hline & furfuryl alcohol & $98-00-0$ & $2 \pm 1$ \\
\hline
\end{tabular}




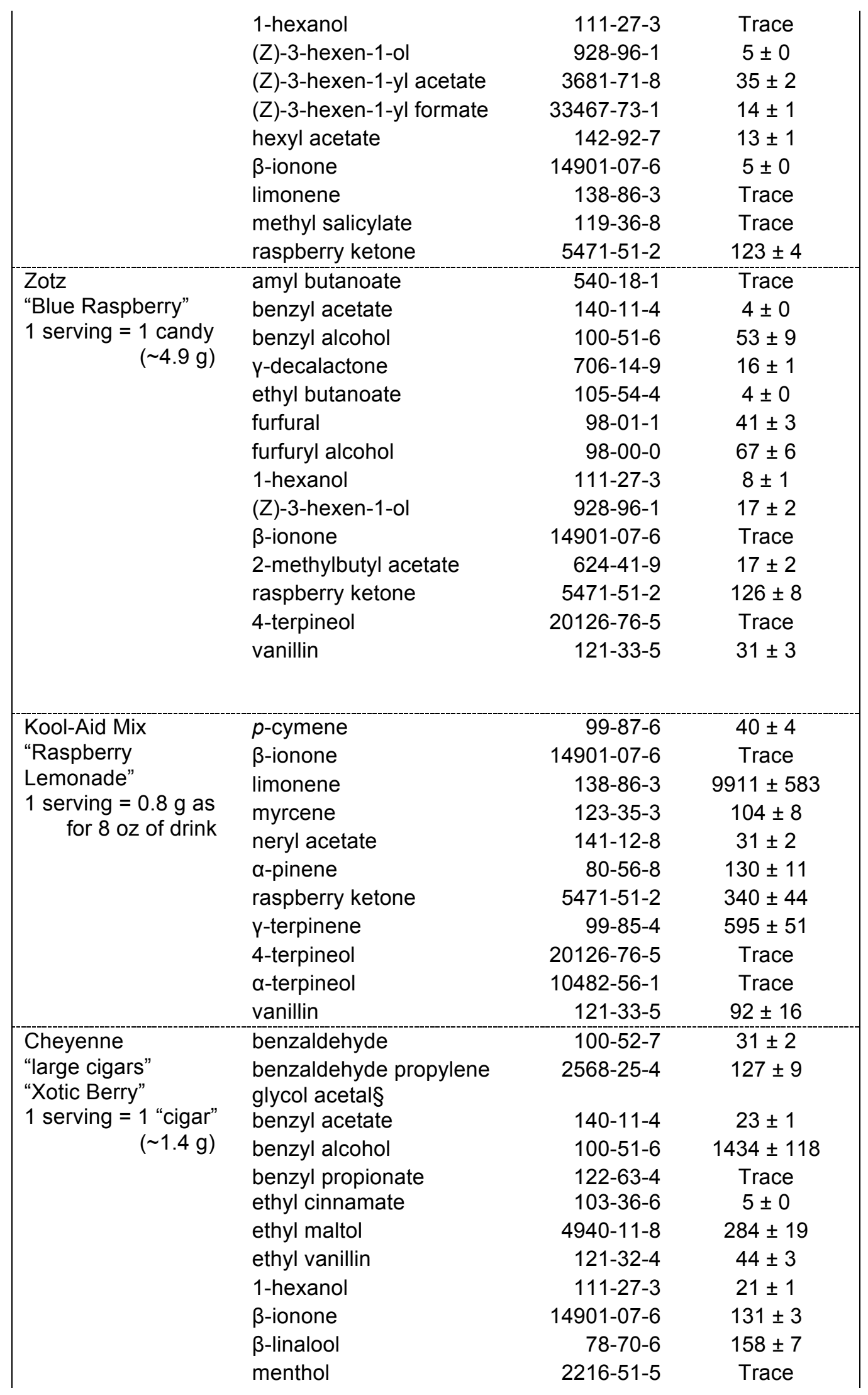




\begin{tabular}{|c|c|c|c|}
\hline & $\begin{array}{l}\text { phenethyl alcohol } \\
\text { raspberry ketone } \\
\text { vanillin }\end{array}$ & $\begin{array}{r}60-12-8 \\
5471-51-2 \\
121-33-5\end{array}$ & $\begin{array}{c}\text { Trace } \\
431 \pm 22 \\
139 \pm 8\end{array}$ \\
\hline \multirow{24}{*}{$\begin{array}{l}\text { Skoal moist snuff } \\
\text { "Berry Blend" } \\
1 \text { serving }=1.0 \mathrm{~g}\end{array}$} & benzaldehyde & $100-52-7$ & $375 \pm 12$ \\
\hline & $\begin{array}{l}\text { benzaldehyde propylene } \\
\text { glycol acetal }\end{array}$ & $2568-25-4$ & $869 \pm 25$ \\
\hline & benzyl acetate & $140-11-4$ & $6 \pm 0$ \\
\hline & benzyl alcohol & $100-51-6$ & $1519 \pm 10$ \\
\hline & ethyl butanoate & $105-54-4$ & $34 \pm 2$ \\
\hline & ethyl cinnamate & $103-36-6$ & $262 \pm 9$ \\
\hline & ethyl isovalerate & $108-64-5$ & $26 \pm 0$ \\
\hline & 1-hexanol & $111-27-3$ & $20 \pm 0$ \\
\hline & (Z)-3-hexen-1-ol & $928-96-1$ & $128 \pm 3$ \\
\hline & (Z)-3-hexen-1-yl acetate & $3681-71-8$ & $21 \pm 0$ \\
\hline & hexyl acetate & $142-92-7$ & $4 \pm 0$ \\
\hline & $\beta$-ionone & $14901-07-6$ & $4 \pm 0$ \\
\hline & isoamyl butanoate & $106-27-4$ & $88 \pm 4$ \\
\hline & limonene & $138-86-3$ & $17 \pm 1$ \\
\hline & $\beta$-linalool & $78-70-6$ & $103 \pm 3$ \\
\hline & menthol & $2216-51-5$ & $424 \pm 13$ \\
\hline & $\begin{array}{l}p \text {-methyl benzaldehyde } \\
\text { ( } p \text {-tolualdehyde) }\end{array}$ & $104-87-0$ & $111 \pm 4$ \\
\hline & methyl salicylate & $119-36-8$ & $6195 \pm 149$ \\
\hline & 2-methylbutyl acetate & $624-41-9$ & $4 \pm 2$ \\
\hline & $\begin{array}{l}\text { phenethyl alcohol } \\
\text { piperonal }\end{array}$ & $\begin{array}{r}60-12-8 \\
120-57-0\end{array}$ & $\begin{array}{c}7 \pm 0 \\
63 \pm 2\end{array}$ \\
\hline & raspberry ketone & $5471-51-2$ & $784 \pm 39$ \\
\hline & 4-terpineol & $20126-76-5$ & $61 \pm 3$ \\
\hline & y-undecalactone & $104-67-6$ & $8 \pm 0$ \\
\hline & vanillin & $121-33-5$ & $108 \pm 3$ \\
\hline \multirow{18}{*}{$\begin{array}{l}\text { Zig Zag } \\
\text { "blunt wrap" } \\
\text { "Blueberry" } \\
1 \text { serving = } 1 \text { wrap } \\
(\sim 0.7 \mathrm{~g})\end{array}$} & benzaldehyde & $100-52-7$ & $5 \pm 0$ \\
\hline & benzyl acetate & $140-11-4$ & $3 \pm 1$ \\
\hline & benzyl alcohol & $100-51-6$ & $2032 \pm 29$ \\
\hline & Y-decalactone & $706-14-9$ & $92 \pm 12$ \\
\hline & ethyl cinnamate & $103-36-6$ & Trace \\
\hline & ethyl isovalerate & $108-64-5$ & Trace \\
\hline & ethyl maltol & $4940-11-8$ & $14 \pm 2$ \\
\hline & ethyl vanillin & $121-32-4$ & $5 \pm 4$ \\
\hline & (Z)-3-hexen-1-ol & $928-96-1$ & $7 \pm 3$ \\
\hline & limonene & $138-86-3$ & $23 \pm 4$ \\
\hline & $\beta$-linalool & $78-70-6$ & $16 \pm 3$ \\
\hline & methyl anthranilate & $134-20-3$ & $4 \pm 2$ \\
\hline & methyl cinnamate & $103-26-4$ & $3 \pm 0$ \\
\hline & piperonal & $120-57-0$ & Trace \\
\hline & raspberry ketone & $5471-51-2$ & $25 \pm 24$ \\
\hline & a-terpineol & $10482-56-1$ & Trace \\
\hline & Y-undecalactone & $104-67-6$ & $9 \pm 7$ \\
\hline & vanillin & $121-33-5$ & $175 \pm 36$ \\
\hline
\end{tabular}


${ }^{1}$ CASRN $=$ Chemical Abstracts Services Registry Number.

2"Trace" indicates the compound was confirmed as present but detected at $<0.3$ $\mathrm{ng} / \mu \mathrm{L}$ in solution. This corresponds to $<3 \mu \mathrm{g} /$ serving for all Jolly Ranchers, Zotz, moist snuff and tobacco wrap products, $<1.5 \mu \mathrm{g} / \mathrm{serving}$ for Life Savers, $<4.5$ $\mu \mathrm{g} / \mathrm{serving}$ for Cheyenne cigars, and $<24 \mu \mathrm{g} /$ serving for raspberry lemonade KoolAid.

${ }^{\S}$ Sum of syn and anti isomers of the acetal. 


\section{Appendix B. PINOT NOIR Tables}

\subsection{Sample Information}

\begin{tabular}{|l|l|l|l|r|}
\hline \multicolumn{2}{|l}{ Table B.1. PINOT NOIR Sample Information } \\
\hline Data File & Day & Time & Temp $\left({ }^{\circ} \mathrm{C}\right)$ & RH $(\%)$ \\
\hline VBOC2012091005-2D & $7 / 29 / 12$ & $11: 00$ & 25.9 & 69.9 \\
\hline VBOC2012090702-2D & $7 / 29 / 12$ & $14: 00$ & 40.1 & 23.6 \\
\hline VBOC2012090614-2D & $7 / 29 / 12$ & $16: 30$ & 40.3 & 25.3 \\
\hline VBOC2012090615-2D & $7 / 30 / 12$ & $11: 00$ & 30.0 & 56.2 \\
\hline VBOC2012091006-2D & $7 / 30 / 12$ & $14: 00$ & 34.5 & 45.3 \\
\hline VBOC20120830010-2D & $7 / 31 / 12$ & $14: 30$ & 38.8 & 23.2 \\
\hline VBOC201203113-2D & $7 / 31 / 12$ & $16: 30$ & 40.7 & 20.0 \\
\hline VBOC20120830011-2D & $8 / 1 / 12$ & $11: 00$ & 32.5 & 43.6 \\
\hline VBOC201203108-2D & $8 / 1 / 12$ & $13: 45$ & 37.5 & 29.3 \\
\hline VBOC2012090606-2D & $8 / 2 / 12$ & $11: 10$ & 27.2 & 69.2 \\
\hline VBOC2012090504-2D & $8 / 2 / 12$ & $14: 00$ & 30.7 & 53.2 \\
\hline VBOC2012090611-2D & $8 / 2 / 12$ & $15: 45$ & 31.4 & 49.7 \\
\hline VBOC2012090513-2D & $8 / 3 / 12$ & $11: 00$ & 31.8 & 51.8 \\
\hline
\end{tabular}




\subsection{Cluster Results}

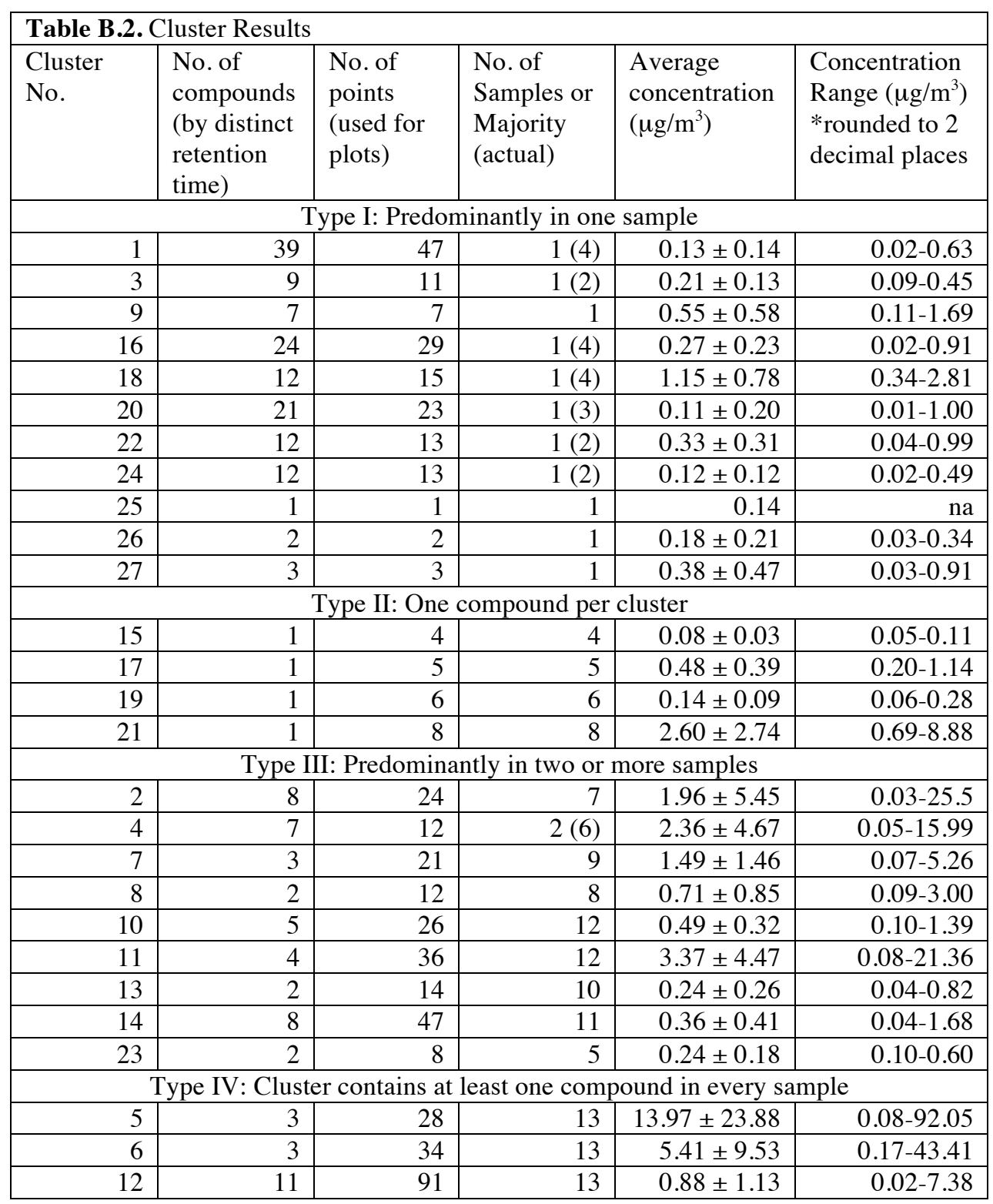




\subsection{Cluster Environmental Variables}

\begin{tabular}{|c|c|c|c|c|c|}
\hline $\begin{array}{l}\text { Cluster } \\
\text { No. }\end{array}$ & Date & Time of Day & Temp $\left({ }^{\circ} \mathrm{C}\right)$ & $\begin{array}{l}\text { Relative } \\
\text { Humidity }(\mathrm{RH}) \\
(\%)\end{array}$ & $\begin{array}{l}\text { Average } \\
\text { Temp }\left({ }^{\circ} \mathrm{C}\right) \\
\text { RH }(\%)\end{array}$ \\
\hline \multicolumn{6}{|c|}{ Type I: Predominantly in one sample } \\
\hline \multirow{3}{*}{1} & $7 / 30 / 12$ & 11:00 & 30 & 56.2 & \multirow{3}{*}{$\begin{array}{l}39.9 \pm 2.2 \\
22.6 \pm 7.4\end{array}$} \\
\hline & 7/31/12 & $16: 30$ & 40.7 & 20 & \\
\hline & $8 / 1 / 12$ & $13: 45$ & 37.5 & 29.3 & \\
\hline \multirow{2}{*}{3} & $7 / 29 / 12$ & 14:00 & 40.1 & 23.6 & $39.6 \pm 1.1$ \\
\hline & $8 / 1 / 12$ & $13: 45$ & 37.5 & 29.3 & $24.6 \pm 2.3$ \\
\hline \multirow{2}{*}{9} & \multirow{2}{*}{$8 / 1 / 12$} & \multirow{2}{*}{$11: 00$} & \multirow{2}{*}{32.5} & \multirow{2}{*}{43.6} & $32.5 \pm 0.0$ \\
\hline & & & & & $43.6 \pm 0.0$ \\
\hline \multirow{3}{*}{16} & 7/30/12 & 11:00, 14:00 & $30.0,34.5$ & $56.2, \mathbf{4 5 . 3}$ & \multirow{3}{*}{$\begin{array}{l}34.6 \pm 1.4 \\
44.2 \pm 5.7\end{array}$} \\
\hline & $8 / 1 / 12$ & $13: 45$ & 37.5 & 29.3 & \\
\hline & $8 / 3 / 12$ & 11:00 & 31.8 & 51.8 & \\
\hline \multirow{4}{*}{18} & $7 / 29 / 12$ & $16: 30$ & 40.3 & 25.3 & \multirow{4}{*}{$\begin{array}{l}32.1 \pm 2.3 \\
47.8 \pm 6.5\end{array}$} \\
\hline & $8 / 1 / 12$ & $11: 00$ & 32.5 & 43.6 & \\
\hline & $8 / 2 / 12$ & $15: 45$ & 31.4 & 49.7 & \\
\hline & $8 / 3 / 12$ & 11:00 & 31.8 & 51.8 & \\
\hline \multirow{3}{*}{20} & $7 / 29 / 12$ & $16: 30$ & 40.3 & 25.3 & \multirow{3}{*}{$\begin{array}{l}38.7 \pm 1.0 \\
24.3 \pm 4.6\end{array}$} \\
\hline & $7 / 30 / 12$ & $14: 00$ & 34.5 & 45.3 & \\
\hline & 7/31/12 & $14: 30$ & 38.8 & 23.2 & \\
\hline \multirow{2}{*}{22} & \multirow{2}{*}{$7 / 30 / 12$} & \multirow{2}{*}{ 11:00, 14:00 } & \multirow{2}{*}{ 30.0, 34.5} & \multirow{2}{*}{$\mathbf{5 6 . 2}, 45.3$} & $30.3 \pm 1.2$ \\
\hline & & & & & $55.4 \pm 3.0$ \\
\hline \multirow{2}{*}{24} & $7 / 31 / 12$ & $14: 30$ & 38.8 & 23.2 & $37.6 \pm 0.4$ \\
\hline & $8 / 1 / 12$ & $13: 45$ & 37.5 & 29.3 & $28.8 \pm 1.7$ \\
\hline \multirow{2}{*}{25} & \multirow{2}{*}{$8 / 2 / 12$} & $11 \cdot 10$ & 272 & 692 & $27.2 \pm 0.0$ \\
\hline & & 11.10 & 21.2 & 09.2 & $69.2 \pm 0.0$ \\
\hline 26 & $8 / 3 / 12$ & $11: 00$ & 318 & 518 & $31.8 \pm 0.0$ \\
\hline 20 & $0 / 3 / 12$ & 11.00 & & & $51.8 \pm 0.0$ \\
\hline 27 & $7 / 29 / 12$ & $11 \cdot 00$ & 259 & 690 & $25.9 \pm 0.0$ \\
\hline & 1129112 & & 25.9 & 09.9 & $69.9 \pm 0.0$ \\
\hline & & Type II: One & ompound per clus & & \\
\hline & $7 / 29 / 12$ & $14: 00,16: 30$ & $40.1,40.3$ & $23.6,25.3$ & \\
\hline 15 & $7 / 30 / 12$ & $14: 00$ & 34.5 & 45.3 & $50.4 \pm 2.1$ \\
\hline & $7 / 31 / 12$ & $14: 30$ & 38.8 & 23.2 & \\
\hline & $7 / 29 / 12$ & $11: 00$ & 25.9 & 69.9 & \\
\hline 17 & $7 / 30 / 12$ & 11:00 & 30.0 & 56.2 & $30.4 \pm 4.5$ \\
\hline 17 & $8 / 1 / 12$ & $13: 45$ & 37.5 & 29.3 & $54.9 \pm 16.7$ \\
\hline & $8 / 2 / 12$ & $11: 10,15: 45$ & $27.2,31.4$ & $69.2,49.7$ & \\
\hline & $7 / 29 / 12$ & $11: 00,14: 00,16: 30$ & $25.9,40.1,40.3$ & $69.9,23.6,25.3$ & \\
\hline 10 & $7 / 30 / 12$ & $11: 00$ & 30.0 & 56.2 & $35.4 \pm 6.0$ \\
\hline 19 & $7 / 31 / 12$ & $14: 30$ & 38.8 & 23.2 & $37.9 \pm 20.1$ \\
\hline & $8 / 1 / 12$ & $13: 45$ & 37.5 & 29.3 & \\
\hline & $7 / 29 / 12$ & $16: 30$ & 40.3 & 25.3 & \\
\hline & $7 / 30 / 12$ & $14: 00$ & 34.5 & 45.3 & \\
\hline 21 & $7 / 31 / 12$ & $16: 30$ & 40.7 & 20.0 & $33.8 \pm 5.0$ \\
\hline 21 & $8 / 1 / 12$ & $11: 00,13: 45$ & $32.5,37.5$ & $43.6,29.3$ & $43.6 \pm 17.2$ \\
\hline & $8 / 2 / 12$ & $11: 10,14: 00$ & $27.2,30.7$ & $69.2,53.2$ & \\
\hline & $8 / 3 / 12$ & $11: 00$ & 31.8 & 51.8 & \\
\hline
\end{tabular}




\begin{tabular}{|c|c|c|c|c|c|}
\hline \multicolumn{6}{|c|}{ Type III: Predominantly in two or more samples } \\
\hline \multirow{5}{*}{2} & $7 / 29 / 12$ & $11: 00,14: 00$ & $25.9,40.1$ & $69.9,23.6$ & \\
\hline & $7 / 30 / 12$ & 14:00 & 34.5 & 45.3 & \\
\hline & 7/31/12 & $14: 30,16: 30$ & $38.8,40.7$ & $23.2,20.0$ & $38.3 \pm 3.4$ \\
\hline & $8 / 1 / 12$ & $13: 45$ & 37.5 & 29.3 & \\
\hline & $8 / 3 / 12$ & 11:00 & 31.8 & 51.8 & \\
\hline \multirow{4}{*}{4} & $7 / 29 / 12$ & 14:00 & 40.1 & 23.6 & \\
\hline & $7 / 30 / 12$ & $11: 00,14: 00$ & $30.0,34.5$ & $56.2,45.3$ & $38 \pm 3.3$ \\
\hline & 7/31/12 & $14: 30, \mathbf{1 6 : 3 0}$ & $38.8, \mathbf{4 0 . 7}$ & $23.2, \mathbf{2 0 . 0}$ & $30.4 \pm 11.6$ \\
\hline & $8 / 1 / 12$ & $13: 45$ & 37.5 & 29.3 & \\
\hline \multirow{5}{*}{7} & $7 / 29 / 12$ & $16: 30$ & 40.3 & 25.3 & \\
\hline & $7 / 30 / 12$ & 11:00 & 34.5 & 45.3 & \\
\hline & 7/31/12 & 14:30, 16:30 & $38.8,40.7$ & $23.2,20.0$ & $\begin{array}{r}54.5 \pm 4.8 \\
400 \pm 17 ?\end{array}$ \\
\hline & 8/1/12 & 11:00, 13:45 & $32.5,37.5$ & $43.6,29.3$ & \\
\hline & $8 / 2 / 12$ & 11:10, 14:00, 15:45 & $27.2,30.7,31.4$ & $69.2,53.2,49.7$ & \\
\hline \multirow{5}{*}{8} & $7 / 29 / 12$ & 11:00 & 25.9 & 69.9 & \\
\hline & $7 / 30 / 12$ & 11:00 & 30.0 & 56.2 & \\
\hline & 7/31/12 & $14: 30,16: 30$ & $38.8,40.7$ & $23.2,20.0$ & $33.9 \pm 5.7$ \\
\hline & 8/1/12 & $13: 45$ & 37.5 & 29.3 & \\
\hline & $8 / 2 / 12$ & $\mathbf{1 1 : 1 0}, 14: 00,15: 45$ & 27.2, $30.7,31.4$ & 69.2, 53.2, 49.7 & \\
\hline \multirow{6}{*}{10} & $7 / 29 / 12$ & $11: 00,14: 00,16: 30$ & $25.9,40.1,40.3$ & $69.9,23.6,25.3$ & \\
\hline & 7/30/12 & 11:00, 14:00 & $30.0,34.5$ & $56.2, \mathbf{4 5 . 3}$ & \\
\hline & 7/31/12 & $16: 30$ & 40.7 & 20.0 & $35.1 \pm 4.5$ \\
\hline & 8/1/12 & 11:00, 13:45 & $\mathbf{3 2 . 5}, 37.5$ & 43.6, 29.3 & $39.2 \pm 15.2$ \\
\hline & $8 / 2 / 12$ & $11: 10,14: 00,15: 45$ & $27.2,30.7,31.4$ & $69.2,53.2,49.7$ & \\
\hline & $8 / 3 / 12$ & $11: 00$ & 31.8 & 51.8 & \\
\hline \multirow{6}{*}{11} & $7 / 29 / 12$ & $11: 00,14: 00,16: 30$ & $25.9,40.1,40.3$ & $69.9,23.6,25.3$ & \\
\hline & $7 / 30 / 12$ & $\mathbf{1 1 : 0 0 , 1 4 : 0 0 ~}$ & $\mathbf{3 0 . 0}, 34.5$ & $\mathbf{5 6 . 2}, 45.3$ & \\
\hline & 7/31/12 & $16: 30$ & 40.7 & 20.0 & $33.5 \pm 4.7$ \\
\hline & 8/1/12 & 11:00, 13:45 & $32.5,37.5$ & $43.6,29.3$ & $44.2 \pm 16.1$ \\
\hline & $8 / 2 / 12$ & $11: 10,14: 00, \mathbf{1 5 : 4 5}$ & $27.2,30.7, \mathbf{3 1 . 4}$ & $69.2,53.2,49.7$ & \\
\hline & $8 / 3 / 12$ & $11: 00$ & 31.8 & 51.8 & \\
\hline \multirow{5}{*}{13} & $7 / 29 / 12$ & $11: 00,14: 00,16: 30$ & $25.9,40.1,40.3$ & $69.9,23.6,25.3$ & \\
\hline & $7 / 30 / 12$ & $11: 00,14: 00$ & $30.0,34.5$ & $56.2,45.3$ & \\
\hline & 7/31/12 & $14: 30,16: 30$ & $38.8,40.7$ & $23.2,20.0$ & $34.8 \pm 5.5$ \\
\hline & 8/1/12 & 11:00, 13:45 & $32.5,37.5$ & 43.6, 29.3 & $40.1 \pm 19.4$ \\
\hline & $8 / 2 / 12$ & 11:10 & 27.2 & 69.2 & \\
\hline \multirow{6}{*}{14} & $7 / 29 / 12$ & $14: 00,16: 30$ & $40.1,40.3$ & $23.6,25.3$ & \\
\hline & $7 / 30 / 12$ & $11: 00,14: 00$ & $30.0,34.5$ & $56.2,45.3$ & \\
\hline & $7 / 31 / 12$ & $14: 30,16: 30$ & $38.8,40.7$ & $23.2,20.0$ & $36.2 \pm 4.1$ \\
\hline & 8/1/12 & 11:00, 13:45 & $32.5,37.5$ & $43.6,29.3$ & $34.6 \pm 13.9$ \\
\hline & $8 / 2 / 12$ & $11: 10,14: 00$ & $27.2,30.7$ & $69.2,53.2$ & \\
\hline & $8 / 3 / 12$ & $11: 00$ & 31.8 & 51.8 & \\
\hline \multirow{4}{*}{23} & $7 / 29 / 12$ & 14:00, 16:30 & $40.1,40.3$ & $23.6,25.3$ & \\
\hline & 7/30/12 & 11:00 & 30.0 & 56.2 & $35.1 \pm 5.7$ \\
\hline & $8 / 1 / 12$ & 11:00 & 32.5 & 43.6 & $40.4 \pm 18.4$ \\
\hline & $8 / 2 / 12$ & $11: 10$ & 27.2 & 69.2 & \\
\hline \multicolumn{6}{|c|}{ Type IV: Cluster contains at least one compound in every sample } \\
\hline \multirow{6}{*}{5} & $7 / 29 / 12$ & $11: 00,14: 00,16: 30$ & $25.9,40.1,40.3$ & $69.9,23.6,25.3$ & \\
\hline & $7 / 30 / 12$ & $11: 00,14: 00$ & $30.0,34.5$ & $56.2,45.3$ & \\
\hline & $7 / 31 / 12$ & $14: 30,16: 30$ & $38.8,40.7$ & $23.2,20.0$ & $33.7 \pm 4.9$ \\
\hline & $8 / 1 / 12$ & $11: 00,13: 45$ & $32.5,37.5$ & $43.6,29.3$ & $43.9 \pm 16.8$ \\
\hline & $8 / 2 / 12$ & $11: 10,14: 00,15: 45$ & $27.2,30.7,31.4$ & $69.2,53.2,49.7$ & \\
\hline & $8 / 3 / 12$ & $11: 00$ & 31.8 & 51.8 & \\
\hline
\end{tabular}




\begin{tabular}{|r|r|r|r|r|r|}
\hline & $7 / 29 / 12$ & $11: 00,14: 00,16: 30$ & $25.9,40.1,40.3$ & $69.9,23.6,25.3$ & \\
& $7 / 30 / 12$ & $11: 00,14: 00$ & $30.0,34.5$ & $56.2,45.3$ & \\
& $7 / 31 / 12$ & $14: 30,16: 30$ & $38.8,40.7$ & $23.2,20.0$ & $33.8 \pm 5.0$ \\
& $8 / 1 / 12$ & $11: 00,13: 45$ & $32.5,37.5$ & $43.6,29.3$ & $43.6 \pm 16.8$ \\
& $8 / 2 / 12$ & $11: 10,14: 00,15: 45$ & $27.2,30.7,31.4$ & $69.2,53.2,49.7$ & \\
& $8 / 3 / 12$ & $11: 00$ & 31.8 & 51.8 & \\
\hline \multirow{4}{*}{12} & $7 / 29 / 12$ & $11: 00,14: 00,16: 30$ & $25.9,40.1,40.3$ & $69.9,23.6,25.3$ & \\
& $7 / 30 / 12$ & $11: 00,14: 00$ & $30.0,34.5$ & $56.2,45.3$ & \\
& $7 / 31 / 12$ & $14: 30,16: 30$ & $38.8,40.7$ & $23.2,20.0$ & $34.5 \pm 4.7$ \\
& $8 / 1 / 12$ & $11: 00,13: 45$ & $32.5,37.5$ & $43.6,29.3$ & $41.3 \pm 15.9$ \\
& $8 / 2 / 12$ & $11: 10,14: 00,15: 45$ & $27.2,30.7,31.4$ & $69.2,53.2,49.7$ & \\
& $8 / 3 / 12$ & $11: 00$ & 31.8 & 51.8 & \\
\hline
\end{tabular}




\subsection{Compounds Assigned by Cluster}

\begin{tabular}{|c|c|c|c|}
\hline \multicolumn{4}{|c|}{ Cluster 1: Predominantly detected on $7 / 31 / 12$ at $4: 30 \mathrm{PM}$} \\
\hline Compound & $R T_{c}$ & $I$ & $R$ \\
\hline Unknown 15 & 794.3719 & 794 & 3.719 \\
\hline Heptane, 3-ethyl-5-methylene- & 838.0806 & 838 & 0.806 \\
\hline Cyclopropane, 1-methyl-2-(3-methylpentyl)- & 951.0801 & 951 & 0.801 \\
\hline 4-Nonene, 5-methyl- & 964.0812 & 964 & 0.812 \\
\hline 1,4-Hexadiene, 3-ethyl-4,5-dimethyl- & 983.0923 & 983 & 0.923 \\
\hline 1,1'-Bicycloheptyl & 998.0876 & 998 & 0.876 \\
\hline Benzene, (1-methylpropyl)- & 1020.1527 & 1020 & 1.527 \\
\hline Benzene, 1-methyl-2-(1-methylethyl)- & 1031.1542 & 1031 & 1.542 \\
\hline Cyclohexane, butyl- & 1037.0882 & 1037 & 0.882 \\
\hline Cyclodecane & 1041.0858 & 1041 & 0.858 \\
\hline Bicyclo[3.1.0]hex-2-ene, 4-methylene-1-(1-methylethyl)- & 1067.1619 & 1067 & 1.619 \\
\hline Benzene, 2-ethyl-1,4-dimethyl- & 1094.1697 & 1094 & 1.697 \\
\hline 2-Octene, 4-ethyl- & 1097.0773 & 1097 & 0.773 \\
\hline Ethanone, 1-(1,2,2,3-tetramethylcyclopentyl)-, (1R-cis)- & 1131.0858 & 1131 & 0.858 \\
\hline Benzene, 1,2,4,5-tetramethyl- & 1180.2059 & 1180 & 2.059 \\
\hline 2-Decanone & 1199.1712 & 1199 & 1.712 \\
\hline 2-Decenal, (Z)- & 1275.2241 & 1275 & 2.241 \\
\hline Cyclooctane, 1,4-dimethyl-, trans- & 1336.0806 & 1336 & 0.806 \\
\hline Cyclohexanone, 3-butyl- & 1359.0806 & 1359 & 0.806 \\
\hline 2,4,4-Trimethyl-3-(3-methylbutyl)cyclohex-2-enone & 1373.2225 & 1373 & 2.225 \\
\hline 2-Undecenal & 1379.2167 & 1379 & 2.167 \\
\hline $\begin{array}{l}\text { 1,2,4-Methenoazulene, decahydro-1,5,5,8a-tetramethyl-, } \\
\text { [1S-(1à,2à,3aá,4à,8aá,9R*)]- }\end{array}$ & 1405.1208 & 1405 & 1.208 \\
\hline Cyclopentanone, 2-cyclopentylidene- & 1411.3760 & 1411 & 3.760 \\
\hline Cyclohexane, 1-methyl-2-propyl- & 1415.0923 & 1415 & 0.923 \\
\hline 2,4,4-Trimethyl-3-(3-methylbutyl)cyclohex-2-enone & 1421.2266 & 1421 & 2.266 \\
\hline Cyclohexane, (1-methylpropyl)- & 1508.0899 & 1508 & 0.899 \\
\hline Oxalic acid, di(cyclohexylmethyl) ester & 1508.0923 & 1508 & 0.923 \\
\hline 6,11-Dimethyl-2,6,10-dodecatrien-1-ol & 1510.1250 & 1510 & 1.250 \\
\hline 5-tert-Butylpyrogallol & 1512.3306 & 1512 & 3.306 \\
\hline Cyclohexane, 1-isopropyl-1-methyl- & 1516.0930 & 1516 & 0.930 \\
\hline Oxalic acid, cyclohexylmethyl isohexyl ester & 1521.0948 & 1521 & 0.948 \\
\hline 2-Pentanone, 3-[(acetyloxy)methyl]-3,4-dimethyl-, (.+-.)- & 1538.0784 & 1538 & 0.784 \\
\hline Benzene, (1-butylhexyl)- & 1544.1271 & 1544 & 1.271 \\
\hline Nonane, 3-methylene- & 1587.0911 & 1587 & 0.911 \\
\hline
\end{tabular}




\begin{tabular}{|c|c|c|c|}
\hline 1,4-Hexadiene, 2,3,4,5-tetramethyl- & 1598.1250 & 1598 & 1.250 \\
\hline Cyclohexane, (1-methylpropyl)- & 1609.0917 & 1609 & 0.917 \\
\hline Cyclohexane, 1-(cyclohexylmethyl)-2-methyl-, cis- & 1621.1377 & 1621 & 1.377 \\
\hline Unknown 40 & 1678.3787 & 1678 & 3.787 \\
\hline Cyclohexane, 1-methyl-2-propyl- & 1718.0973 & 1718 & 0.973 \\
\hline \multicolumn{4}{|c|}{ Cluster 3: 7/29/12 at 2:00PM } \\
\hline Compound & $R T_{c}$ & $I$ & $R$ \\
\hline 3-Heptene, 4-propyl- & 848.0795 & 848 & 0.795 \\
\hline 4-Nonene, 3-methyl-, (Z)- & 948.0789 & 948 & 0.789 \\
\hline 3,4-Diethyl-3-hexene & 955.0852 & 955 & 0.852 \\
\hline 4-Nonene, 3-methyl-, (Z)- & 964.0823 & 964 & 0.823 \\
\hline 4-Nonene, 5-methyl- & 982.0818 & 982 & 0.818 \\
\hline 3-Octene, 2,2-dimethyl- & 1014.0835 & 1014 & 0.835 \\
\hline Nonane, 3-methylene- & 1071.0823 & 1071 & 0.823 \\
\hline 1,3-Benzodioxole, 5-(2-propenyl)- & 1603.4196 & 1603 & 4.196 \\
\hline Unknown 16 & 1829.0521 & 1829 & 0.521 \\
\hline \multicolumn{4}{|c|}{ Cluster 9: 8/1/12 at 11:00 AM } \\
\hline Compound & $R T_{c}$ & $I$ & $R$ \\
\hline 2-Butenal, 2-methyl-, (E)- & 748.2952 & 748 & 2.952 \\
\hline 4-Nonene, 3-methyl-, (Z)- & 811.0812 & 811 & 0.812 \\
\hline 3,4-Diethyl-2-hexene & 918.0751 & 918 & 0.751 \\
\hline Benzene, 1-methyl-2-propyl- & 1067.1580 & 1067 & 1.580 \\
\hline Linalool & 1102.2896 & 1102 & 2.896 \\
\hline 5-Methyl-2-(2-methyl-2-tetrahydrofuryl)tetrahydrofuran & 1255.0756 & 1255 & 0.756 \\
\hline Cyclohexane, 1-ethyl-1,3-dimethyl-, trans- & 1352.0823 & 1352 & 0.823 \\
\hline \multicolumn{4}{|c|}{ Cluster 16: $7 / 30 / 12$ at 2:00PM } \\
\hline Compound & $R T_{c}$ & $I$ & $R$ \\
\hline 3-Ethyl-4-octene & 930.0784 & 930 & 0.784 \\
\hline 3-Nonene, 3-methyl-, (E)- & 961.0835 & 961 & 0.835 \\
\hline 3-Octene, 4-ethyl- & 964.0806 & 964 & 0.806 \\
\hline 3-Ethyl-3-octene & 979.0795 & 979 & 0.795 \\
\hline 1,3-Heptadiene, 3-ethyl-2-methyl- & 983.0930 & 983 & 0.930 \\
\hline Cyclohexane, 1,1,3,5-tetramethyl-, cis- & 1004.0762 & 1004 & 0.762 \\
\hline 2-Nonene, 3-methyl-, (E)- & 1006.0846 & 1006 & 0.846 \\
\hline 1,3-Heptadiene, 3-ethyl-2-methyl- & 1006.0954 & 1006 & 0.954 \\
\hline 3-Ethyl-4-octene & 1009.0778 & 1009 & 0.778 \\
\hline 3-Octene, 4-ethyl- & 1026.0806 & 1026 & 0.806 \\
\hline Cyclohexane, 1,1,3,5-tetramethyl-, trans- & 1030.0818 & 1030 & 0.818 \\
\hline Cyclohexane, 1,2-diethyl-, cis- & 1033.0829 & 1033 & 0.829 \\
\hline Cyclodecane & 1039.0870 & 1039 & 0.870 \\
\hline
\end{tabular}




\begin{tabular}{|c|c|c|c|}
\hline Cyclohexane, 1,1,3,5-tetramethyl-, trans- & 1047.0852 & 1047 & 0.852 \\
\hline Ethanone, 1-(1,2,2,3-tetramethylcyclopentyl)-, (1R-cis)- & 1048.0870 & 1048 & 0.870 \\
\hline Benzene, butyl- & 1067.1603 & 1067 & 1.603 \\
\hline 1-Hexene, 4,4-diethyl- & 1081.0917 & 1081 & 0.917 \\
\hline 5,7-Dimethyloctahydrocoumarin & 1094.0818 & 1094 & 0.818 \\
\hline Unknown 16 & 1121.0852 & 1121 & 0.852 \\
\hline 3-Octene, 2,2-dimethyl- & 1136.0870 & 1136 & 0.870 \\
\hline 1-Decene & 1192.1285 & 1192 & 1.285 \\
\hline Cyclooctane, ethyl- & 1480.0795 & 1480 & 0.795 \\
\hline Unknown 25 & 1833.0521 & 1833 & 0.521 \\
\hline Unknown 32 & 1906.0521 & 1906 & 0.521 \\
\hline \multicolumn{4}{|c|}{ Cluster 18: 8/2/12 at 3:45 PM } \\
\hline Compound & $R T_{c}$ & I & $R$ \\
\hline Ethanone, 1-(1,2,2,3-tetramethylcyclopentyl)-, (1R-cis)- & 896.1105 & 896 & 1.105 \\
\hline 3-Ethyl-4-octene & 918.1065 & 918 & 1.065 \\
\hline 3-Heptene, 4-propyl- & 936.1115 & 936 & 1.115 \\
\hline [1,1'-Bicyclopentyl]-2-one & 939.0823 & 939 & 0.823 \\
\hline 4-Allyl-1,6-heptadiene-4-ol & 955.1165 & 955 & 1.165 \\
\hline trans-4-Decene & 964.1130 & 964 & 1.130 \\
\hline Ethanone, 1-(1,2,2,3-tetramethylcyclopentyl)-, (1R-cis)- & 1094.1100 & 1094 & 1.100 \\
\hline 3,4-Diethyl-2-hexene & 1506.1095 & 1506 & 1.095 \\
\hline Cyclooctane, 1,4-dimethyl-, trans- & 1551.0806 & 1551 & 0.806 \\
\hline Cyclopentane, (2-methylbutyl)- & 1564.1100 & 1564 & 1.100 \\
\hline Octane, 3-methyl-6-methylene- & 1590.1145 & 1590 & 1.145 \\
\hline Sabinene & 1610.1134 & 1610 & 1.134 \\
\hline \multicolumn{4}{|c|}{ Cluster 20: 7/31/12 at 2:30 PM } \\
\hline Compound & $R T_{c}$ & $I$ & $R$ \\
\hline 2-Butenal, 3-methyl- & 791.4282 & 791 & 4.282 \\
\hline 1,5-Heptadien-4-one, 3,3,6-trimethyl- & 834.0773 & 834 & 0.773 \\
\hline Benzene, tert-butyl- & 1003.1565 & 1003 & 1.565 \\
\hline à-Phellandrene & 1012.1181 & 1012 & 1.181 \\
\hline Oxalic acid, bis(isobutyl) ester & 1023.0734 & 1023 & 0.734 \\
\hline à- Terpinene & 1025.1188 & 1025 & 1.188 \\
\hline$\beta$-Phellandrene & 1041.1271 & 1041 & 1.271 \\
\hline gamme terpinene & 1064.1271 & 1064 & 1.271 \\
\hline Bicyclo[4.1.0]hept-3-ene, 3,7,7-trimethyl-, (1S)- & 1066.1264 & 1066 & 1.264 \\
\hline 2,2'-Bi-2H-pyran, octahydro- & 1078.0734 & 1078 & 0.734 \\
\hline Terpinolene & 1092.1321 & 1092 & 1.321 \\
\hline Benzene, 2-ethyl-1,3-dimethyl- & 1124.1880 & 1124 & 1.880 \\
\hline Benzene, 1,2,3,4-tetramethyl- & 1144.1848 & 1144 & 1.848 \\
\hline
\end{tabular}




\begin{tabular}{|c|c|c|c|}
\hline Benzene, 1-methyl-4-(1-methylpropyl)- & 1158.1527 & 1158 & 1.527 \\
\hline 1H-Indene, 2,3-dihydro-4-methyl- & 1160.2167 & 1160 & 2.167 \\
\hline 1H-Indene, 2,3-dihydro-4-methyl- & 1172.2275 & 1172 & 2.275 \\
\hline Cyclohexanol, 3,3,5-trimethyl-, acetate, cis- & 1201.1542 & 1201 & 1.542 \\
\hline Ethanone, 1-[4-(1-methylethyl)phenyl]- & 1340.3615 & 1340 & 3.615 \\
\hline Menthol, 1'-(butyn-3-one-1-yl)-, (1S,2S,5R)- & 1678.3774 & 1678 & 3.774 \\
\hline Unknown 9 & 1678.3801 & 1678 & 3.801 \\
\hline 1,2-Benzenedicarboxylic acid, bis(2-methylpropyl) ester & 1855.3536 & 1855 & 3.536 \\
\hline \multicolumn{4}{|c|}{ Cluster 22: 7/30/12 2:00 PM } \\
\hline Compound & $R T_{c}$ & $I$ & $R$ \\
\hline Unknown 4 & 809.0876 & 809 & 0.876 \\
\hline Heptane, 2,2,3,5-tetramethyl- & 981.0724 & 981 & 0.724 \\
\hline $\begin{array}{l}\text { 3-Cyclopentylpropionic acid, 2-tetrahydrofurylmethyl } \\
\text { ester }\end{array}$ & 1023.0745 & 1023 & 0.745 \\
\hline 7-Octen-2-ol, 2,6-dimethyl- & 1075.2375 & 1075 & 2.375 \\
\hline 5-Methyl-2-(2-methyl-2-tetrahydrofuryl)tetrahydrofuran & 1086.0745 & 1086 & 0.745 \\
\hline Undecane & 1100.0767 & 1100 & 0.767 \\
\hline Bicyclo[3.1.1]heptan-3-one, 2,6,6-trimethyl-, (1à,2á,5à)- & 1190.0812 & 1190 & 0.812 \\
\hline Undecane & 1199.0784 & 1199 & 0.784 \\
\hline 5-Undecanone & 1277.1467 & 1277 & 1.467 \\
\hline Undecanal & 1314.1642 & 1314 & 1.642 \\
\hline Undecane & 1340.0756 & 1340 & 0.756 \\
\hline 1-Octene, 3,7-dimethyl- & 1564.0784 & 1564 & 0.784 \\
\hline \multicolumn{4}{|c|}{ Cluster 24: 8/1/12 1:45 PM } \\
\hline Compound & $R T_{c}$ & $I$ & $R$ \\
\hline Bicyclo[2.1.0]pentane & 548.0756 & 548 & 0.756 \\
\hline 1-Octene, 3,7-dimethyl- & 758.0767 & 758 & 0.767 \\
\hline 1-Octene, 2,6-dimethyl- & 975.0823 & 975 & 0.823 \\
\hline 2-Octene, 3,7-dimethyl-, (Z)- & 1006.0852 & 1006 & 0.852 \\
\hline Benzene, 1-methyl-3-propyl- & 1063.1580 & 1063 & 1.580 \\
\hline Unknown 21 & 1091.0806 & 1091 & 0.806 \\
\hline 1-Decene & 1092.0846 & 1092 & 0.846 \\
\hline Ethanone, 1-(1,2,2,3-tetramethylcyclopentyl)-, (1R-cis)- & 1367.0835 & 1367 & 0.835 \\
\hline Cyclohexane, 1-ethyl-1,3-dimethyl-, trans- & 1459.0801 & 1459 & 0.801 \\
\hline Cyclooctane, 1,4-dimethyl-, trans- & 1476.0806 & 1476 & 0.806 \\
\hline Cyclohexane, 1-ethyl-1,3-dimethyl-, trans- & 1480.0801 & 1480 & 0.801 \\
\hline Unknown 50 & 1904.0530 & 1904 & 0.530 \\
\hline \multicolumn{4}{|c|}{ Cluster 25: 8/2/12 at 11:10 AM } \\
\hline Compound & $R T_{c}$ & $I$ & $R$ \\
\hline 1,7-Nonadien-4-ol, 4,8-dimethyl- & 1259.1650 & 1259 & 1.650 \\
\hline \multicolumn{4}{|c|}{ Cluster 26: 8/3/12 at 11:00 AM } \\
\hline
\end{tabular}




\begin{tabular}{|l|l|r|r|}
\hline Compound & \multicolumn{1}{|l|}{$R T_{c}$} & \multicolumn{1}{l|}{$l \mid$} & \multicolumn{1}{l|}{$R$} \\
\hline 3,4-Diethyl-2-hexene & \multicolumn{1}{|l|}{1009.0773} & 1009 & 0.773 \\
\hline Cyclohexane, 2,4-diisopropyl-1,1-dimethyl- & 1077.0806 & 1077 & 0.806 \\
\hline \multicolumn{3}{|c|}{ Cluster 27: 7/29/12 at 11:00 AM } \\
\hline Compound & \multicolumn{1}{|c|}{$R T_{c}$} & $I$ & $R$ \\
\hline 2H-Pyran, tetrahydro-2-[(tetrahydro-2-furanyl)methoxy]- & 1078.0740 & 1078 & 0.740 \\
\hline Sabinene & 1091.1134 & 1091 & 1.134 \\
\hline 2-Decen-1-ol & 1285.1650 & 1285 & 1.650 \\
\hline
\end{tabular}

\begin{tabular}{|l|l|r|r|r|}
\hline \multicolumn{2}{|l|}{ Table B.4.2. Compounds Assigned to Type II Clusters } \\
\hline Cluster No. & Compound Name & \multicolumn{1}{l|}{$T_{c}$} & \multicolumn{1}{l|}{} & \multicolumn{1}{l|}{} \\
\hline 15 & $\beta$-Pinene & 985.1094 & 985 & 1.094 \\
\hline 17 & trans-3-Decene & 992.0829 & 992 & 0.829 \\
\hline 19 & à-Thujene & 930.0948 & 930 & 0.948 \\
\hline 21 & Cyclooctane, 1,4-dimethyl-, trans- & 1083.0801 & 1083 & 0.801 \\
\hline
\end{tabular}

\begin{tabular}{|l|l|l|l|}
\hline \multicolumn{3}{|c|}{ Table B.4.3. Compounds Assigned to Cluster Type III } \\
\hline \multicolumn{4}{|c|}{ Cluster 2 } \\
\hline Compound & $R T_{c}$ & $I$ & $R$ \\
\hline Benzene, 1-methyl-2-(1-methylethyl)- & 1074.1634 & 1074 & 1.634 \\
\hline Benzene, 1-methyl-3-propyl- & 1067.1588 & 1067 & 1.588 \\
\hline Benzene, 1-methyl-4-(1-methylethenyl)- & 1105.2167 & 1105 & 2.167 \\
\hline Benzene, 2-ethyl-1,3-dimethyl- & 1097.1720 & 1097 & 1.720 \\
\hline Benzene, 2-ethyl-1,3-dimethyl- & 1102.1736 & 1102 & 1.736 \\
\hline Benzoic acid, 2-ethylhexyl ester & 1722.2391 & 1722 & 2.391 \\
\hline Dodecyl acrylate & 1690.1527 & 1690 & 1.527 \\
\hline Homosalate & 1874.3024 & 1874 & 3.024 \\
\hline & & & \\
\hline Compound & $R T_{c}$ & $I$ & $R$ \\
\hline trans-4-Decene & 975.0818 & 975 & 0.818 \\
\hline 2,4-Pentadien-1-ol, 3-pentyl-, (2Z)- & 1041.0846 & 1041 & 0.846 \\
\hline Benzene, (1-methylpropyl)- & 1063.1588 & 1063 & 1.588 \\
\hline 1-Octyn-3-ol, 4-ethyl- & 1112.1482 & 1112 & 1.482 \\
\hline Cyclohexanone, 4-(1,1-dimethylpropyl)- 4 & 1189.1760 & 1189 & 1.760 \\
\hline Longifolene & 1440.1321 & 1440 & 1.321 \\
\hline Butylated Hydroxytoluene & 1525.2051 & 1525 & 2.051 \\
\hline
\end{tabular}




\begin{tabular}{|c|c|c|c|}
\hline \multicolumn{4}{|l|}{ Cluster 7} \\
\hline Cyclohexane, 2-ethenyl-1,1-dimethyl-3-methylene- & 1119.1208 & 1119 & 1.208 \\
\hline 2-Ethylhexyl salicylate & 1814.2491 & 1814 & 2.491 \\
\hline Homosalate & 1898.3229 & 1898 & 3.229 \\
\hline \multicolumn{4}{|l|}{ Cluster 8} \\
\hline Compound & $R T_{c}$ & $I$ & $R$ \\
\hline Geranyl acetone & 1461.2150 & 1461 & 2.150 \\
\hline Thujopsene & 1464.1386 & 1464 & 1.386 \\
\hline \multicolumn{4}{|l|}{ Cluster 10} \\
\hline Compound & $R T_{c}$ & $I$ & $R$ \\
\hline 3,4-Diethyl-3-hexene & 927.0773 & 927 & 0.773 \\
\hline Tricyclene & 930.0942 & 930 & 0.942 \\
\hline 2-Octene, 4-ethyl- & 935.0795 & 935 & 0.795 \\
\hline trans-4-Decene & 995.0835 & 995 & 0.835 \\
\hline Cyclooctane, 1,4-dimethyl-, trans- & 1571.0818 & 1571 & 0.818 \\
\hline \multicolumn{4}{|l|}{ Cluster 11} \\
\hline Compound & $R T_{c}$ & $I$ & $R$ \\
\hline 3-Octene, 4-ethyl- & 945.0795 & 945 & 0.795 \\
\hline 2-Decen-1-ol & 1177.1626 & 1177 & 1.626 \\
\hline Decanal & 1212.1681 & 1212 & 1.681 \\
\hline [1,1'-Bicyclopentyl]-2-one & 1301.2928 & 1301 & 2.928 \\
\hline \multicolumn{4}{|l|}{ Cluster 13} \\
\hline à-Cedrene & 1447.1278 & 1447 & 1.278 \\
\hline Benzene, 1-methyl-4-(1,2,2-trimethylcyclopentyl)-, (R)- & 1538.1848 & 1538 & 1.848 \\
\hline \multicolumn{4}{|l|}{ Cluster 14} \\
\hline Compound & $R T_{c}$ & $I$ & $R$ \\
\hline 2-Pentanone, 3-[(acetyloxy)methyl]-3,4-dimethyl-, (.+-.)- & 896.0778 & 896 & 0.778 \\
\hline Sabinene & 979.1127 & 979 & 1.127 \\
\hline$\beta$-Myrcene & 992.1147 & 992 & 1.147 \\
\hline 3-Carene & 1017.1114 & 1017 & 1.114 \\
\hline Z-Ocimene & 1039.1236 & 1039 & 1.236 \\
\hline Z-Ocimene & 1052.1278 & 1052 & 1.278 \\
\hline Benzene, 1,2,4,5-tetramethyl- & 1148.1904 & 1148 & 1.904 \\
\hline Benzene, 1,3-bis(1,1-dimethylethyl)- & 1263.1174 & 1263 & 1.174 \\
\hline \multicolumn{4}{|l|}{ Cluster 23} \\
\hline Compound & $R T_{c}$ & $I$ & $R$ \\
\hline 2-Propenoic acid, 2-ethylhexyl ester & 1189.1437 & 1189 & 1.437 \\
\hline Methyl 4,6-decadienyl ether & 1626.1452 & 1626 & 1.452 \\
\hline
\end{tabular}




\begin{tabular}{|c|c|c|c|}
\hline \multicolumn{4}{|l|}{ Table B.4.4. Type IV } \\
\hline \multicolumn{4}{|c|}{ Cluster 5} \\
\hline Compound & $R T_{c}$ & $I$ & $R$ \\
\hline Isoprene & 510.0718 & 510 & 0.718 \\
\hline Nonane, 3-methylene- & 986.0835 & 986 & 0.835 \\
\hline Methyl 4,6-decadienyl ether & 1428.1042 & 1428 & 1.042 \\
\hline \multicolumn{4}{|c|}{ Cluster 6} \\
\hline Methacrolein & 564.1697 & 564 & 1.697 \\
\hline Methyl vinyl ketone & 590.2591 & 590 & 2.591 \\
\hline 3-Methylheptyl acetate & 1153.1357 & 1153 & 1.357 \\
\hline \multicolumn{4}{|c|}{ Cluster 12} \\
\hline Cyclohexane, 1,1,3,5-tetramethyl-, cis- & 894.0784 & 894 & 0.784 \\
\hline Cyclohexane, 1,1,3,5-tetramethyl-, cis- & 914.0801 & 914 & 0.801 \\
\hline 3-Ethyl-4-octene & 939.0806 & 939 & 0.806 \\
\hline à-Pinene & 941.0942 & 941 & 0.942 \\
\hline Heptane, 3-ethyl-5-methylene- & 946.0818 & 946 & 0.818 \\
\hline 1-Decene & 951.0806 & 951 & 0.806 \\
\hline Camphene & 957.1048 & 957 & 1.048 \\
\hline trans-4-Decene & 992.0823 & 992 & 0.823 \\
\hline Limonene & 1036.1222 & 1036 & 1.222 \\
\hline p-Cymene & 1037.1550 & 1037 & 1.550 \\
\hline 1-Octene, 3,7-dimethyl- & 1088.0801 & 1088 & 0.801 \\
\hline
\end{tabular}




\section{Appendix C. MATLAB Code for PINOT NOIR data}

$\%$ Data is a matrix $\mathrm{n} \times \mathrm{m}$, where each row (n) refers to one compound, columns $\%(\mathrm{~m})$ correspond to each sample and each entry give compound concentration $\left.\%\left(\mu \mathrm{g} / \mathrm{m}^{\wedge} 3\right)\right)$

$\%$ Similiarity measure: Spearman; linkage metric: average

$\%$ Dendrogram compressed into 30 nodes

$\% \mathrm{~T}$ gives where each row (variable) falls into the node

$\mathrm{Y}=$ pdist(data,'spearman')

$\mathrm{ZA}=$ linkage (Y,'average')

figure(1)

$[\mathrm{H}, \mathrm{T}$,outperm $]=$ dendrogram $(\mathrm{ZA})$

$\%$ To calculate cophenetic correlation (how well linkage matrix that codes the $\%$ dendrogram represents the original data matrix)

$\mathrm{ca}=\operatorname{cophenet}(\mathrm{ZA}, \mathrm{Y})$

$\%$ To generate dendrogram with all 204 variables

figure(2)

H193=dendrogram $(Z A, 204)$

$\%$ Cluster into 27 groups (try many different clusters to determine optimal $\%$ number)

$\mathrm{C} 25=$ cluster $(Z A, '$ maxclust' 27$)$

$\%$ To plot results create a matrix that collapses all concentrations into one column, $\%$ with corresponding compounds, retention times and other variables such as

$\%$ temperature, relative humidity, time of day, date, etc in separate columns

\%Example: 2D plot of two retention times with cluster number represented by $\%$ color and symbol shape. Where $\mathrm{c}$ is the column of corresponding cluster \% number, RIX is retention index and RRY is second dimension retention ratio h2d=gscatter(RIX,RRY,c,[],'ox+*sdv^<>ph.')

$\%$ For 3D plot with clusters represented by color and symbol shape, code modified $\%$ from http://www.mathworks.com/matlabcentral/answers/92577-how-can-i-

\%create-a-3d-grouped-scatter-plot-in-statistics-toolbox-7-2-r2009b

$\mathrm{h}=\operatorname{gscatter}\left(\mathrm{x}, \mathrm{y}, \mathrm{c},[],{ }^{\prime} \mathrm{ox}+{ }^{*} \mathrm{sdv}^{\wedge}<>\mathrm{ph} .{ }^{\prime}\right)$;

$\%$ For each unique group in ' $c$ ', set the ZData

$\mathrm{gu}=$ unique $(\mathrm{c})$;

for $\mathrm{k}=1$ :numel(gu)

end

$\operatorname{set}(\mathrm{h}(\mathrm{k})$, 'ZData', $\mathrm{z}(\mathrm{c}==\mathrm{gu}(\mathrm{k})))$;

$\operatorname{view}(3)$ 